\title{
Implementation Approach for Plug-in Electric Vehicles at Joint Base Lewis McChord: Task 4
}

\author{
Stephen Schey
}

Jim Francfort

December 2014

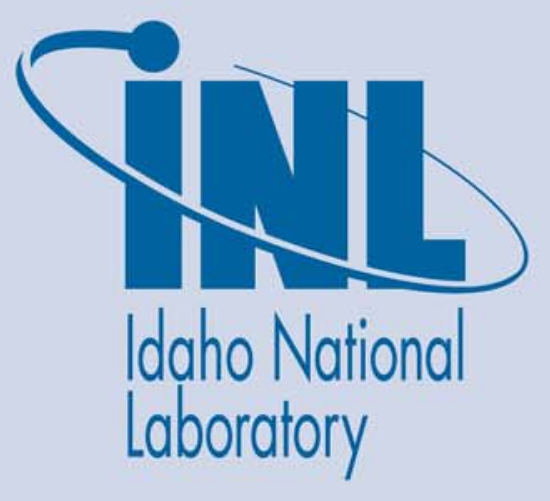

The INL is a U.S. Department of Energy National Laboratory operated by Battelle Energy Alliance 


\section{DISCLAIMER}

This information was prepared as an account of work sponsored by an agency of the U.S. Government. Neither the U.S. Government nor any agency thereof, nor any of their employees, makes any warranty, expressed or implied, or assumes any legal liability or responsibility for the accuracy, completeness, or usefulness, of any information, apparatus, product, or process disclosed, or represents that its use would not infringe privately owned rights. References herein to any specific commercial product, process, or service by trade name, trade mark, manufacturer, or otherwise, does not necessarily constitute or imply its endorsement, recommendation, or favoring by the U.S. Government or any agency thereof. The views and opinions of authors expressed herein do not necessarily state or reflect those of the U.S. Government or any agency thereof. 


\title{
Implementation Approach for Plug-in Electric Vehicles at Joint Base Lewis McChord: Task 4
}

\author{
Stephen Schey \\ Jim Francfort ${ }^{2}$ \\ ${ }^{1}$ Stephen Schey, Project Manager, Infrastructure Planning and Analysis, Intertek Testing Services, \\ North America, Phoenix, AZ \\ ${ }^{2}$ Jim Francfort, Vehicle Systems Principal Investigator, Idaho National Laboratory operated by \\ Battelle Energy Alliance, Idaho Falls, ID
}

December 2014

Idaho National Laboratory

Idaho Falls, Idaho 83415

http://avt.inl.gov

Prepared for the

U.S. Department of Energy

Office of Nuclear Energy

Under DOE Idaho Operations Office

Contract DE-AC07-05ID14517 


\section{ABSTRACT}

Battelle Energy Alliance, LLC, managing and operating contractor for the U.S. Department of Energy's Idaho National Laboratory, is the lead laboratory for the U.S. Department of Energy's advanced vehicle testing. Battelle Energy Alliance, LLC contracted with Intertek Testing Services, North America (Intertek) to conduct several U.S. Department of Defense-based studies to identify potential U.S. Department of Defense transportation systems that are strong candidates for introduction or expansion of plug-in electric vehicles (PEVs). This study focused on Joint Base Lewis McChord (JBLM), which is located in Washington State.

Task 1 consisted of a survey of the non-tactical fleet of vehicles at JBLM to begin the review of vehicle mission assignments and the types of vehicles in service. In Task 2, daily operational characteristics of select vehicles were identified and vehicle movements were recorded in data loggers in order to characterize the vehicles' missions. In Task 3, the results of the data analysis and observations were provided. Individual observations of the selected vehicles provided the basis for recommendations related to PEV adoption (i.e., whether a battery electric vehicle or plug-in hybrid electric vehicle [collectively referred to as PEVs] can fulfill the mission requirements0, as well as the basis for recommendations related to placement of PEV charging infrastructure.

This report focuses on an implementation plan for the near-term adoption of PEVs into the JBLM fleet.

Intertek acknowledges the support of Idaho National Laboratory and JBLM fleet managers and personnel for participation in this study.

Intertek is pleased to provide this report and is encouraged by the enthusiasm and support from JBLM personnel. 


\section{EXECUTIVE SUMMARY}

Federal agencies are mandated ${ }^{a}$ to purchase alternative fuel vehicles, increase consumption of alternative fuels, and reduce petroleum consumption. Available plug-in electric vehicles (PEVs) provide an attractive option in the selection of alternative fuel vehicles. PEVs, which consist of both battery electric vehicles (BEVs) and plug-in hybrid electric vehicles (PHEVs), have significant advantages over internal combustion engine (ICE) vehicles in terms of energy efficiency, reduced petroleum consumption, and reduced production of greenhouse gas (GHG) emissions, and they provide performance benefits with quieter, smoother operation. This study intended to evaluate the extent to which Joint Base Lewis McChord (JBLM) could convert part or all of their fleet of vehicles from petroleum-fueled vehicles to PEVs.

More fuel-efficient ICE vehicles, including hybrid electric vehicles, exist that may provide improvements for the current fleet; however, PEVs are the focus of this study.

$\mathrm{BEVs}$ provide the greatest benefit when it comes to fuel and emissions savings because all motive power is provided by the energy stored in the onboard battery pack. These vehicles use no petroleum and emit no pollutants at their point of use. PHEVs provide similar savings when their battery provides all or the majority of motive power (depending on the PHEV design); however, they also have the ability to extend their operating range with an onboard ICE. Because a PHEV can meet all transportation range needs, adoption of a PHEV will be dependent on its ability to meet other transportation needs such as cargo or passenger capability. Operation of PHEVs in charge-depleting mode, where all or a majority of the motive power is provided by the battery, can be increased with opportunity charging at available charging stations. However, it should be noted that not all PHEVs have a mode where the battery provides all motive power at all speeds. Previous work on this study focused on the non-tactical fleet of vehicles at JBLM to identify a subset of 60 vehicles for data logging in an effort to identify vehicles that may be replaced with PEVs, with emphasis on $\mathrm{BEVs}$ that provide maximum benefit. This report provides an approach for the near-term adoption of PEVs at JBLM.

The geographic size of JBLM creates significant travel demands on its vehicle fleet and provides opportunities for conversion of some vehicles to PEVs. JBLM identified 1,595 vehicles in its fleet; four JBLM fleet managers selected 60 vehicles as representative of their fleets for participation in the study. The results of the data logging and analysis for these 60 vehicles and the extrapolation to the entire fleet were previously reported in the Task 3 report.

The Task 3 report observed that a mix of BEVs and PHEVs are capable of performing most of the required missions using BEVs for the short trips and PHEVs for the longer trips. It also observed that the replacement of vehicles in the current fleet could result in significant reductions in the emission of GHGs and in petroleum use, as well as reductions in fleet operating costs. The other

\footnotetext{
${ }^{a}$ Energy Policy act of 1992, Energy Policy Act of 2005, Executive Order 13423, and Energy Independence and Security Act of
} 2007. 
Task 3 report identified potential PEV charging locations should PEV replacement occur.

This report presents a replacement approach for the adoption of PEVs at JBLM. This approach provides a gradual introduction of PEVs into JBLM operation in these four groups and into the balance of the non-tactical fleet. The gradual approach provides a transitional period to allow greater experience in the operation, maintenance, and support of PEVs in their daily missions. The vehicles introduced by this approach provide for $30 \%$ of the fleet as PEVs in 2022, assuming the size of the fleet remains as it was in 2013. The projected PEV adoption rate for sedans, non-sedans, and total fleet is presented in Figure ES-1.

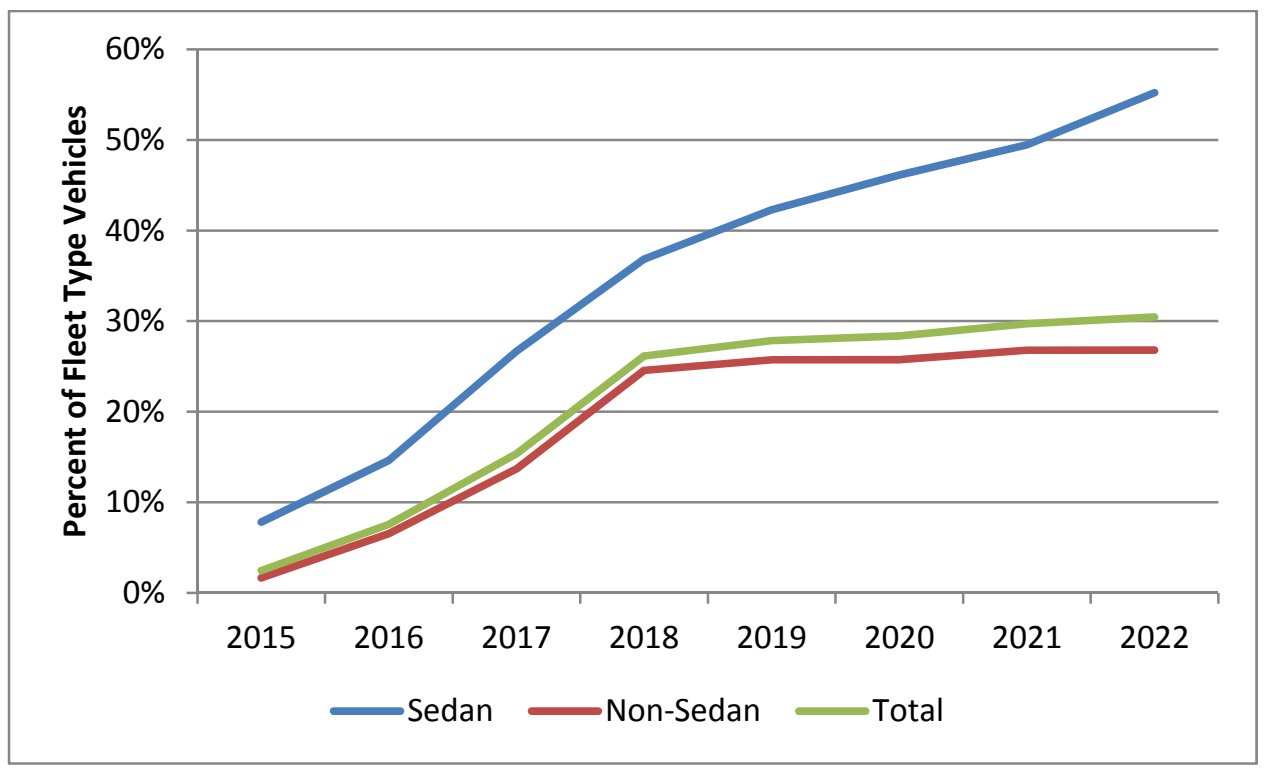

Figure ES-1. Projected PEV adoption rate at JBLM.

JBLM will decide whether to adopt PEVs as provided by the General Services Administration (GSA) only, which now consists only of sedan type vehicles, or to justify the adoption of non-GSA-listed vehicles. While the greater emphasis and initial adoption is for GSA-listed vehicles, both approaches are presented in this report. 


\section{CONTENTS}

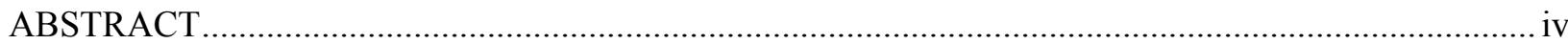

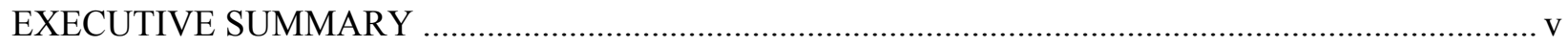

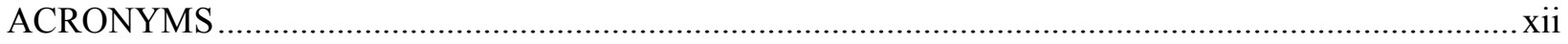

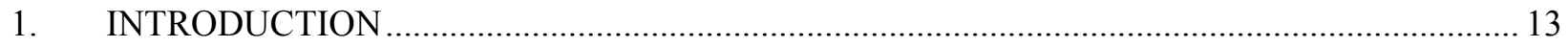

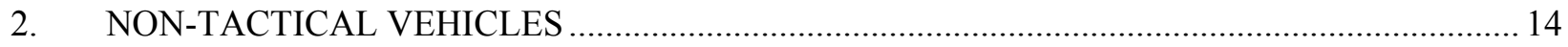

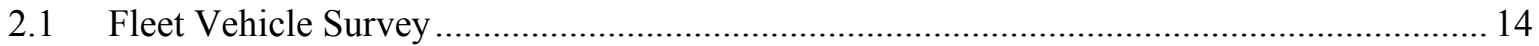

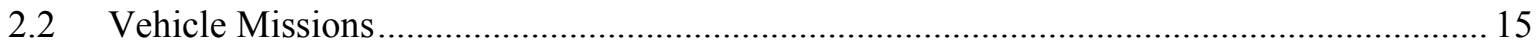

2.3 General Services Administration Vehicle Replacement Requirements ............................. 16

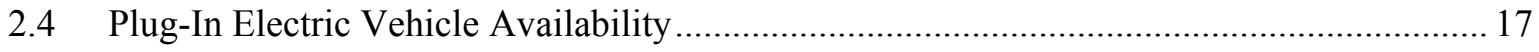

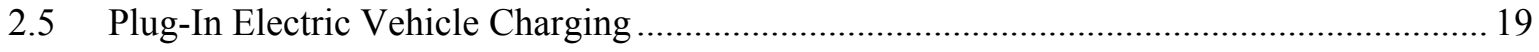

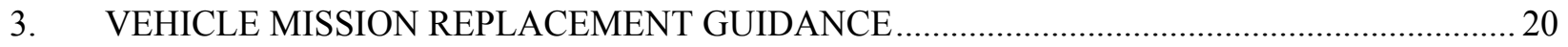

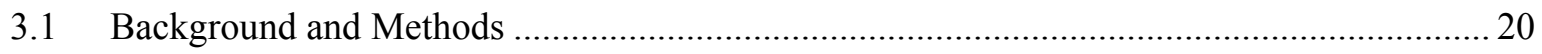

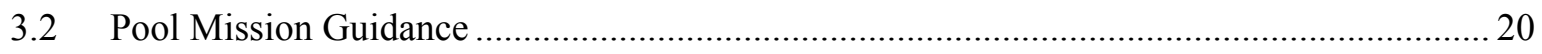

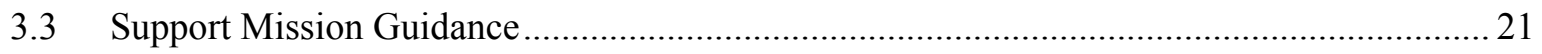

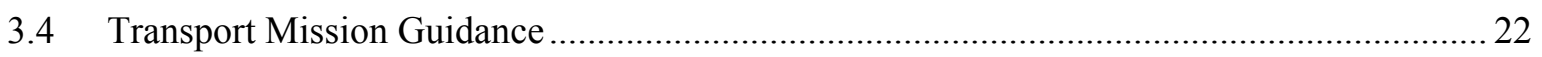

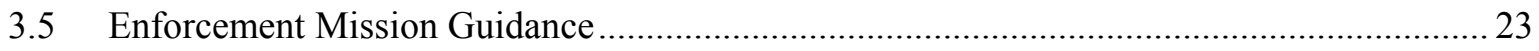

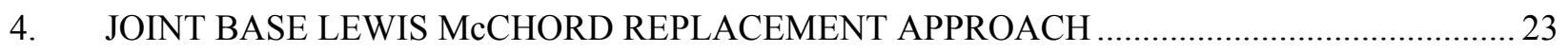

4.1 Joint Base Lewis McChord Summary Replacement Approach ......................................... 24

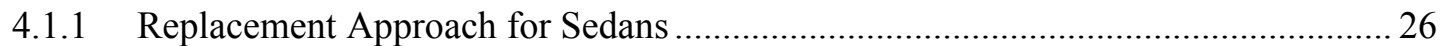

4.1.2 Replacement Approach for Non-Sedan Vehicles.................................................... 27

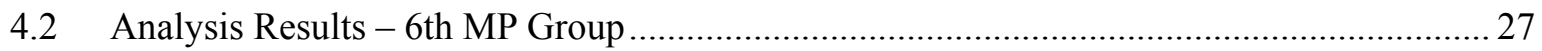

4.2.1 Replacement Approach for 6th MP Group Sedans ................................................ 28

4.2.2 Replacement Approach for 6th MP Group Non-Sedan Vehicles ............................. 28

4.3 Analysis Results - Directorate of Community Activities Support Group ......................... 28

4.3.1 Replacement Approach for the Directorate of Community Activities

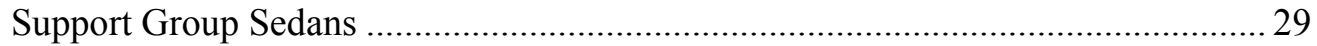

4.3.2 Replacement Approach for the Directorate of Community Activities

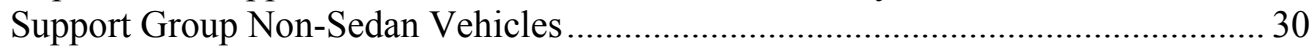




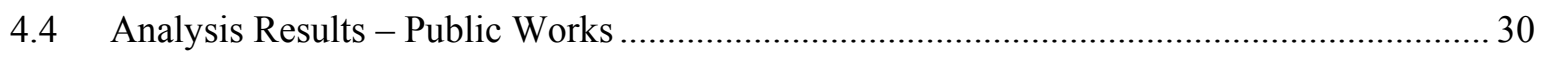

4.4.1 Replacement Approach for Public Works Sedans ................................................... 31

4.4.2 Replacement Approach for Public Works Non-Sedan Vehicles............................... 31

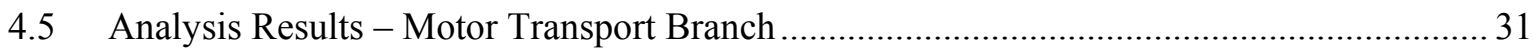

4.5.1 Replacement Approach for Motor Transport Branch Sedans .................................. 32

4.5.2 Replacement Approach for Motor Transport Non-Sedan Vehicles ........................... 32

4.6 Balance of Joint Base Lewis McChord Fleet ................................................................... 33

4.6.1 Replacement Approach for Balance of Fleet Sedans ................................................ 33

4.6.2 Replacement Approach for Balance of Fleet Non-Sedan Vehicles .......................... 34

5. PLUG-IN ELECTRIC VEHICLE CHARGING INFRASTRUCTURE ......................................... 34

5.1 Plug-In Electric Vehicle Charging Infrastructure for Sedans ........................................... 35

5.2 Plug-In Electric Vehicle Charging Infrastructure for Non-Sedan Fleet.............................. 35

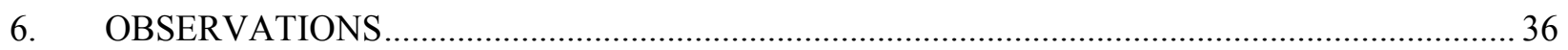

Appendix A, 6th MP Group Vehicle Data Sheets ........................................................................... A-1

Appendix B, DCA Support Group Vehicle Data Sheets.......................................................................... B-1

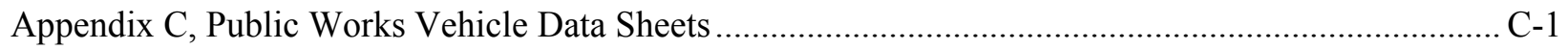

Appendix D, Motor Transport Branch Vehicle Data Sheets.............................................................. D-1

Appendix E, 6th MP Group Vehicle Replacement Approach ............................................................. E-1

Appendix F, DCA Support Group Vehicle Analysis .........................................................................

Appendix G, Public Works Group Vehicle Analysis..........................................................................

Appendix H, Motor Transport Branch Vehicle Analysis......................................................................

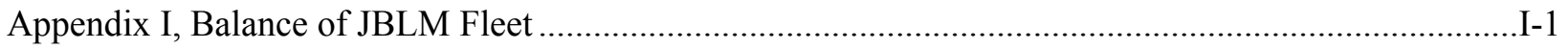

\section{FIGURES}

ES-1. Projected PEV adoption rate at JBLM.............................................................................

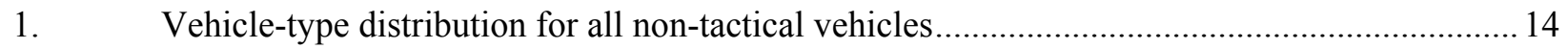

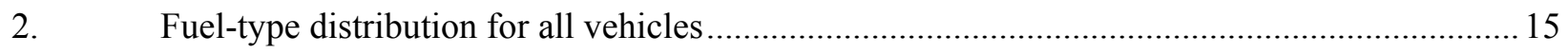

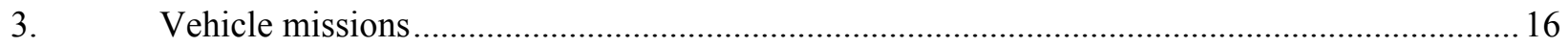




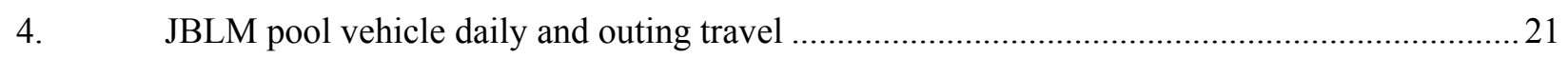

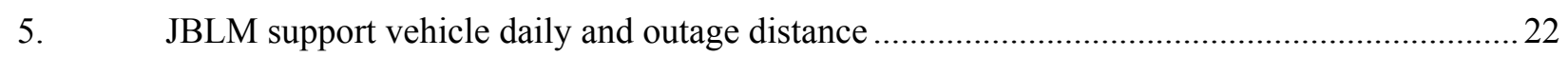

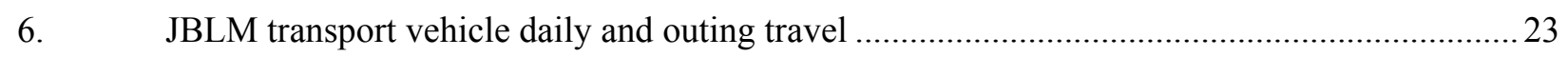

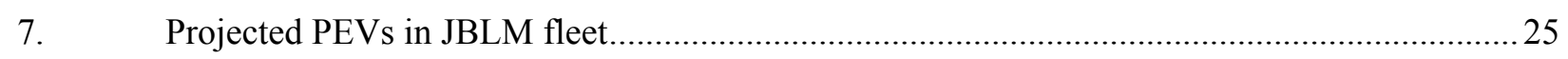

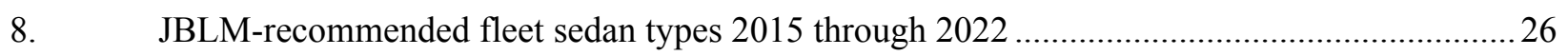

\section{TABLES}

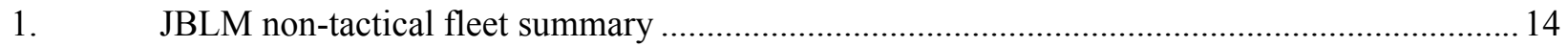

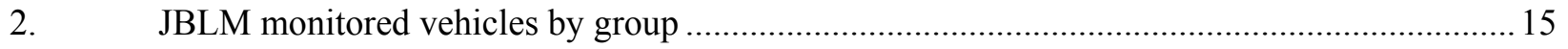

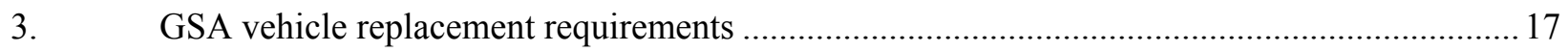

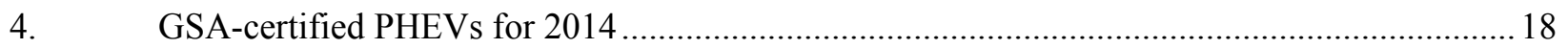

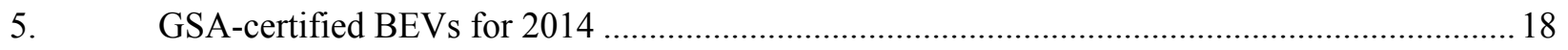

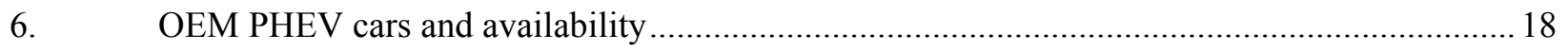

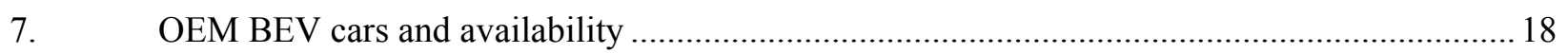

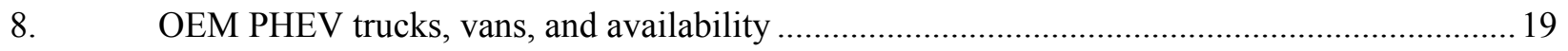

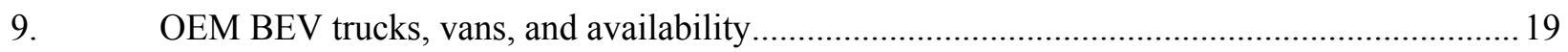

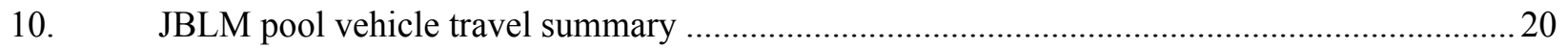

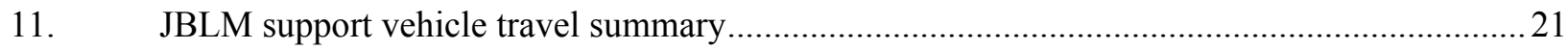

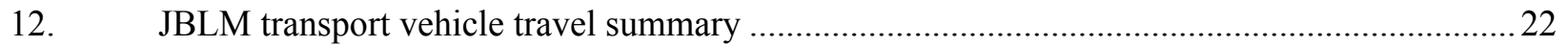

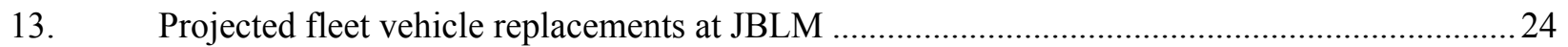

14. Projected approach for the introduction of PEVs into the JBLM fleet...................................25

15 .Planned approach for the introduction of PEV sedans at JBLM .......................................26

16. Planned approach for the introduction of non-sedan PEVs at JBLM ....................................27

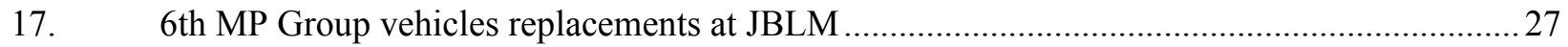

18. Planned approach for the introduction of PEV sedans in the 6th MP Group .........................28

19. Planned approach for the introduction of non-sedan PEVs in the 6th MP Group ...................28 
20. Projected DCA Support Group vehicle replacements at JBLM ...........................................29

21. Planned approach for the introduction of PEV sedans in the DCA Support Group ..................29

22. Planned approach for the introduction of non-sedan PEVs in the DCA Support Group............ 30

23. Projected Public Works vehicle replacements at JBLM......................................................... 30

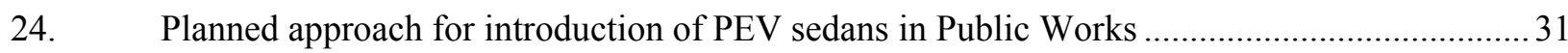

25. Planned approach for the introduction of non-sedan PEVs in Public Works ............................31

26. Projected Motor Transport Branch vehicle replacements at JBLM......................................... 32

27. Planned approach for the introduction of PEV sedans for the Motor Transport Branch............ 32

28. Planned approach for the introduction of non-sedan PEVs for the Motor Transport

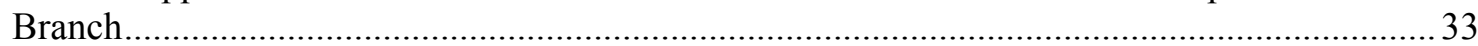

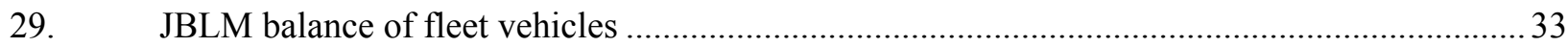

30. Planned approach for the introduction of PEV sedans in the balance of the JBLM fleet........... 34

31. Planned approach for the introduction of non-sedan PEVs in the balance of the JBLM

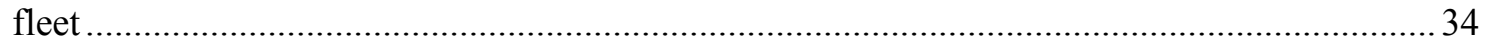

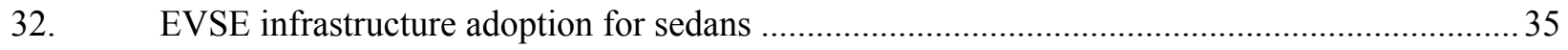

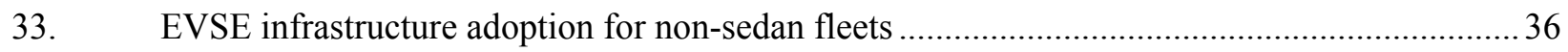

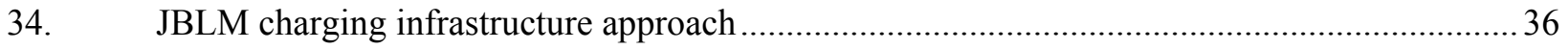

A-1. JBLM 6th MP Group vehicle replacement (GSA-listed vehicle) ........................................... A-1

A-2. JBLM 6th MP Group vehicle replacement (all potential vehicles) ........................................A-1

B-1. JBLM DCA Support Group vehicle replacement (GSA-listed vehicle)................................ B-1

B-2. JBLM DCA Support Group vehicle replacement (all potential vehicles) ............................ B-1

C-1. JBLM Public Works vehicle replacement (GSA-listed vehicle) ….......................................

C-2. JBLM Public Works vehicle replacement (all potential vehicles)........................................ C-1

D-1. JBLM Motor Transport Branch vehicle replacement (GSA-listed vehicle) ........................... D-1

D-2. JBLM Motor Transport Branch vehicle replacement (all potential vehicles) ........................ D-1

E-1. 6th MP Group all monitored vehicle replacement approach ............................................. E-1

E-2. 6th MP Group sedan fleet replacement approach .......................................................... E-1 
E-3. 6th MP Group near-term vehicles replacement approach …............................................. E-2

F-1. DCA Support Group all monitored vehicle replacement approach .................................... F-1

F-2. DCA Support Group sedan fleet replacement approach................................................ F-1

F-3. DCA Support Group near-term replacement approach ................................................... F-2

G-1. Public Works all monitored vehicle replacement approach .................................................

G-2. Public Works sedan fleet replacement approach ..............................................................

G-3. Public Works near-term replacement approach............................................................

H-1. Motor Transport Branch GSA vehicle replacement approach.............................................. H-1

H-2. Motor Transport Branch non-sedan monitored vehicle replacement approach........................ H-1

H-3. Motor Transport Branch sedan fleet replacement approach .................................................

H-4. Motor Transport Branch near-term non-sedan replacement approach ..................................H-4

I-1. Balance of Fleet sedan fleet replacement approach ............................................................ I-1

I-2. Balance of Fleet near-term replacement approach ........................................................... I-2 


\section{ACRONYMS}

$\mathrm{AC} \quad$ alternating current

BEV battery electric vehicle

CD charge depleting

CS charge sustaining

DC direct current

EPA U.S. Environmental Protection Agency

EVSE electric vehicle supply equipment

GHG greenhouse gas emissions

GSA General Services Administration

ICE internal combustion engine

Intertek Intertek Testing Services, North America

JBLM Joint Base Lewis McChord

OEM original equipment manufacturer

PEV plug-in electric vehicle (includes BEVs and PHEVs, but not hybrid electric vehicles)

PHEV plug-in hybrid electric vehicle

SUV sports utility vehicle 


\section{Implementation Approach for Plug-in Electric Vehicles at Joint Base Lewis McChord: Task 4 \\ 1. INTRODUCTION}

The U.S. Department of Energy and the U.S. Department of Defense signed a memorandum of understanding on July 22, 2010, for strengthening the coordination of efforts to enhance national energy security and to demonstrate federal government leadership in transitioning the United States to a low-carbon economy. The memorandum of understanding included efforts in the areas of energy efficiency, fossil fuels, alternative fuels, efficient transportation technologies and fueling infrastructure, grid security, smart grid, and energy storage.

In support of the memorandum of understanding, the Idaho National Laboratory, with funding provided by the U.S. Department of Energy's Vehicle Technologies Office and Federal Energy Management Program, directed Intertek Testing Services, North America (Intertek) to conduct several U.S. Department of Defense-based studies to identify potential transportation systems that are strong candidates for introduction or expansion of plug-in electric vehicles (PEVs). Intertek previously has conducted similar fleet, city, state, and countrywide studies using their Micro-Climate ${ }^{\circledR}$ assessment process, which consists of the following four main tasks:

- Task 1, Conduct a fleet and infrastructure assessment

- Task 2, Identify target electrification vehicles

- Task 3, Perform detailed assessment of target electrification vehicles and charging infrastructure

- Task 4, Provide an implementation approach for adoption of electric vehicles.

Assessment of the potential for replacing Joint Base Lewis McChord (JBLM; in Tacoma, Washington) fleet vehicles with PEVs starts with an assessment of the fleet vehicles' missions and vehicle characteristics. This assessment was conducted through a written survey completed by fleet managers and through field interviews of fleet drivers, as well as through instrumentation of vehicles. The Task 1 report, titled, Assessment of Data and Survey Results for Joint Base Lewis McChord, dated June 2013, provided a summary and assessment of General Services Administration (GSA) data and survey results.

PEVs generally are classified into two vehicle types: battery electric vehicles (BEVs) and plug-in hybrid electric vehicles (PHEVs). A BEV contains an onboard battery that provides all motive power. PHEVs also have an onboard battery that provides some motive power, but there is also another motive power source (such as a gasoline engine). PHEVs have, in general, two modes: (1) charge-depleting (CD) mode where the battery provides all or most (depending on the PHEV design) of the motive power and the battery is being depleted, and (2) charge-sustaining (CS) mode where the non-battery power source provides the majority of the motive power, while being supplemented by the battery power. The battery state of charge is maintained within a designed range. A BEV can be considered to operate solely in CD mode. Collectively, BEVs and PHEVs are referred to as PEVs.

The Task 1 report documented the identification of fleet vehicles that appeared to be good candidates for replacement by PEVs. The Task 2 report, titled, Identification of Joint Base Lewis McChord Vehicles for Installation of Data Loggers, dated June 2013, identified the 60 vehicles within the candidate groups for further monitoring and analysis through addition of vehicle data loggers. The data loggers were installed and data collected on the selected vehicles. The Task 3 report, titled, Detailed Assessment of Target Electrification Vehicles at Joint Base Lewis McChord, dated August 2014, provided a summary and details of the data collection for the monitored vehicles and extrapolated that to the entire non-tactical fleet of vehicles at JBLM. The other Task 3 report, titled, Detailed Assessment of Charging Infrastructure 
for Plug-in Electric Vehicles at Joint Base Lewis McChord, dated August 2014, provided the related charging infrastructure assessment. This report provides an implementation approach for adoption of PEVs at JBLM in the next few years.

\section{NON-TACTICAL VEHICLES \\ 2.1 Fleet Vehicle Survey}

JBLM reported 1,566 vehicles in its non-tactical fleet, not counting specialty vehicles, low-speed vehicles and non-powered vehicles (e.g., trailers). Four group fleet managers were involved in the monitoring of vehicles. Table 1 provides a summary of the vehicle types by class and group. Note that the inventory list does not always allow specific differentiation between cargo or passenger vans because the same body frame may be used for each. Consequently, some assumptions are made on type.

Table 1. JBLM non-tactical fleet summary.

\begin{tabular}{|c|c|c|c|c|c|c|c|c|c|c|}
\hline Fleet & $\begin{array}{c}\text { Sedan } \\
\text { Compact/ } \\
\text { Sub Com }\end{array}$ & $\begin{array}{c}\text { Sedan } \\
\text { Midsize/ } \\
\text { Large }\end{array}$ & SUV & $\begin{array}{l}\text { Mini } \\
\text {-van }\end{array}$ & $\begin{array}{c}\text { Cargo } \\
\text { Van }\end{array}$ & $\begin{array}{l}\text { Pass } \\
\text { Van }\end{array}$ & $\begin{array}{c}\text { Pickup } \\
\text { or LD } \\
\text { Truck } \\
\end{array}$ & $\begin{array}{c}\text { MD or } \\
\text { HD } \\
\text { Truck }\end{array}$ & Bus & Total \\
\hline 6th MP & 3 & 8 & 2 & 2 & - & 1 & 4 & - & - & 20 \\
\hline DCA & 8 & 2 & - & 1 & 8 & 8 & 19 & 5 & 1 & 52 \\
\hline Public Work & 5 & 1 & 10 & 3 & 22 & 52 & 121 & 33 & - & 247 \\
\hline Motor Transport & 26 & 96 & 115 & 98 & 110 & 202 & 280 & 73 & 56 & 1,056 \\
\hline Other & 12 & 18 & 44 & 25 & 10 & 25 & 51 & 3 & 1 & 189 \\
\hline Total & 54 & 125 & 171 & 129 & 150 & 288 & 475 & 114 & 58 & 1,564 \\
\hline
\end{tabular}

Figure 1 shows vehicle-type distribution for all vehicles for comparison.

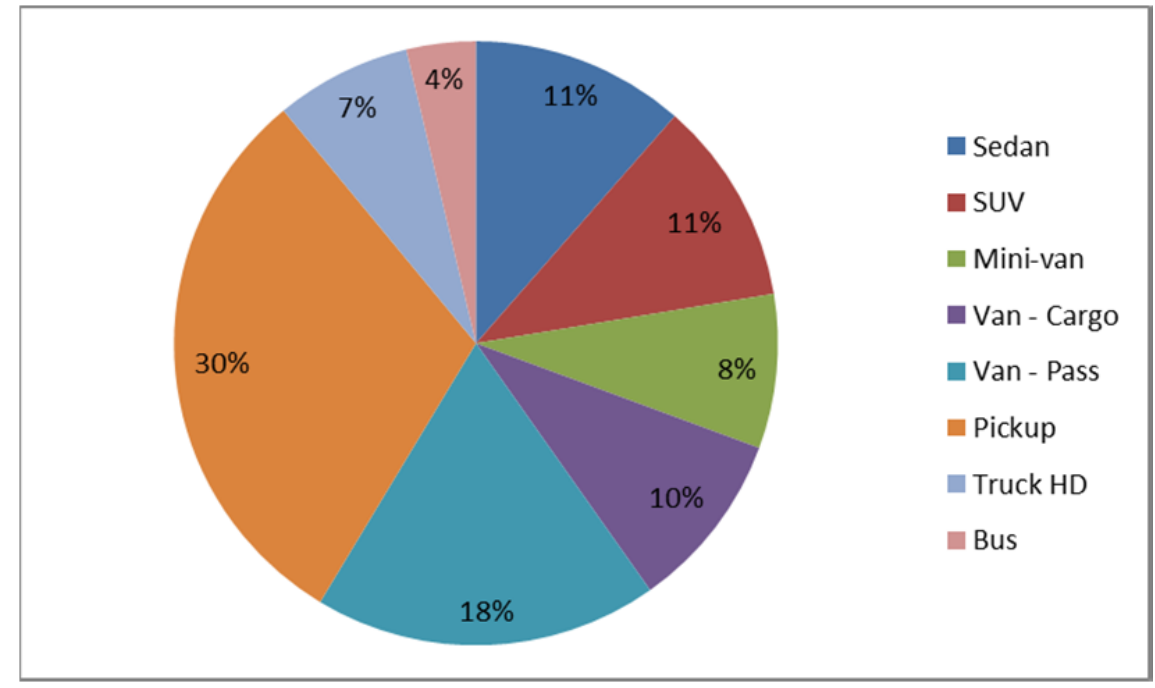

Figure 1. Vehicle-type distribution for all non-tactical vehicles.

JBLM identified 60 vehicles for further study, as described in the Task 2 report. This subset of vehicles contained eight sedans, seven minivans, four sports utility vehicles (SUVs), 20 pickup trucks, seven cargo vans, 11 passenger vans, and three heavy-duty trucks. (Note that one vehicle monitored was identified as assigned to two different fleet groups; therefore, the total in the table is greater than 60.) Table 2 categorizes the monitored vehicles. This distribution is approximately representative of the entire non-tactical fleet. 
Table 2. JBLM monitored vehicles by group.

\begin{tabular}{lcccccccccc}
\hline & $\begin{array}{c}\text { Sedan } \\
\text { Compact/ }\end{array}$ & $\begin{array}{c}\text { Sedan } \\
\text { Fidsize/ }\end{array}$ & \multicolumn{9}{c}{ Mini } & Cargo & Pass & $\begin{array}{c}\text { Pickup } \\
\text { or LD }\end{array}$ & MD or \\
Fo & Sub Com & Large & SUV & -van & Van & Van & Truck & Truck & Bus & Total \\
\hline $6^{\text {th }}$ MP & - & - & 1 & 1 & - & - & 1 & - & - & 3 \\
DCA & - & - & - & - & 1 & 1 & 1 & 1 & - & 4 \\
Public Work & - & - & - & 2 & - & 3 & 9 & - & - & 14 \\
Motor Transport & 4 & 4 & 3 & 5 & 6 & 7 & 9 & 2 & - & 40 \\
Total & 4 & 4 & 4 & 8 & 7 & 11 & 20 & 3 & - & 61 \\
\hline
\end{tabular}

Fleet vehicles are used for a variety of purposes by several different divisions on base. Section 2.2 provides detail on these purposes or missions. The category of the mission can be helpful in the identification of PEVs as potential replacements.

The initial survey also identified the fuel used by the fleet vehicles. In particular, cars and light trucks are powered predominantly by gasoline. These vehicle types make up the majority of the fleet and are the most likely candidates for replacement by electric vehicles, because, to date, auto manufacturers have focused on providing electric vehicles of this size. Diesel-powered vehicles also make up a sizeable fraction of the fleet; diesel is the predominant fuel used in larger vehicles. In particular, medium trucks are likely candidates for replacement by electric vehicles because manufacturers plan to provide more vehicles of this size in the coming years. Figure 2 illustrates the fuel types in use at JBLM.

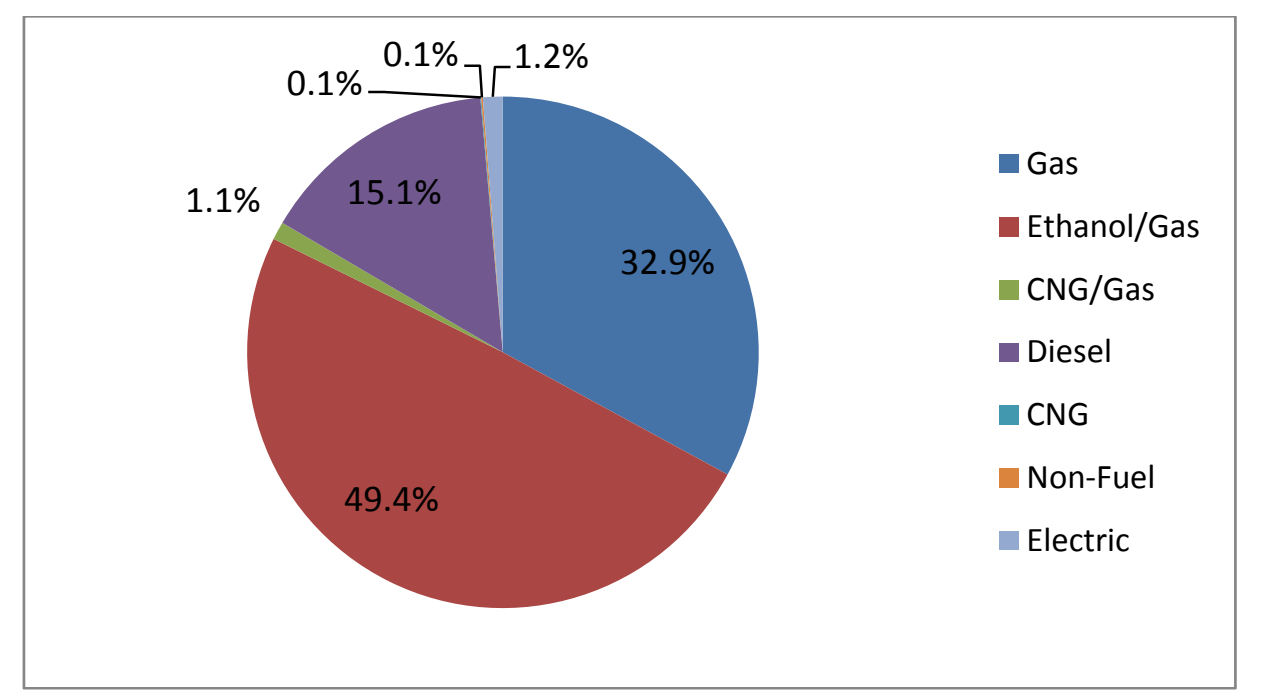

Figure 2. Fuel-type distribution for all vehicles.

\subsection{Vehicle Missions}

The vehicle mission is an important characteristic in the fleet study. Intertek has established the following seven mission/vehicle categories for analysis (examples are depicted in Figure 3):

1. Pool vehicles: A pool vehicle is any automobile (other than the low-speed vehicles identified below) manufactured primarily for use in passenger transportation, with not more than 10 passengers.

2. Enforcement vehicles: Vehicles specifically approved in an agency's appropriation act for use in apprehension, surveillance, police, or other law enforcement work. This category also includes site security vehicles, parking enforcement, and general use, but the vehicles are capable of requirements to support enforcement activities. 
3. Support vehicles: Vehicles assigned to a specific work function or group to support the mission of that group. Vehicles are generally passenger vehicles or light-duty pickup trucks and may contain after-market modifications to support the mission.

2. Transport vehicles: Light, medium, or heavy-duty trucks used to transport an operator and tools or equipment of a non-specific design or nature. The vehicle's possible uses include repair, maintenance, and delivery.

3. Specialty vehicles: Vehicles designed to accommodate a specific purpose or mission (such as ambulances, mobile cranes, and handicap controls).

4. Shuttles/buses: Vehicles designed to carry more than 12 passengers and further outlined in 49 CFR 532.2.

5. Low-speed vehicles: Vehicles that are legally limited to roads with posted speed limits up to 35 or $45 \mathrm{mph}$ (depending on state law) and that have a limited load-carrying capability.

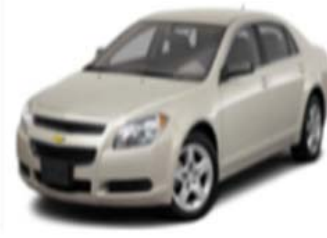

Pool Vehicle

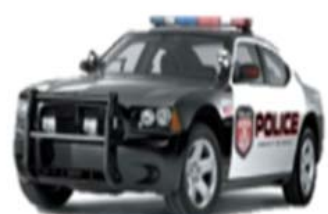

Enforcement Vehicle

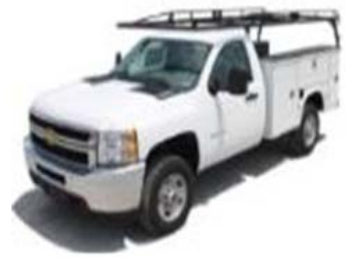

Support Vehicle

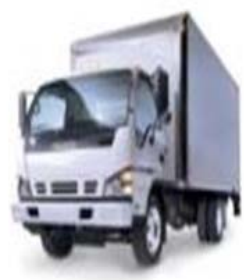

Transport Vehicle

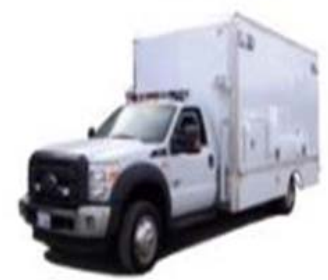

Specialty Vehicle

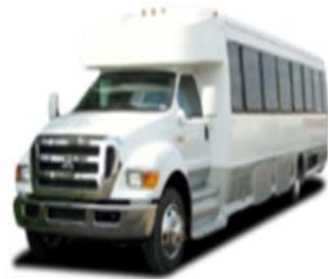

Shuttle / Bus

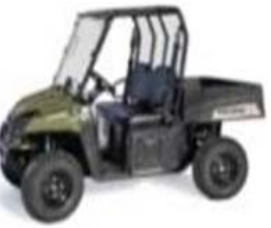

Low Speed

Vehicles

Figure 3. Vehicle missions.

Vehicle mission assignments can be useful in identifying the type of potential replacement PEVs (Section 3).

\subsection{General Services Administration Vehicle Replacement Requirements}

Table 3 presents the replacement requirements for fleet vehicles. Note that both the age and mileage requirements need to be met in order for the vehicle to qualify for replacement, except where noted as "or." 
Table 3. GSA vehicle replacement requirements.

\begin{tabular}{lccc}
\hline & GSA Vehicle Replacement Requirements & \\
& Fuel Type & Years & Miles \\
\hline Passenger vehicles & Gasoline or & 3 & 36,000 \\
& Alternative Fuel & 4 & 24,000 \\
& Vehicle & 5 & Any mileage \\
& Hybrid & Any age & 75,000 \\
& Low-Speed BEV & 5 & Any mileage \\
& Non-diesel & 6 & Any mileage \\
\hline Light trucks 4 x 2 & Diesel & 7 or & 65,000 \\
& Hybrid & 8 or & 150,000 \\
& Non-diesel & 7 & Any mileage \\
\hline Light trucks 4 x 4 & Diesel & 7 or & 60,000 \\
& Hybrid & 8 or & 150,000 \\
& Non-diesel & 7 & Any mileage \\
\hline Medium trucks & Diesel & 10 or & 100,000 \\
& Non-diesel & 10 or & 150,000 \\
\hline Heavy Trucks & Diesel & 12 or & 100,000 \\
& & 12 or & 250,000 \\
\hline
\end{tabular}

\subsection{Plug-In Electric Vehicle Availability}

The adoption of PHEVs and BEVs is a primary goal of GSA and supports many directives in this area. As GSA increases its certification of PHEVs and BEVs, agencies can plan for vehicle replacement through GSA for passenger vehicles and trucks. GSA provides a summary of light and medium-duty passenger vehicles available for lease or purchase through the GSA portal, ${ }^{3}$ although not all BEVs and PHEVs currently on the market are 'certified' to be GSA replacements. Vehicles not on the GSA list of 'certified' vehicles require an agency to self-certify a functional need or alternative measures for exemptions. Tables 4 and 5 summarize the vehicles that may be suitable replacements and are certified replacements through GSA. Note that the "CD/CS" column provides the U.S. Environmental Protection Agency (EPA) fuel economy values for the CD and CS modes of the PHEVs, while the city and highway fuel economy values are provided for BEVs. The fuel economy of the PHEV CD mode and BEVs are provided in units of miles-per-gallon-of-gasoline-equivalent (MPGe). This metric allows for electricity consumption to be compared with fuel consumption during CS mode (or against conventional vehicles). The Nissan Leaf and Mitsubishi i-MiEV are not included in the alternative fuel guide for 2014, but they have appeared in previous guides. For JBLM, the replacement is dependent on vehicle configuration characteristics and its ability to meet the vehicle's mission.

Original equipment manufacturers (OEM) provide information related to a vehicle's range in CD mode and EPA provides test results. However, actual results may vary depending on several factors other than travel that may also deplete a vehicle's battery. Such factors include changes in the battery's capacity over time, area topography, weather conditions (e.g., cabin cooling/heating), payload, etc. This report will

\footnotetext{
${ }^{2}$ http://www.gsa.gov/graphics/fas/VehicleReplacementStandardsJune2011Redux.pdf [accessed January 10, 2014]

${ }^{3}$ http://www.gsa.gov/portal/content/104211 [accessed August 1, 2014]
} 
identify a BEV's "safe range" as 70 miles (this is typically less than the advertised range of most BEV OEMs) and a PHEV's safe range in CD mode as 40 miles.

Tables 4 through 9 provide summaries of PHEVs and BEVs either currently available or near commercialization in both passenger cars and pickup trucks, but do not appear on the GSA 'certified' vehicle list. These vehicles may qualify for use by the agency through demonstrating a functional need.

Table 4. GSA-certified PHEVs for 2014

\begin{tabular}{lcccc}
\multicolumn{1}{c}{ Make/Model } & GSA Class & Type & CD/CS & GSA Incremental Price \\
\hline Chevrolet Volt & Sedan, Subcompact & PHEV & $98 \mathrm{MPGe} / 37 \mathrm{mpg}$ & $\$ 17,087.18$ \\
Ford C-MAX Energi & Sedan, Subcompact & PHEV & $88 \mathrm{MPGe} / 38 \mathrm{mpg}$ & $\$ 14,899.52$ \\
Ford Fusion Energi & Sedan, Compact & PHEV & $88 \mathrm{MPGe} / 38 \mathrm{mpg}$ & $\$ 19,289.99$ \\
\hline
\end{tabular}

Table 5. GSA-certified BEVs for 2014.

\begin{tabular}{ccccc} 
Make/Model & GSA Class & Type & City/Highway & GSA Incremental Price \\
\hline Ford Focus Electric & Sedan, Subcompact & BEV & $110 / 99 \mathrm{MPGe}$ & $\$ 16,573.09$ \\
\hline
\end{tabular}

Note that EPA differs from GSA in vehicle class designation. EPA identifies the Volt as a compact, the C-MAX Energi as a midsize, the Fusion Energi as a midsize, and the Focus as a compact. ${ }^{4}$

Table 6. OEM PHEV cars and availability.

\begin{tabular}{cccc}
\hline Make & EPA Class & Model & $\begin{array}{c}\text { Model Year/Estimated Year } \\
\text { for Commercialization }\end{array}$ \\
\hline Chevrolet & Compact & Volt & 2011 \\
Ford & Midsize & C-MAX Energi & 2013 \\
Ford & Midsize & Fusion Energi & 2013 \\
Toyota & Midsize & Prius PHEV & 2012 \\
Honda & Midsize & Accord PHEV & 2014 \\
BMW & Subcompact & i3 REx & 2014 \\
BMW & Subcompact & i8 & 2014 \\
Audi & Compact & A3 eTron PHEV & 2015 (estimate) \\
Volvo & SUV & V60 Plug-in & 2016 (estimate) \\
\hline
\end{tabular}

Table 7. OEM BEV cars and availability.

\begin{tabular}{cccc} 
Make & EPA Class & Model & $\begin{array}{c}\text { Model Year/Estimated Year } \\
\text { for Commercialization }\end{array}$ \\
\hline Nissan & Midsize & Leaf & 2011 \\
Ford & Compact & Focus Electric & 2012 \\
Tesla & Large & Model S & 2012 \\
Fiat & Mini & 500e & 2013 \\
Honda & Small Station Wagon & Fit EV & 2013 \\
BMW & Subcompact & i3 & 2014 \\
\hline
\end{tabular}

\footnotetext{
${ }^{4}$ http://www.fueleconomy.gov/feg/Find.do?action=sbs\&id=34130 [accessed August 1, 2014].
} 


\begin{tabular}{cccc}
\hline Make & EPA Class & Model & $\begin{array}{c}\text { Model Year/Estimated Year } \\
\text { for Commercialization }\end{array}$ \\
\hline Chevrolet & Subcompact & Spark EV & 2014 \\
smart & Two Seater & ED & 2014 \\
Kia & Small Station Wagon & Soul EV & 2014 \\
Volkswagen & Compact & Golf e-Golf & 2015 \\
Mercedes-Benz & Midsize & B-Class ED & 2015 (estimate) \\
Volvo & Compact & C30 Electric & 2016 (estimate) \\
\hline
\end{tabular}

Table 8. OEM PHEV trucks, vans, and availability.

\begin{tabular}{cccc} 
Make & EPA Class & Model & $\begin{array}{c}\text { Model Year/Estimated Year } \\
\text { for Commercialization }\end{array}$ \\
\hline Via & Standard Pickup Truck & VTRUX VR300 & 2013 \\
Via & Special Purpose Vehicle & VTRUX Cargo Van & 2013 \\
Via & Vans, Cargo Type & VTRUX Pass Van & 2013 \\
Mitsubishi & Small SUV & Outlander PHEV & 2015 (estimate) \\
Land Rover & Standard SUV & C30 Electric & 2016 (estimate) \\
\hline
\end{tabular}

Table 9. OEM BEV trucks, vans, and availability.

\begin{tabular}{cccc} 
Make & EPA Class & Model & $\begin{array}{c}\text { Model Year/Estimated Year } \\
\text { for Commercialization }\end{array}$ \\
\hline Toyota & SUV & RAV4 EV & $\begin{array}{c}2013 \text { (California only - } \\
\text { nationwide release date } \\
\text { unknown) }\end{array}$ \\
Tesla & Standard SUV & Model X & 2015 (estimate) \\
Land Rover & Standard SUV & C30 Electric & 2016 (estimate) \\
\hline
\end{tabular}

As further indication of the expanding market for PEVs, companies are offering after-market vehicle upgrades involving the addition of plug-in capabilities to OEM vehicles. For example, Echo Automotive headquartered in Scottsdale, Arizona offers a "...low-cost, bolt-on, plug-in hybrid system that can quickly be installed on new or existing fleet vehicles to increase fuel efficiency and decrease operating costs - all without affecting the OEM power train or requiring costly infrastructure." ${ }^{, 5}$ EAOS conducts upgrades of Ford F-series pickup trucks to PHEV models and has delivered vehicles to the U.S. Air Force ${ }^{6}$. Options such as these conversions might be of benefit for vehicles in the JBLM fleet for which no replacement PEV is currently available.

\subsection{Plug-In Electric Vehicle Charging}

Refueling electric vehicles presents some challenges and some opportunities not encountered when refueling petroleum-fueled vehicles. Recharging the battery of a PHEV follows the same methodology as that for BEVs. The Task 3 infrastructure report provides detailed information on recharging PEVs.

${ }^{5}$ http://www.echoautomotive.com/index.php?option=com content\&view=article\&id=8 [accessed July 14, 2014].

${ }^{6}$ http://www.evaos.com [accessed November 20, 2014]. 
Most PEV manufacturers supply an alternating current (AC) Level 1 cordset with the vehicle, which provides sufficient capabilities for some drivers, but more typically provides an emergency backup capability because of the long recharge times. AC recharging capabilities found in the public arena more typically are AC Level 2.

Because the battery of a BEV is typically much larger than that of a PHEV, recharge times are longer. BEVs that see daily mileage near the limits of the advertised range do better when recharged using AC Level 2 electric vehicle supply equipment (EVSE) or direct current (DC) fast charging (DCFC), because AC Level 1 recharge times are usually extensive. PHEVs, on the other hand, generally can use AC Level 1 EVSE for overnight charging to ensure a fully charged battery at the start of daily use. AC Level 2 EVSE units provide greater range in the shortest amount of time when intermediate or opportunity charging. DCFC provides the fastest recharge capability for those vehicles equipped with DCFC inlets; however, currently there are no PHEVs with DCFC capability available and no announced plans for one to be introduced. It is important to note that the Task 3 reports show that the PEVs studied do not need to rely on DCFC to complete their missions.

\section{VEHICLE MISSION REPLACEMENT GUIDANCE}

\subsection{Background and Methods}

Section 2.2 identified the mission categories for analysis. The Task 3 report provided specific information for the monitored fleet based on vehicle mission. When suitable PEV types are available to replace the ICE vehicles in the current fleet, the specific mission of the vehicle to be replaced can be a guide in determining whether a BEV or PHEV should be selected. As previously noted, the greater fuel cost savings and GHG reductions occur with BEVs than PHEVs, which suggests a greater emphasis on BEVs. For JBLM, the missions monitored included pool, support, and transport.

Aside from specific mission functions, the distance a PEV can travel in CD mode between charge opportunities is the most important factor in considering vehicle replacement. The two most significant considerations in vehicle analysis include the vehicle daily travel and vehicle outings.

\subsection{Pool Mission Guidance}

Thirty-five of the vehicles monitored at JBLM provided a pool mission. These vehicles included sedans of all sizes, SUVs, minivans, pickup trucks, passenger and cargo vans, and one heavy-duty truck. The overall summary for these vehicles is shown in Table 10. These vehicles traveled 29,255 miles, logged 1,537 hours, and idled for 416 hours.

Table 10. JBLM pool vehicle travel summary.

\begin{tabular}{lcccc}
\hline \multicolumn{4}{c}{ Pool Vehicles Travel Summary } & \\
& Per Day & Per Outing & Per Trip & \\
& Average/Peak & Average/Peak & Average/Peak & Total \\
\hline Travel Distance (Miles) & $27.9 / 571.2$ & $10.1 / 1,566.9$ & $3.8 / 202.5$ & 29,255 \\
Travel Time (Minutes) & $87.9 / 777.0$ & $32.0 / 1,897.0$ & $12.0 / 257.0$ & 92,244 \\
Idle Time (Minutes) & $23.8 / \mathrm{NA}$ & $8.7 / \mathrm{NA}$ & $3.2 / \mathrm{NA}$ & 25,011 \\
\hline
\end{tabular}

Figure 4 shows the daily travel and outing travel for the group of pool vehicles.

The highest daily travel distances of 571 miles and other infrequent trips above 100 miles do not display well on the above graphs because, individually, they contribute less than $1 \%$. The BEV safe range is considered to be 70 miles (blue and green bars in Figure 4) (i.e., while BEV range can vary based on several factors, most BEVs provide at least 70 miles of vehicle range on a single battery charge). However, collectively, the daily travel greater than 70 miles provides $9 \%$ of all daily travel. The single 
outings above 70 miles also do not display well on the above scale because each contribute less than $1 \%$ of outings, but collectively provide $3 \%$.
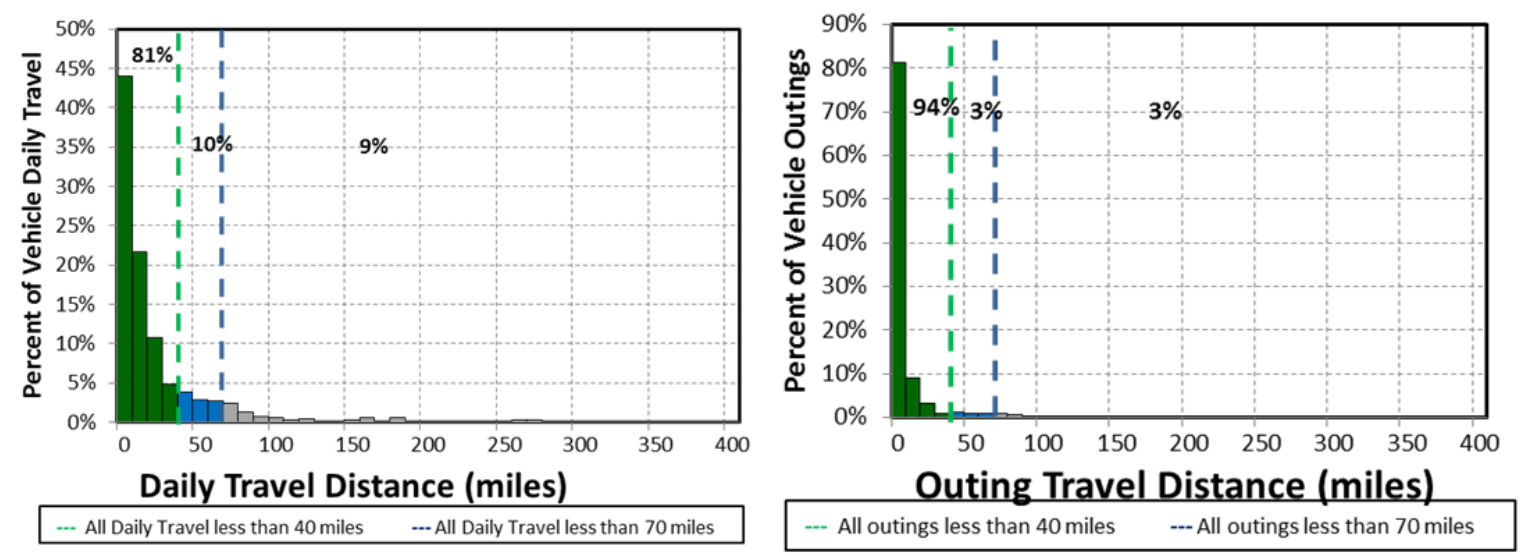

Figure 4. JBLM pool vehicle daily and outing travel.

When driven, the average travel distance per day for pool vehicles is 27.9 miles. On $91 \%$ of the vehicle travel days, the daily travel was less than the 70 miles considered to be within the BEV safe range. Meanwhile, $81 \%$ of vehicle travel days were less than the 40 miles considered to be within the CD range of a PHEV (green bars of Figure 4).

The average outing distance driven by pool vehicles was 10.1 miles, with $97 \%$ of the outing travel less than the 70 miles considered to be within the BEV safe range (blue and green bars in Figure 4). Meanwhile, $97 \%$ of vehicle outings were less than 40 miles considered to be within the CD range of a PHEV (green bars of Figure 4).

In general, if a suitable PEV body style meets vehicle requirements, $91 \%$ of the pool fleet could be BEVs and $9 \%$ PHEVs to allow for daily travel greater than the range of the BEV. The fleet manager would likely desire a more conservative approach to allow for flexibility, but this shows the high capability of BEVs to meet this pool mission at JBLM.

\subsection{Support Mission Guidance}

Nineteen of the vehicles monitored at JBLM provided a support mission. These vehicles included medium and large sedans, SUVs, minivans, pickup trucks, and passenger and cargo vans. The overall summary for these vehicles is shown in Table 11. These vehicles traveled 29,257 miles, logged 2,324 hours, and idled for 476 hours.

Table 11. JBLM support vehicle travel summary.

\begin{tabular}{|c|c|c|c|c|}
\hline \multicolumn{5}{|c|}{ Support Vehicles Travel Summary } \\
\hline & $\begin{array}{c}\text { Per Day } \\
\text { Average/Peak }\end{array}$ & $\begin{array}{c}\text { Per Outing } \\
\text { Average/Peak }\end{array}$ & $\begin{array}{c}\text { Per Trip } \\
\text { Average/Peak }\end{array}$ & Total \\
\hline Travel Distance (Miles) & $42.2 / 598.5$ & $12.8 / 1,236.1$ & $5.2 / 245.6$ & 29,257 \\
\hline Travel Time (Minutes) & $201.2 / 1,502.0$ & $60.8 / 1,440.0$ & $24.9 / 512.0$ & 139,463 \\
\hline Idle Time (Minutes) & $41.2 / \mathrm{NA}$ & $12.5 / \mathrm{NA}$ & $5.1 / \mathrm{NA}$ & 28,582 \\
\hline
\end{tabular}

Figure 5 shows the daily travel and outing travel for the group of support vehicles. 
The outing graph does not show the highest outings of 1,236 and 608.8 miles for clarity of scale. The scale of the graph also does not show the single outings above 70 miles, which individually provide $0 \%$ of the outings but collectively, account for $2 \%$.
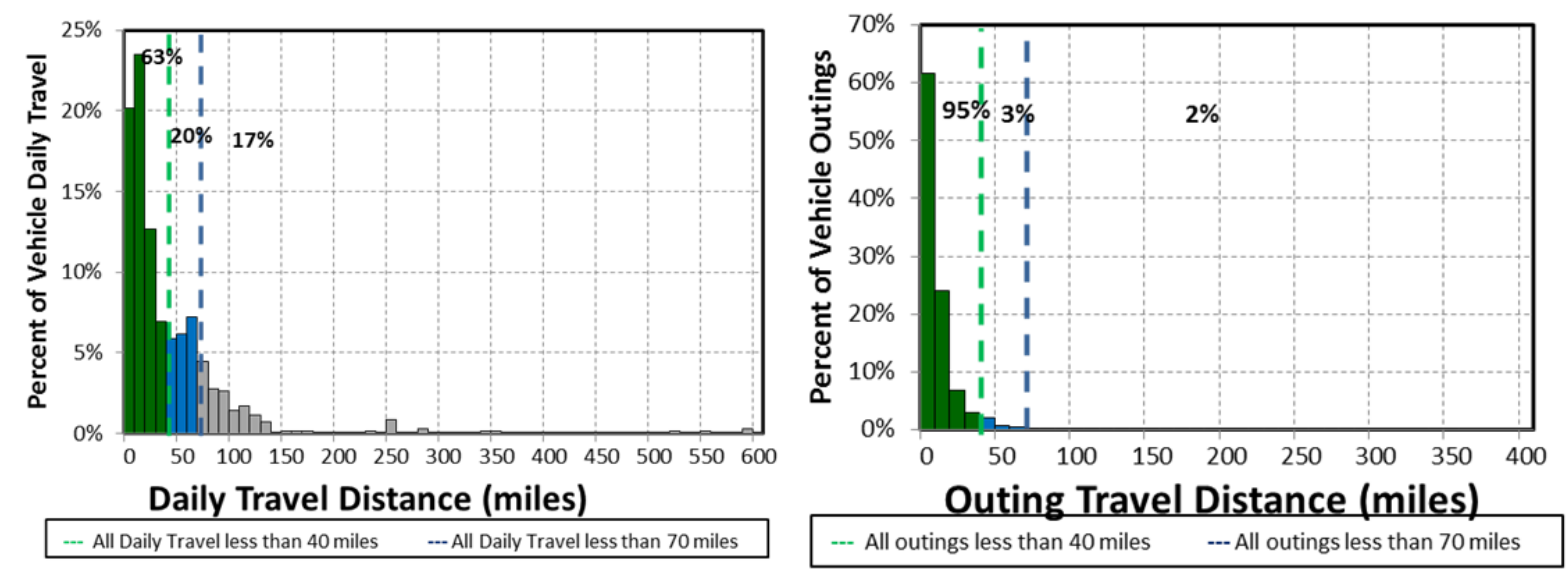

Figure 5. JBLM support vehicle daily and outage distance.

When driven, the average travel distance per day for support vehicles was 42.2 miles. On $83 \%$ of the vehicle travel days, the daily travel was less than the 70 miles considered to be within the BEV safe range (blue and green bars in Figure 5). Meanwhile, 63\% of vehicle travel days were less than the 40 miles considered to be within the CD range of a PHEV (green bars of Figure 5).

The average outing distance driven by support vehicles was 12.8 miles, with $98 \%$ of the outing travel less than the 70 miles considered to be within the BEV safe range (blue and green bars in Figure 5). Meanwhile, $95 \%$ of vehicle outings were less than 40 miles considered to be within the CD range of a PHEV (green bars of Figure 5).

In general, if a suitable PEV body style meets the vehicle requirements, $83 \%$ of a support fleet could be BEVs and $17 \%$ PHEVs to allow for daily travel greater than the range of the BEV. The fleet manager would likely desire a more conservative approach to allow for flexibility, but this shows the high capability of BEVs to meet this support mission at JBLM.

\subsection{Transport Mission Guidance}

Six of the vehicles monitored at JBLM provided a transport mission. Four vehicles failed to report sufficient data for analysis as noted in the Task 3 report. This is most likely due to infrequent use because there were few data points logged. These vehicles included pickup trucks, cargo vans, and heavy-duty trucks. The overall summary for these vehicles is shown in Table 12. These vehicles traveled 1,783 miles, logged 14.5 hours, and idled for 73 hours.

Table 12. JBLM transport vehicle travel summary.

\begin{tabular}{lcccc}
\hline \multicolumn{5}{c}{ Transport Vehicles Travel Summary } \\
& $\begin{array}{c}\text { Per Day } \\
\text { Average/Peak }\end{array}$ & $\begin{array}{c}\text { Per Outing } \\
\text { Average/Peak }\end{array}$ & $\begin{array}{c}\text { Per Trip } \\
\text { Average/Peak }\end{array}$ & Total \\
\hline Travel Distance (Miles) & $55.7 / 393.8$ & $24.5 / 393.8$ & $6.8 / 142.5$ & 1,783 \\
Travel Time (Minutes) & $245.9 / 669.0$ & $108.0 / 673.0$ & $30.0 / 218.0$ & 7,870 \\
Idle Time (Minutes) & $138.4 / \mathrm{NA}$ & $60.7 / \mathrm{NA}$ & $16.9 / \mathrm{NA}$ & 4,430 \\
\hline
\end{tabular}

Figure 6 shows the daily travel and outing travel for the group of transport vehicles. 

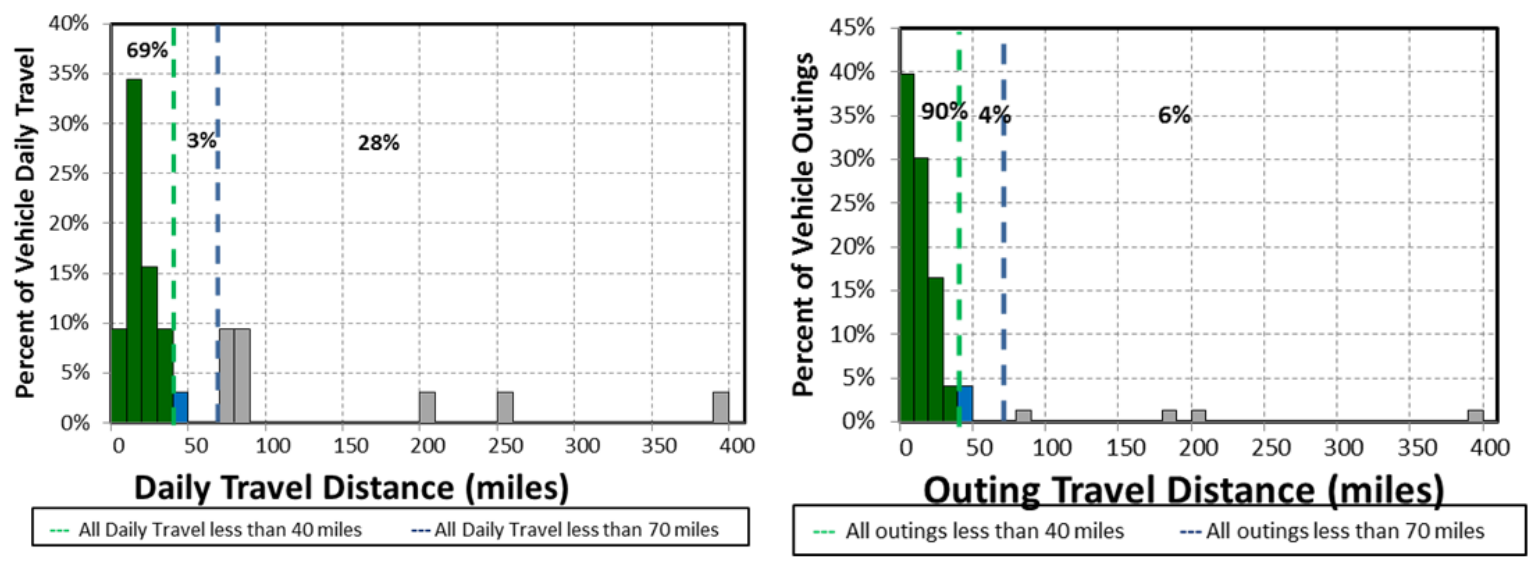

Figure 6. JBLM transport vehicle daily and outing travel.

The average travel distance per day when driven for transport vehicles was 55.7 miles. On $72 \%$ of the vehicle travel days, the daily travel was less than the 70 miles considered to be within the BEV safe range (blue and green bars in Figure 6). Meanwhile, 69\% of vehicle travel days were less than the 40 miles considered to be within the CD range of a PHEV (green bars of Figure 6).

The average outing distance driven by support vehicles is 24.5 miles, with $94 \%$ of the outing travel less than the 70 miles considered to be within the BEV safe range (blue and green bars in Figure 6). Meanwhile, $90 \%$ of vehicle outings were less than the 40 miles considered to be within the CD range of a PHEV (green bars of Figure 6).

In general, if a suitable PEV body style meets the vehicle requirements, $72 \%$ of a transport fleet could be BEVs and $28 \%$ PHEV to allow for daily travel greater than the range of the BEV. The fleet manager would likely desire a more conservative approach to allow for flexibility, but this shows the high capability of BEVs to meet this transport mission at JBLM.

\subsection{Enforcement Mission Guidance}

Enforcement vehicles typically are light-duty motor vehicles specifically approved in an agency's appropriation act for use in apprehension, surveillance, police, or other law enforcement work. Enforcement missions can vary by agency, location, and jurisdiction; however, they typically utilize sedans, minivans, vans, or small pickup trucks and typically do not carry specific cargo or equipment with the exception of K-9 units. Although no enforcement vehicles were monitored at JBLM, they generally involve relatively short travel distances and daily travel and tend to have high idle times. Many PEVs can provide suitable replacements for these vehicles, although, at times, the finite range of a BEV may not meet enforcement mission requirements. PHEVs can typically complete most enforcement missions, whereas BEVs can support routine travel functions such as parking enforcement.

\section{JOINT BASE LEWIS McCHORD REPLACEMENT APPROACH}

Sixty vehicles, belonging to four different fleet managers, were included in the study at JBLM. The specific requirements of each fleet manager necessitated that these data be analyzed for each individual fleet. The results were then extrapolated to the entire non-tactical fleet at JBLM.

Tables 4 and 5 identified that at the time of this report, GSA had certified four vehicles for replacement as PEVs: three PHEVs and one PEV. Consequently, the group of potential replacements involves only sedans - a rather small subset of fleet vehicles and only $11 \%$ of the vehicles at JBLM.

Tables 6 through 9 identified other vehicles that currently are or soon to be available but not listed by GSA. These vehicles provide potential replacements for all non-tactical fleet vehicles, except heavy-duty 
trucks, buses, and specialty vehicles. While the PEV market has introduced and delivered several specialty vehicles on heavy-duty truck frames (e.g., bucket trucks) and electric buses to several customers, their charging needs are typically also specialized and not included in this report. If all of these PEVs are included for replacement consideration, the potential includes $89 \%$ of the vehicles at JBLM.

After-market vehicle modifications are also available for converting ICE vehicles to PHEVs and may be considered by JBLM for vehicles types not currently available.

Appendices A through D provide the details of each monitored vehicle as reported in the Task 3 report. The replacement approach for each of the groups and the balance of the JBLM vehicles are presented in Appendices E through I.

There are four approaches identified for each group:

- Monitored vehicles

- GSA-listed PEVs only

- All potential PEV types

- Full fleet

- GSA-listed PEVs only

- All potential PEV types.

The extensive analysis conducted for monitored vehicles (Task 3 ) results in high confidence that the suggested vehicle can meet mission requirements. The suggested vehicles for the full fleet rely on the extrapolation of those monitored vehicles and the guidance identified in Section 3.

The overall plan is presented in this section and is followed by the effects to each of the fleet groups.

\subsection{Joint Base Lewis McChord Summary Replacement Approach}

Table 13 identified the types of vehicles by fleet group at JBLM at the time of the analysis. Supporting the incorporation of PEVs into this fleet is the objective of this task. At the time of the vehicle analysis, six PEVs were included in the fleet inventory at JBLM, not counting the low-speed vehicles. This group includes one Nissan Leaf and five Chevrolet Volts. Four of these vehicles were included in the Motor Transport Branch fleet. In general, fleet managers at JBLM have little experience managing PEVs and a considered approach for incorporation of these vehicles is suggested.

Table 13. Projected fleet vehicle replacements at JBLM.

\begin{tabular}{cccccccc} 
& & \multicolumn{7}{c}{ Cargo } & Pass. \\
Year & Sedan & SUV & Minivan & Van & Van & Pickup & Total \\
\hline 2015 & 48 & 66 & 91 & 93 & 109 & 274 & 681 \\
2016 & 27 & 27 & 18 & 19 & 52 & 51 & 194 \\
2017 & 36 & 48 & 11 & 5 & 64 & 47 & 211 \\
2018 & 28 & 25 & 7 & 22 & 62 & 90 & 234 \\
2019 & 13 & 5 & 2 & 1 & 1 & 7 & 29 \\
2020 & 8 & - & - & - & - & - & 8 \\
2021 & 7 & - & - & 10 & - & 6 & 23 \\
2022 & 12 & - & - & - & - & - & 12 \\
Total & 179 & 171 & 129 & 150 & 288 & 475 & 1,392 \\
\hline
\end{tabular}

The full fleet inventory was analyzed in 2013 and replacement vehicles are projected for 2015 and the following years. While some of these vehicles may have been replaced in 2014, there are sufficient vehicles available to substitute for specific vehicles if necessary. 
Table 14 provides the full fleet replacement projections based on GSA replacement criteria. Many of the JBLM vehicles have exceeded the minimal replacement criteria and this is expected to continue in the coming years in these projections. Note that heavy-duty trucks, specialty vehicles, and buses are excluded from this list.

The projected approach to PEV introduction is to replace selected ICE vehicles with PEVs as they would normally be replaced. The replacement approach presents a structured and gradual introduction of PEVs into the JBLM fleet. This approach is based on an increasing percentage of PEVs as replacements are considered over the next 8 years. While there are few PEVs currently in the JBLM fleet, this approach allows for growth in experience in managing, supporting, and maintaining the PEV fleet.

The projected introduction of PEVs into the fleet presented in Table 14 is based on an initial focus on sedans because they are the easiest to incorporate into the various missions and because these are the only types currently listed on the GSA schedule. Some of the remaining vehicle types are included to gain initial experience with the vehicle types, although they are not listed on the GSA schedule. GSA may list some of these vehicles in the next few years.

Table 14. Projected approach for the introduction of PEVs into the JBLM fleet.

\begin{tabular}{ccccccccc}
\hline Year & Sedan & SUV & Minivan & Van & Van & Pickup & Total & $\begin{array}{c}\text { Percent of all } \\
\text { Replacements }\end{array}$ \\
\hline 2015 & 17 & 2 & 6 & 3 & 1 & 8 & 37 & $5 \%$ \\
2016 & 12 & 9 & 9 & 8 & 13 & 20 & 71 & $37 \%$ \\
2017 & 21 & 15 & 10 & 4 & 30 & 28 & 108 & $51 \%$ \\
2018 & 18 & 16 & 6 & 18 & 33 & 59 & 150 & $64 \%$ \\
2019 & 10 & 4 & 2 & 1 & 1 & 6 & 24 & $83 \%$ \\
2020 & 7 & - & - & - & - & - & 7 & $88 \%$ \\
2021 & 6 & - & - & 8 & - & 5 & 19 & $83 \%$ \\
2022 & 8 & - & - & - & - & - & 8 & $67 \%$ \\
Total & 99 & 46 & 33 & 42 & 78 & 126 & 424 & \\
\hline
\end{tabular}

The vehicles introduced by this schedule would result in $30 \%$ of the fleet being PEVs in the year 2022 ,assuming the size of the fleet remains as it was in 2013 (Figure 7).

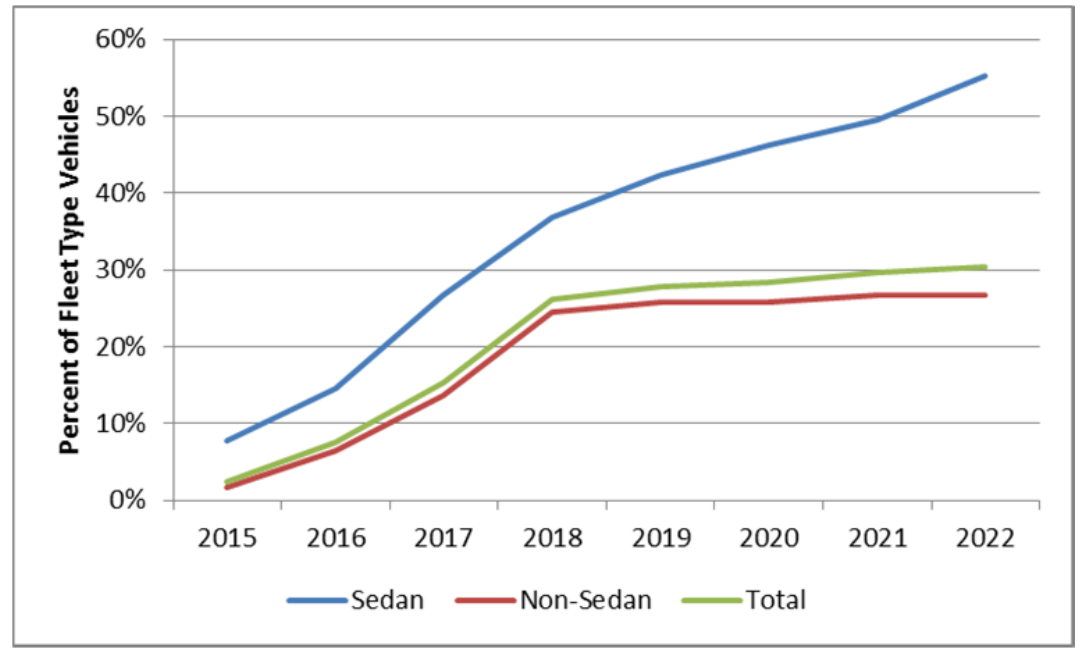

Figure 7. Projected PEVs in JBLM fleet. 
When considering the replacement of vehicles with PEVs, JBLM fleet managers may note the vehicle mission guidance of Section 3. It would be most desirable to select a BEV if the body type and capabilities meet the vehicle's mission in order to gain the most benefit in fuel cost and GHG emission reduction. In most cases, the greatest component of a particular fleet can be BEVs. The analysis in Task 3 shows the average vehicle travels less than 3,600 miles per year. This is an average of 300 miles per month or 75 miles per week. This also reflects the opportunity to increase the percentage of BEVs over PHEVs in each fleet.

\subsubsection{Replacement Approach for Sedans}

Table 15 presents a planned approach for the replacement of sedans with PEVs; this is the sedan portion of Table 14. With this approach, at the end of the 8-year period, 55\% of fleet sedans will be PEVs, with 53\% BEVs and 47\% PHEVs.

Table 15. Planned approach for the introduction of PEV sedans at JBLM.

\begin{tabular}{cccccccc}
\hline Year & ICE & PHEV & BEV & $\begin{array}{c}\text { Total } \\
\text { PEVs }\end{array}$ & $\begin{array}{c}\text { Vehicles } \\
\text { Replaced }\end{array}$ & $\begin{array}{c}\text { Percentage } \\
\text { PEV/Year }\end{array}$ & $\begin{array}{c}\text { Cumulative } \\
\text { Percent PEV }\end{array}$ \\
\hline 2015 & 31 & 8 & 9 & 17 & 48 & $35 \%$ & $9 \%$ \\
2016 & 15 & 6 & 6 & 12 & 27 & $44 \%$ & $16 \%$ \\
2017 & 15 & 11 & 10 & 21 & 36 & $58 \%$ & $28 \%$ \\
2018 & 10 & 7 & 11 & 18 & 28 & $64 \%$ & $38 \%$ \\
2019 & 3 & 5 & 5 & 10 & 13 & $77 \%$ & $44 \%$ \\
2020 & 1 & 3 & 4 & 7 & 8 & $88 \%$ & $47 \%$ \\
2021 & 1 & 4 & 2 & 6 & 7 & $86 \%$ & $51 \%$ \\
2022 & 4 & 3 & 5 & 8 & 12 & $67 \%$ & $55 \%$ \\
Total & 80 & 47 & 52 & 99 & 179 & & \\
\hline
\end{tabular}

Assuming the total fleet inventory remains at 179 sedans, this replacement approach results in the fleet composition shown in Figure 8 for the years 2015 through 2022.

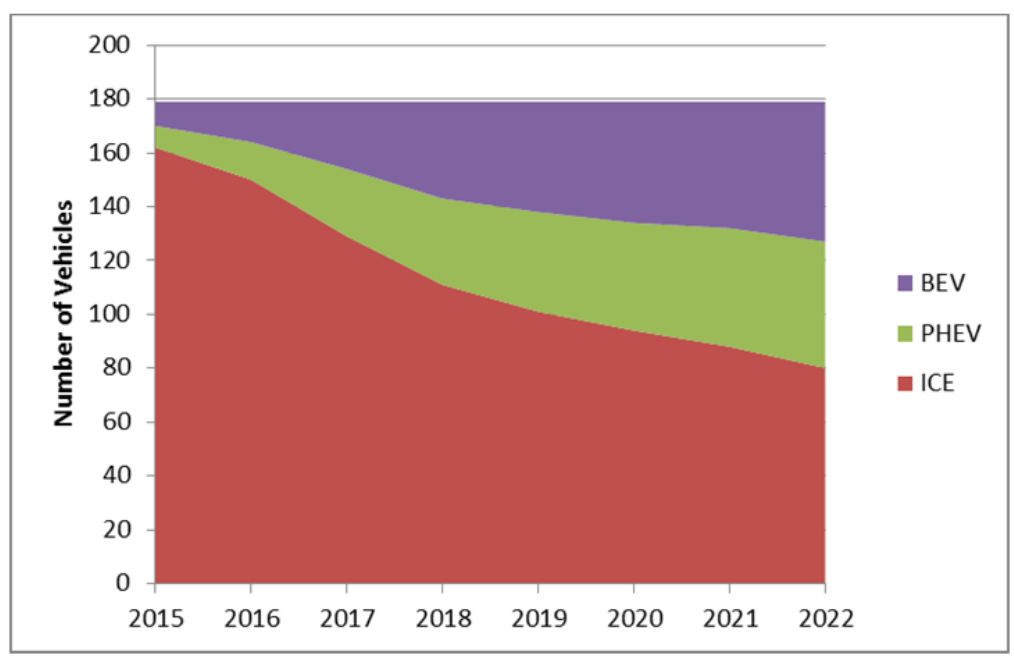

Figure 8. JBLM-recommended fleet sedan types 2015 through 2022.

See Table J-1 in Appendix J for a list of suggested replacement PEV sedans. 


\subsubsection{Replacement Approach for Non-Sedan Vehicles}

As noted above, the non-sedan portion of the JBLM fleet is presented separately because there are no current GSA-listed vehicles as potential replacements. These are included in the suggested replacement approach to allow JBLM to gain initial experience with the vehicle types. GSA may list some of these vehicles in the next few years. The non-sedan portion of Table 14 is shown in Table 16.

Table 16. Planned approach for the introduction of non-sedan PEVs at JBLM.

\begin{tabular}{|c|c|c|c|c|c|c|c|}
\hline Year & SUV & Minivan & $\begin{array}{c}\text { Cargo } \\
\text { Van }\end{array}$ & $\begin{array}{l}\text { Pass. } \\
\text { Van }\end{array}$ & Pickup & Total & $\begin{array}{l}\text { Percentage } \\
\text { PEV/Year }\end{array}$ \\
\hline 2015 & 2 & 6 & 3 & 1 & 8 & 20 & $3 \%$ \\
\hline 2016 & 9 & 9 & 8 & 13 & 20 & 59 & $35 \%$ \\
\hline 2017 & 15 & 10 & 4 & 30 & 28 & 87 & $50 \%$ \\
\hline 2018 & 16 & 6 & 18 & 33 & 59 & 132 & $64 \%$ \\
\hline 2019 & 4 & 2 & 1 & 1 & 6 & 14 & $88 \%$ \\
\hline 2020 & - & - & - & - & - & 0 & $0 \%$ \\
\hline 2021 & - & - & 8 & - & 5 & 13 & $81 \%$ \\
\hline 2022 & - & - & - & - & - & 0 & $0 \%$ \\
\hline Total & 46 & 33 & 42 & 78 & 126 & 325 & \\
\hline Percent & $27 \%$ & $26 \%$ & $28 \%$ & $27 \%$ & $27 \%$ & $27 \%$ & \\
\hline
\end{tabular}

With this approach, at the end of the 8-year period and assuming 1,213 vehicles remain in the total fleet, $27 \%$ of the non-sedan fleets will be PEVs, with approximately $27 \%$ of each type a PEV.

\subsection{Analysis Results - 6th MP Group}

The 6th MP Group fleet contains 20 vehicles; three of those vehicles were monitored in this study. The vehicles monitored included a minivan, an SUV, and a pickup truck. The details of each vehicle monitored are included in Appendix A. Appendix E provides the detailed evaluation for the approach summarized in the following sections.

Table 17 identifies the projected year the current vehicle will be replaced based on GSA requirements and extrapolated vehicle mileage. This table factors into the full table provided in Table 14.

Table 17. 6th MP Group vehicles replacements at JBLM.

\begin{tabular}{cccccccccc}
\hline & $\begin{array}{c}\text { Sedan } \\
\text { Compact/ } \\
\text { Year }\end{array}$ & $\begin{array}{c}\text { Sub Com } \\
\text { Sidsize }\end{array}$ & $\begin{array}{c}\text { Sedan } \\
\text { Large }\end{array}$ & $\begin{array}{c}\text { Mini- } \\
\text { van }\end{array}$ & SUV & $\begin{array}{c}\text { Cargo } \\
\text { Van }\end{array}$ & $\begin{array}{c}\text { Pass. } \\
\text { Van }\end{array}$ & $\begin{array}{c}\text { Pickup } \\
\text { or LD } \\
\text { Truck }\end{array}$ & Total \\
\hline 2015 & 1 & - & - & 2 & 1 & - & 1 & 1 & 6 \\
2016 & 2 & - & 2 & - & - & - & - & - & 4 \\
2017 & - & 1 & 1 & - & 1 & - & - & - & 3 \\
2018 & - & - & 2 & - & - & - & - & 3 & 5 \\
2019 & - & 1 & - & - & - & - & - & - & 1 \\
2020 & - & - & - & - & - & - & - & - & 0 \\
2021 & - & 1 & - & - & - & - & - & - & 1 \\
2022 & - & - & - & - & - & - & - & - & 0 \\
Total & 3 & 3 & 5 & 2 & 2 & 0 & 1 & 4 & 20 \\
\hline
\end{tabular}




\subsubsection{Replacement Approach for 6th MP Group Sedans}

Table 18 presents a planned approach for the replacement of sedans with PEVs that flows into the totals shown in Table 15. The percentage of vehicles replaced each year by PEVs is also shown.

Table 18. Planned approach for the introduction of PEV sedans in the 6th MP Group.

\begin{tabular}{cccccc}
\hline Year & ICE & PHEV & BEV & Total PEVs & Percentage PEV/Year \\
\hline 2015 & - & - & 1 & 1 & $100 \%$ \\
2016 & 3 & - & 1 & 1 & $25 \%$ \\
2017 & 1 & 1 & - & 1 & $50 \%$ \\
2018 & 1 & - & 1 & 1 & $50 \%$ \\
2019 & - & - & 1 & 1 & $100 \%$ \\
2020 & - & - & - & - & - \\
2021 & - & - & 1 & 1 & $100 \%$ \\
2022 & - & - & - & - & - \\
Total & 5 & 1 & 5 & 6 & \\
Percent & $45 \%$ & $9 \%$ & $45 \%$ & $55 \%$ & \\
\hline
\end{tabular}

The final complement of sedans includes 55\% PEVs, with a PEV component of $67 \%$ BEVs and $33 \%$ PHEVs. See Appendix E for the list of vehicles recommended for replacement in this approach.

\subsubsection{Replacement Approach for 6th MP Group Non-Sedan Vehicles}

Table 19 presents a planned approach for the replacement of non-sedans with PEVs that flows into the totals shown in Table 16. The percentage of non-sedan vehicles replaced each year by PEVs is also shown.

Table 19. Planned approach for the introduction of non-sedan PEVs in the 6th MP Group.

\begin{tabular}{cccccccc}
\hline Year & SUV & Minivan & Cargo Van & Pass. Van & Pickup & Total & Percentage PEV/Year \\
\hline 2015 & - & 1 & - & - & - & 1 & $20 \%$ \\
2016 & - & - & - & - & - & - & - \\
2017 & 1 & - & - & - & - & 1 & $100 \%$ \\
2018 & - & - & - & - & 2 & 2 & $67 \%$ \\
2019 & - & - & - & - & - & - & - \\
2020 & - & - & - & - & - & - & - \\
2021 & - & - & - & - & - & - & - \\
2022 & - & - & - & - & - & - & - \\
Total & 1 & 1 & - & - & 2 & 4 & \\
Percent & $50 \%$ & $50 \%$ & - & $0 \%$ & $50 \%$ & $44 \%$ & \\
\hline
\end{tabular}

In this approach, the final complement of non-sedans includes $44 \%$ PEVs. The proportion of each vehicle type is shown in Table 19. See Appendix E for the list of vehicles recommended for replacement in this approach.

\subsection{Analysis Results - Directorate of Community Activities Support Group}

The Directorate of Community Activities (DCA) support group fleet contains 52 vehicles; four of those vehicles were monitored in this study. This section provides a replacement strategy for this group. 
The details of each vehicle monitored are included in Appendix B. Appendix F provides the detailed evaluation for the approach summarized in the following sections.

The projected year the current vehicle will be replaced based on GSA requirements and extrapolated vehicle mileage is shown in Table 20. Note the heavy-duty trucks and bus are not included. This table is the DCA Support Group portion of Table 14.

Table 20. Projected DCA Support Group vehicle replacements at JBLM.

\begin{tabular}{cccccccccc}
\hline & $\begin{array}{c}\text { Sedan } \\
\text { Compact/ } \\
\text { Year }\end{array}$ & $\begin{array}{c}\text { Sub Com } \\
\text { Sudsize }\end{array}$ & $\begin{array}{c}\text { Sedan } \\
\text { Large }\end{array}$ & $\begin{array}{c}\text { Mini- } \\
\text { van }\end{array}$ & SUV & $\begin{array}{c}\text { Cargo } \\
\text { Van }\end{array}$ & $\begin{array}{c}\text { Pass. } \\
\text { Van }\end{array}$ & $\begin{array}{c}\text { Pickup } \\
\text { or LD } \\
\text { Truck }\end{array}$ & Total \\
\hline 2015 & - & - & - & - & - & 3 & 1 & 3 & 7 \\
2016 & - & - & - & - & - & 2 & 5 & 10 & 17 \\
2017 & - & - & - & - & - & - & 1 & 4 & 5 \\
2018 & - & 1 & - & - & - & 3 & 1 & 1 & 6 \\
2019 & - & - & - & 1 & - & - & - & 1 & 2 \\
2020 & - & - & - & - & - & - & - & - & 0 \\
2021 & 1 & 1 & - & - & - & - & - & - & 2 \\
2022 & 7 & - & - & - & - & - & - & - & 7 \\
Total & 8 & 2 & 0 & 1 & 0 & 8 & 8 & 19 & 46 \\
\hline
\end{tabular}

\subsubsection{Replacement Approach for the Directorate of Community Activities Support Group Sedans}

Table 21 presents a planned approach for the replacement of sedans with PEVs that flows into the totals shown in Table 15. The percentage of vehicles replaced each year by PEVs is also shown. Note that of the 10 sedans in the DCA Support Group, none are projected for replacement until 2018.

Table 21. Planned approach for the introduction of PEV sedans in the DCA Support Group.

\begin{tabular}{cccccc}
\hline Year & ICE & PHEV & BEV & Total PEVs & Percentage PEV/Year \\
\hline 2015 & - & - & - & - & - \\
2016 & - & - & - & - & - \\
2017 & - & - & - & - & - \\
2018 & - & - & 1 & 1 & $100 \%$ \\
2019 & - & - & - & - & - \\
2020 & - & - & - & - & - \\
2021 & 1 & 1 & - & 1 & $50 \%$ \\
2022 & 4 & 1 & 2 & 3 & $43 \%$ \\
Total & 5 & 2 & 3 & 5 & \\
Percent & $50 \%$ & $20 \%$ & $30 \%$ & $50 \%$ & \\
\hline
\end{tabular}

The final complement of sedans includes $50 \%$ PEVs, with a PEV component of $60 \%$ BEVs and $40 \%$ PHEVs. See Appendix F for the list of vehicles recommended for replacement in this approach. 


\subsubsection{Replacement Approach for the Directorate of Community Activities Support Group Non-Sedan Vehicles}

Table 22 presents a planned approach for the replacement of non-sedans with PEVs that flows into the totals shown in Table 16. The percentage of non-sedan vehicles replaced each year by PEVs is also shown.

Table 22. Planned approach for the introduction of non-sedan PEVs in the DCA Support Group.

\begin{tabular}{cccccccc}
\hline Year & SUV & Minivan & Cargo Van & Pass. Van & Pickup & Total & Percentage PEV/Year \\
\hline 2015 & - & - & - & - & 1 & 1 & $14 \%$ \\
2016 & - & - & 1 & 1 & 1 & 3 & $18 \%$ \\
2017 & - & - & - & 1 & 2 & 3 & $60 \%$ \\
2018 & - & - & 2 & 1 & - & 3 & $60 \%$ \\
2019 & - & 1 & - & - & 1 & 2 & $100 \%$ \\
2020 & - & - & - & - & - & 0 & - \\
2021 & - & - & - & - & - & 0 & - \\
2022 & - & - & - & - & - & 0 & - \\
Total & - & 1 & 3 & 3 & 5 & 12 & \\
Percent & $0 \%$ & $100 \%$ & $38 \%$ & $38 \%$ & $26 \%$ & $33 \%$ & \\
\hline
\end{tabular}

In this approach, the final complement of non-sedans includes 33\% PEVs. The proportion of each vehicle type is also shown. See Appendix F for the list of vehicles recommended for replacement in this approach.

\subsection{Analysis Results - Public Works}

The Public Works fleet contains 250 vehicles; 14 of these vehicles were monitored in this study. This section provides a replacement strategy for this group. The details of each vehicle monitored are included in Appendix C. Appendix G provides the detailed evaluation for the approach summarized in the following sections.

Table 23 identifies the projected year the current vehicle will be replaced based on GSA requirements and extrapolated vehicle mileage. Note the heavy-duty trucks and specialty vehicles are not included. This table is a subset of Table 14 .

Table 23. Projected Public Works vehicle replacements at JBLM.

\begin{tabular}{|c|c|c|c|c|c|c|c|c|c|}
\hline Year & $\begin{array}{c}\text { Sedan } \\
\text { Compact/ } \\
\text { Subcompact }\end{array}$ & $\begin{array}{c}\text { Sedan } \\
\text { Midsize }\end{array}$ & $\begin{array}{l}\text { Sedan } \\
\text { Large }\end{array}$ & $\begin{array}{l}\text { Mini- } \\
\text { van }\end{array}$ & SUV & $\begin{array}{c}\text { Cargo } \\
\text { Van }\end{array}$ & $\begin{array}{c}\text { Pass. } \\
\text { Van }\end{array}$ & $\begin{array}{l}\text { Pickup } \\
\text { or LD } \\
\text { Truck } \\
\end{array}$ & Total \\
\hline 2015 & - & - & - & 1 & 4 & 7 & 9 & 49 & 70 \\
\hline 2016 & - & - & - & - & - & - & 4 & 9 & 13 \\
\hline 2017 & - & - & - & 2 & 1 & 2 & 4 & 20 & 29 \\
\hline 2018 & 2 & - & 1 & - & 2 & 3 & 35 & 37 & 80 \\
\hline 2019 & 2 & - & - & - & 3 & - & - & 1 & 6 \\
\hline 2020 & - & - & - & - & - & - & - & - & - \\
\hline 2021 & 1 & - & - & - & - & 10 & - & 5 & 16 \\
\hline 2022 & - & - & - & - & - & - & - & - & - \\
\hline Total & 5 & 0 & 1 & 3 & 10 & 22 & 52 & 121 & 214 \\
\hline
\end{tabular}




\subsubsection{Replacement Approach for Public Works Sedans}

Table 24 presents a planned approach for the replacement of sedans with PEVs that flows into the totals shown in Table 15. The percentage of vehicles replaced each year by PEVs is also shown.

Table 24. Planned approach for introduction of PEV sedans in Public Works.

\begin{tabular}{cccccc}
\hline Year & ICE & PHEV & BEV & Total PEVs & Percentage PEV/Year \\
\hline 2015 & - & - & - & - & - \\
2016 & - & - & - & - & - \\
2017 & - & - & - & - & - \\
2018 & 2 & - & 1 & 1 & $33 \%$ \\
2019 & 1 & - & 1 & 1 & $50 \%$ \\
2020 & - & - & - & - & - \\
2021 & - & - & 1 & 1 & $100 \%$ \\
- & - & - & - & - & - \\
Total & 3 & - & 3 & 3 & \\
Percent & $50 \%$ & $0 \%$ & $50 \%$ & $50 \%$ & \\
\hline
\end{tabular}

The final complement of sedans includes 50\% PEVs, with the PEV proportion being all BEVs. See Appendix $\mathrm{G}$ for the list of vehicles recommended for replacement in this approach.

\subsubsection{Replacement Approach for Public Works Non-Sedan Vehicles}

Table 25 presents a planned approach for the replacement of non-sedans with PEVs that flows into the totals shown in Table 16. The percentage of non-sedan vehicles replaced each year by PEVs is also shown.

Table 25. Planned approach for the introduction of non-sedan PEVs in Public Works.

\begin{tabular}{cccccccc}
\hline Year & SUV & Minivan & Cargo Van & Pass. Van & Pickup & Total & Percentage PEV/Year \\
\hline 2015 & 1 & - & 1 & - & 2 & 4 & $6 \%$ \\
2016 & - & - & - & 1 & 2 & 3 & $23 \%$ \\
2017 & 1 & 2 & 1 & 3 & 6 & 13 & $45 \%$ \\
2018 & 1 & - & 2 & 12 & 20 & 35 & $45 \%$ \\
2019 & 1 & - & - & - & 1 & 2 & $50 \%$ \\
2020 & - & - & - & - & - & - & - \\
2021 & - & - & 8 & - & 4 & 12 & $80 \%$ \\
2022 & - & - & - & - & - & - & - \\
Total & 4 & 2 & 12 & 16 & 35 & 69 & \\
Percent & $40 \%$ & $67 \%$ & $55 \%$ & $31 \%$ & $29 \%$ & $33 \%$ & \\
\hline
\end{tabular}

In this approach, the final complement of non-sedans includes 33\% PEVs. The proportion of each vehicle type is also shown in Table 25. See Appendix G for the list of vehicles recommended for replacement in this approach.

\subsection{Analysis Results - Motor Transport Branch}

The Motor Transport Branch fleet contains 1,060 vehicles; 40 of those vehicles were monitored in this study. This section provides a replacement strategy for this fleet. The details of each vehicle monitored are included in Appendix D. Appendix H provides the detailed evaluation for the approach summarized in the following sections. 
Table 26 identifies the projected year the current vehicle will be replaced based on GSA requirements and extrapolated vehicle mileage. Without the heavy-duty trucks, specialty vehicles, and low-speed vehicles, 927 vehicles are included. This table factors into the full table provided in Table 14.

Table 26. Projected Motor Transport Branch vehicle replacements at JBLM.

\begin{tabular}{cccccccccc} 
& $\begin{array}{c}\text { Sedan } \\
\text { Compact/ }\end{array}$ & $\begin{array}{c}\text { Sedan } \\
\text { Year }\end{array}$ & $\begin{array}{c}\text { Subcompact } \\
\text { Midsize }\end{array}$ & Large & $\begin{array}{c}\text { Mini- } \\
\text { van }\end{array}$ & SUV & $\begin{array}{c}\text { Cargo } \\
\text { Van }\end{array}$ & $\begin{array}{c}\text { Pass. } \\
\text { Van }\end{array}$ & $\begin{array}{c}\text { Pickup } \\
\text { or LD }\end{array}$ \\
\hline 2015 & 3 & 11 & 31 & 71 & 39 & 75 & 87 & 190 & Total \\
2016 & 3 & 4 & 7 & 14 & 22 & 15 & 38 & 27 & 130 \\
2017 & 4 & 4 & 12 & 7 & 38 & 3 & 51 & 21 & 140 \\
2018 & 6 & 3 & 8 & 6 & 14 & 16 & 26 & 39 & 118 \\
2019 & 6 & 3 & 1 & - & 2 & 1 & - & 2 & 15 \\
2020 & - & 8 & - & - & - & - & - & - & 8 \\
2021 & 1 & 2 & - & - & - & - & - & 1 & 4 \\
2022 & 3 & 1 & 1 & - & - & - & - & - & 5 \\
Total & 26 & 36 & 60 & 98 & 115 & 110 & 202 & 280 & 927 \\
\hline
\end{tabular}

\subsubsection{Replacement Approach for Motor Transport Branch Sedans}

Table 27 presents a planned approach for the replacement of sedans with PEVs that flows into the totals shown in Table 15. The percentage of vehicles replaced each year by PEVs is also shown.

Table 27. Planned approach for the introduction of PEV sedans for the Motor Transport Branch.

\begin{tabular}{cccccc}
\hline Year & ICE & PHEV & BEV & Total PEVs & Percentage PEV/Year \\
\hline 2015 & 30 & 7 & 8 & 15 & $33 \%$ \\
2016 & 7 & 4 & 3 & 7 & $50 \%$ \\
2017 & 8 & 6 & 6 & 12 & $60 \%$ \\
2018 & 6 & 5 & 6 & 11 & $65 \%$ \\
2019 & 2 & 5 & 3 & 8 & $80 \%$ \\
2020 & 1 & 3 & 4 & 7 & $88 \%$ \\
2021 & - & 3 & - & 3 & $100 \%$ \\
2022 & - & 2 & 3 & 5 & $100 \%$ \\
Total & 54 & 35 & 33 & 68 & \\
Percent & $44 \%$ & $29 \%$ & $27 \%$ & $56 \%$ & \\
\hline
\end{tabular}

The final complement of sedans includes 56\% PEVs, with the PEV proportion being $51 \%$ BEVs and 49\% PHEVs. See Appendix H for the list of vehicles recommended for replacement in this approach.

\subsubsection{Replacement Approach for Motor Transport Non-Sedan Vehicles}

Table 28 presents a planned approach for the replacement of non-sedans with PEVs that flows into the totals shown in Table 16. The percentage of non-sedan vehicles replaced each year by PEVs is also shown.

In this approach, the final complement of non-sedans includes $25 \%$ PEVs. The proportion of each vehicle type is also shown in Table. See Appendix $\mathrm{H}$ for the list of vehicles recommended for replacement in this approach. 
Table 28. Planned approach for the introduction of non-sedan PEVs for the Motor Transport Branch.

\begin{tabular}{cccccccc}
\hline Year & SUV & Minivan & Cargo Van & Pass. Van & Pickup & Total & Percentage PEV/Year \\
\hline 2015 & 1 & 3 & 2 & 1 & 3 & 10 & $2 \%$ \\
2016 & 7 & 7 & 6 & 10 & 15 & 45 & $39 \%$ \\
2017 & 10 & 6 & 3 & 24 & 18 & 61 & $51 \%$ \\
2018 & 9 & 5 & 14 & 20 & 30 & 78 & $77 \%$ \\
2019 & 2 & - & 1 & - & 2 & 5 & $100 \%$ \\
2020 & - & - & - & - & - & - & - \\
2021 & - & - & - & - & 1 & 1 & $100 \%$ \\
2022 & - & - & - & - & - & - & - \\
Total & 29 & 21 & 26 & 55 & 69 & 200 & \\
Percent & $25 \%$ & $21 \%$ & $24 \%$ & $27 \%$ & $25 \%$ & $25 \%$ & \\
\hline
\end{tabular}

\subsection{Balance of Joint Base Lewis McChord Fleet}

The balance of the JBLM fleet consists of vehicles assigned to several agencies. None of these vehicles was monitored as part of the study. Table 29 provides the balance of vehicles at JBLM using information provided by JBLM and sorted by vehicle type. This table is a subset of Table 14.

Table 29. JBLM balance of fleet vehicles.

\begin{tabular}{cccccccccc}
\hline & $\begin{array}{c}\text { Sedan } \\
\text { Compact/ } \\
\text { Year }\end{array}$ & $\begin{array}{c}\text { Sedan } \\
\text { Subcompact }\end{array}$ & $\begin{array}{c}\text { Midsize } \\
\text { Sedan } \\
\text { Large }\end{array}$ & $\begin{array}{c}\text { Mini- } \\
\text { van }\end{array}$ & SUV & $\begin{array}{c}\text { Cargo } \\
\text { Van }\end{array}$ & $\begin{array}{c}\text { Pass. } \\
\text { Van }\end{array}$ & $\begin{array}{c}\text { Pickup } \\
\text { or LD } \\
\text { Truck }\end{array}$ & Total \\
\hline 2015 & 1 & 1 & - & 17 & 22 & 8 & 11 & 31 & 91 \\
2016 & 2 & 1 & 6 & 4 & 5 & 2 & 5 & 5 & 30 \\
2017 & 4 & 1 & 9 & 2 & 8 & - & 8 & 2 & 34 \\
2018 & 5 & - & - & 1 & 9 & - & - & 10 & 25 \\
2019 & - & - & - & 1 & - & - & 1 & 3 & 5 \\
2020 & - & - & - & - & - & - & - & - & - \\
2021 & - & - & - & - & - & - & - & - & - \\
2022 & - & - & - & - & - & - & - & - & - \\
Total & 12 & 3 & 15 & 25 & 44 & 10 & 25 & 51 & 185 \\
\hline
\end{tabular}

\subsubsection{Replacement Approach for Balance of Fleet Sedans}

Table 30 presents a planned approach for the replacement of sedans with PEVs that flows into the totals shown in Table 15. The percentage of vehicles replaced each year by PEVs is also shown. Appendix I provides the detailed evaluation for the approach summarized in the following sections.

The final complement of sedans includes 57\% PEVs, with the PEV proportion being $47 \%$ BEVs and $53 \%$ PHEVs. See Appendix I for the list of vehicles recommended for replacement in this approach. 
Table 30. Planned approach for the introduction of PEV sedans in the balance of the JBLM fleet.

\begin{tabular}{cccccc}
\hline Year & ICE & PHEV & BEV & Total PEVs & Percentage PEV/Year \\
2015 & 1 & 1 & & 1 & $50 \%$ \\
2016 & 5 & 2 & 2 & 4 & $44 \%$ \\
2017 & 6 & 4 & 4 & 8 & $57 \%$ \\
2018 & 1 & 2 & 2 & 4 & $80 \%$ \\
2019 & & & & & \\
2020 & & & & & \\
2021 & & & & & \\
2022 & & & & 17 & \\
Total & 13 & 9 & 8 & $57 \%$ & \\
Percent & $43 \%$ & $30 \%$ & $27 \%$ & & \\
\hline
\end{tabular}

\subsubsection{Replacement Approach for Balance of Fleet Non-Sedan Vehicles}

Table 31 presents a planned approach for the replacement of non-sedans with PEVs that flows into the totals shown in Table 16. The percentage of non-sedan vehicles replaced each year by PEVs is also shown.

Table 31. Planned approach for the introduction of non-sedan PEVs in the balance of the JBLM fleet.

\begin{tabular}{cccccccc}
\hline Year & SUV & Minivan & Cargo Van & Pass. Van & Pickup & Total & Percentage PEV/Year \\
\hline 2015 & - & 2 & - & - & 2 & 4 & $4 \%$ \\
2016 & 2 & 2 & 1 & 1 & 2 & 8 & $38 \%$ \\
2017 & 3 & 2 & - & 2 & 2 & 9 & $45 \%$ \\
2018 & 6 & 1 & - & - & 7 & 14 & $70 \%$ \\
2019 & 1 & 1 & - & 1 & 2 & 5 & $100 \%$ \\
2020 & - & - & - & - & - & - & - \\
2021 & - & - & - & - & - & - & - \\
2022 & - & - & - & - & - & - & - \\
Total & 12 & 8 & 1 & 4 & 15 & 40 & \\
Percen & $27 \%$ & $32 \%$ & $10 \%$ & $16 \%$ & $29 \%$ & $26 \%$ & \\
\hline
\end{tabular}

In this approach, the final complement of non-sedans includes $26 \%$ PEVs. The proportion of each vehicle type is also shown in Table 31. See Appendix I for the list of vehicles recommended for replacement in this approach.

\section{PLUG-IN ELECTRIC VEHICLE CHARGING INFRASTRUCTURE}

Preparations for the adoption of PEVs also require the consideration of recharging stations. With the potential replacements identified in the previous section, the deployment of fleet EVSE can be provided.

The Task 3 infrastructure report provides a detailed review of EVSE types and installation considerations. A detailed review of potential charging locations was completed and, for all of the monitored fleets, charging at the vehicle's home base is all that is required. JBLM may find future value in locating additional charging stations for employee or visitor use for privately owned vehicles, but those locations are not identified here.

The Task 3 report identifies AC Level 1 EVSE is sufficient for charging PHEVs, whereas AC Level 2 EVSE is recommended for BEVs. As JBLM begins the planned introduction of PEVs into the fleets, it is recommended that the initial vehicles be provided with AC Level 2 EVSE in order to gain experience 
with the charging systems and to provide the greatest charge return for all vehicles. In this manner, JBLM need not be concerned in the early years whether the vehicle is a PHEV or a BEV, but rather add infrastructure to accommodate AC Level 1 EVSE (that come standard with a PEV purchase) in later years. In addition, the Task 3 report identified that as experience is gained in the management of PEVs, there need not be an EVSE unit for every PEV. However, for these first vehicles, it is recommended that each be assigned its own EVSE unit at its home base.

Based on the replacement approach identified in Section 4, the charging infrastructure needs of sedans and non-sedan vehicles are discussed separately.

\subsection{Plug-In Electric Vehicle Charging Infrastructure for Sedans}

Table 32 provides the projected schedule for the introduction of EVSE to support the sedan replacement approach. As noted, AC Level 2 infrastructure is emphasized in the early adoption years over AC Level 1. In addition, the EVSE is introduced as dual units to reduce installation costs.

Table 32. EVSE infrastructure adoption for sedans.

\begin{tabular}{|c|c|c|c|c|c|c|}
\hline & 6th MP Group & $\begin{array}{l}\text { DCA Support } \\
\text { Group }\end{array}$ & $\begin{array}{l}\text { Public } \\
\text { Works }\end{array}$ & $\begin{array}{l}\text { Motor } \\
\text { Transport } \\
\text { Branch }\end{array}$ & $\begin{array}{c}\text { Balance of } \\
\text { Fleet }\end{array}$ & Total \\
\hline Year & AC L2/AC L1 & AC L2/AC L1 & AC L2/AC L1 & AC L2/AC L1 & ACL2/ACL1 & ACL2/ACL1 \\
\hline 2015 & $2 / 0$ & - & - & $16 / 0$ & $2 / 0$ & $20 / 0$ \\
\hline 2016 & - & - & - & $6 / 0$ & $4 / 0$ & $10 / 0$ \\
\hline 2017 & $0 / 2$ & - & - & $6 / 6$ & $0 / 8$ & $6 / 16$ \\
\hline 2018 & - & $2 / 0$ & $2 / 0$ & $4 / 8$ & $2 / 2$ & $10 / 10$ \\
\hline 2019 & $0 / 2$ & - & - & $2 / 6$ & - & $2 / 8$ \\
\hline 2020 & - & - & - & $0 / 8$ & - & $0 / 8$ \\
\hline 2021 & - & - & $2 / 0$ & $0 / 2$ & - & $2 / 2$ \\
\hline 2022 & - & $2 / 2$ & - & $0 / 4$ & - & $2 / 6$ \\
\hline Total & $2 / 4$ & $4 / 2$ & $4 / 0$ & $34 / 34$ & $8 / 10$ & $52 / 50$ \\
\hline
\end{tabular}

The Task 3 report detailed the potential for maximizing each group's conversion to PEVs and the potential savings in fuel costs and GHG emissions that result. The above table only considers the adoption approach identified in this report and results in fewer EVSE units than that reported in Task 3.

\subsection{Plug-In Electric Vehicle Charging Infrastructure for Non-Sedan Fleet}

Table 33 provides the schedule for the introduction of EVSE to support the non-sedan fleet replacement approach. Again, AC Level 2 infrastructure is emphasized in the early adoption years over AC Level 1. In addition, the EVSE is introduced as dual units to reduce installation costs. This report does not detail the selection of BEVs or PHEVs for the non-sedan fleet; however, the proportion identified in Task 3 is used for the final configurations for each fleet group.

The Task 3 report detailed the potential for maximizing each group's conversion to PEVs and the potential savings in fuel costs and GHG emissions that result. The above table only considers the adoption approach identified in this report and thus results in fewer EVSE units than that reported in Task 3. The Task 3 infrastructure report provides recommendations regarding placement of these EVSE units. 
Table 33. EVSE infrastructure adoption for non-sedan fleets.

\begin{tabular}{ccccccc}
\hline & \multicolumn{7}{c}{$\begin{array}{c}\text { Motor } \\
\text { 6th MP } \\
\text { Group }\end{array}$} & $\begin{array}{c}\text { DCA Support } \\
\text { Group }\end{array}$ & $\begin{array}{c}\text { Public } \\
\text { Works }\end{array}$ & $\begin{array}{c}\text { Transport } \\
\text { Branch } \\
\text { Year }\end{array}$ & AC L2/AC L1 & AC L2/AC L1 & $\begin{array}{c}\text { Balance of } \\
\text { AC2/AC L1 }\end{array}$ & AC L2/AC L1 \\
AC L2/AC L1 & AC L2/AC L1 \\
\hline 2015 & $2 / 0$ & $2 / 0$ & $4 / 0$ & $10 / 0$ & $4 / 0$ & $22 / 0$ \\
2016 & - & $2 / 0$ & $4 / 0$ & $46 / 0$ & $8 / 0$ & $60 / 0$ \\
2017 & - & $0 / 4$ & $6 / 6$ & $20 / 40$ & $2 / 8$ & $28 / 58$ \\
2018 & $0 / 2$ & $0 / 2$ & $20 / 16$ & $12 / 66$ & $4 / 10$ & $36 / 96$ \\
2019 & - & $0 / 2$ & $0 / 2$ & $2 / 4$ & $0 / 4$ & $2 / 12$ \\
2020 & - & - & - & - & - & - \\
2021 & - & - & $4 / 8$ & - & - & $4 / 8$ \\
2022 & - & - & - & - & - & - \\
Total & $2 / 2$ & $4 / 8$ & $38 / 32$ & $90 / 110$ & $18 / 22$ & $152 / 174$ \\
\hline
\end{tabular}

Table 34 summarizes the fleet's charging needs.

Table 34. JBLM charging infrastructure approach.

\begin{tabular}{|c|c|c|c|c|c|c|}
\hline & $\begin{array}{l}\text { 6th MP } \\
\text { Group }\end{array}$ & $\begin{array}{l}\text { DCA Support } \\
\text { Group }\end{array}$ & $\begin{array}{l}\text { Public } \\
\text { Works }\end{array}$ & $\begin{array}{c}\text { Motor Transport } \\
\text { Branch }\end{array}$ & $\begin{array}{l}\text { Balance of } \\
\text { Fleet }\end{array}$ & Total \\
\hline Year & AC L2/AC L1 & AC L2/AC L1 & AC L2/AC L1 & AC L2/AC L1 & AC L2/AC L1 & AC L2/AC L1 \\
\hline Sedan & $2 / 4$ & $4 / 2$ & $4 / 0$ & $34 / 34$ & $8 / 10$ & $52 / 50$ \\
\hline Non-Sedan & $2 / 2$ & $4 / 8$ & $38 / 32$ & $90 / 110$ & $18 / 22$ & $152 / 174$ \\
\hline Total & $4 / 6$ & $8 / 10$ & $42 / 32$ & $124 / 144$ & $26 / 32$ & $204 / 224$ \\
\hline
\end{tabular}

\section{OBSERVATIONS}

As a result of this intensive study, Intertek suggests JBLM is poised for the successful introduction of PEVs into daily operation and that BEVs can provide support for most of the vehicle missions, while providing savings in fuel costs and GHG emissions. In meeting the directives and mandates, the adoption approach outlined here should provide input to JBLM's overall strategy and presents an opportunity to gain experience in the operation, support, and maintenance of PEVs. It is suggested that JBLM may wish to move forward, in the near future, with the replacement of pool, support, and transport vehicles with PEVs as current budget considerations allow. Certainly, the vehicle types studied in this report may be candidates for immediate replacement.

Intertek appreciates presenting the results of this evaluation and working with JBLM personnel in this study. 


\section{Appendix A 6th MP Group Vehicle Data Sheets}

Note: the replacement year identified in the following data sheets is the earliest year available for potential replacement based on the GSA requirements noted in Table 3. The final replacement approach may suggest later years based on vehicle use.

Table A-1 identifies a potential replacement approach for vehicles currently on the GSA list.

Table A-1. JBLM 6th MP Group vehicle replacement (GSA-listed vehicle).

\begin{tabular}{|c|c|c|c|c|c|}
\hline \multicolumn{6}{|c|}{ GSA-Listed Vehicle Replacement Approach } \\
\hline $\begin{array}{c}\text { Fleet } \\
\text { Vehicle Id }\end{array}$ & Make/Model & Year & EPA Class & $\begin{array}{c}\text { GSA Replacement } \\
\text { Vehicle }\end{array}$ & $\begin{array}{c}\text { Replacement } \\
\text { Year }\end{array}$ \\
\hline G61-0546L & GMC Terrain & 2011 & SUV & NA & NA \\
\hline G61-0689A & Ford Ranger & 2004 & Pickup & NA & NA \\
\hline G41-5433B & Dodge Caravan & 2006 & Minivan & NA & NA \\
\hline
\end{tabular}

Table A-2 identifies a potential replacement approach using all currently or soon-to-be available PEVs.

Table A-2. JBLM 6th MP Group vehicle replacement (all potential vehicles).

All Vehicle Replacement Approach

Fleet

\begin{tabular}{cccccc} 
Vehicle Id & Make/Model & Year & EPA Class & Vehicle & Year \\
\hline G61-0546L & GMC Terrain & 2011 & SUV & Toyota Rav4 EV & 2018 \\
G61-0689A & Ford Ranger & 2004 & Pickup & Via VTRUX PU & 2015 \\
G41-5433B & Dodge Caravan & 2006 & Minivan & Nissan Leaf & 2015 \\
\hline
\end{tabular}




\section{Vehicle}

\section{G61-0546L}

\begin{tabular}{|l|l|c|}
\hline & Make/Model/Year & GMC/Terrain/2011 \\
\hline EPA Class Size & SUV \\
\hline Mission & Pool \\
\hline Contact & C. Simmons/6th MP Group \\
\hline Parking Location & Building 4291 \\
\cline { 2 - 3 } & Fleet Vehicle ID & G61-0546L \\
\hline \multirow{4}{*}{ Fuel Type } & Gas/Eth \\
\hline & Potential Replacement PEV Make/Model & Toyota Rav4 EV \\
\cline { 2 - 3 } & Potential Annual Fuel Cost Savings & \$1,469 \\
\cline { 2 - 3 } & Potential Annual GHG Reduction & 7,253 lb-CO $\mathrm{e}$ \\
\hline & EVSE Type for Recharging & AC Level 2 \\
\cline { 2 - 3 } & Estimated Replacement Year & 2018 \\
\cline { 2 - 3 } & Vehicle Age at Estimated Replacement & 7 years \\
\hline & Odometer at Estimated Replacement Date & 45,592 \\
\hline
\end{tabular}

\section{Vehicle G61-0689A}

\begin{tabular}{|c|c|c|}
\hline & Make/Model/Year & Ford/Ranger/2004 \\
\hline & EPA Class Size & Standard Pickup Truck \\
\hline$\frac{1}{2}$ & Mission & Pool \\
\hline & Contact & C. Simmons/6th MP Group \\
\hline & Parking Location & Building 4291 \\
\hline & Fleet Vehicle ID & G61-0689A \\
\hline & Fuel Type & Gas \\
\hline & Potential Replacement PEV Make/Model & Via VTRUX pickup \\
\hline & Potential Annual Fuel Cost Savings & $\$ 354$ \\
\hline $1+61$ & Potential Annual GHG Reduction & $1,738 \mathrm{lb}-\mathrm{CO}_{2} \mathrm{e}$ \\
\hline & EVSE Type for Recharging & AC Level 1 \\
\hline & Estimated Replacement Year & 2015 \\
\hline & Vehicle Age at Estimated Replacement & 11 years \\
\hline & Odometer at Estimated Replacement Date & 27,838 \\
\hline
\end{tabular}


Vehicle G41-5433B

\begin{tabular}{|c|c|c|}
\hline & Make/Model/Year & Dodge/Grand Caravan/2006 \\
\hline & EPA Class Size & Minivan \\
\hline & Mission & Pool \\
\hline & Contact & C. Simmons/6th MP Group \\
\hline & Parking Location & Building 4291 \\
\hline & Fleet Vehicle ID & G41-5433B \\
\hline & Fuel Type & Gas/ETH \\
\hline & Potential Replacement PEV Make/Model & Nissan Leaf \\
\hline & Potential Annual Fuel Cost Savings & $\$ 1,436$ \\
\hline 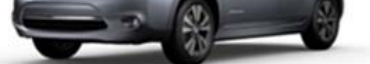 & Potential Annual GHG Reduction & $7,122 \mathrm{lb}-\mathrm{CO}_{2} \mathrm{e}$ \\
\hline & EVSE Type for Recharging & AC Level 2 \\
\hline & Estimated Replacement Year & 2015 \\
\hline & Vehicle Age at Estimated Replacement & 9 years \\
\hline & Odometer at Estimated Replacement Date & 61,106 \\
\hline
\end{tabular}




\section{Appendix B DCA Support Group Vehicle Data Sheets}

Note: the replacement year identified in the following data sheets is the earliest year available for potential replacement based on the GSA requirements noted in Table 3. The final replacement approach may suggest later years based on vehicle use.

Table B-1 identifies a potential replacement approach for vehicles currently on the GSA list.

Table B-1. JBLM DCA Support Group vehicle replacement (GSA-listed vehicle).

\begin{tabular}{|c|c|c|c|c|c|}
\hline \multicolumn{6}{|c|}{ GSA-Listed Vehicle Replacement Approach } \\
\hline $\begin{array}{c}\text { Fleet } \\
\text { Vehicle Id }\end{array}$ & Make/Model & Year & EPA Class & $\begin{array}{c}\text { GSA Replacement } \\
\text { Vehicle }\end{array}$ & $\begin{array}{c}\text { Replacement } \\
\text { Year }\end{array}$ \\
\hline G41-74299 & Ford Ranger & 2004 & Pickup Truck & NA & NA \\
\hline G71-0684A & Chev. C6500 Stake & 2005 & Pickup Truck HD & NA & NA \\
\hline G43-1195H & $\begin{array}{c}\text { Chevrolet } 15 \text { Pas } \\
\text { Van }\end{array}$ & 2011 & Passenger Van & NA & NA \\
\hline G42-0289G & Chevrolet G1300 & 2008 & Cargo Van & NA & NA \\
\hline
\end{tabular}

Table B-2 identifies a potential replacement approach using all currently or soon-to-be available PEVs.

Table B-2. JBLM DCA Support Group vehicle replacement (all potential vehicles).

\section{All Vehicle Replacement Approach}

\begin{tabular}{cccccc}
$\begin{array}{c}\text { Fleet } \\
\text { Vehicle Id }\end{array}$ & Make/Model & Year & EPA Class & Potential Replacement & $\begin{array}{c}\text { Replacement } \\
\text { Vehicle }\end{array}$ \\
\hline G41-74299 & Ford Ranger & 2004 & Pickup Truck & Via VTRUX PU & 2015 \\
G71-0684A & Chev. C6500 Stake & 2005 & Pickup Truck HD & Via VTRUX PU & 2015 \\
G43-1195H & Chevrolet 15 Pass Van & 2011 & Passenger Van & Via VTRUX Van & 2015 \\
G42-0289G & Chevrolet G1300 & 2008 & Cargo Van & Nissan eNV200 & 2016 \\
\hline
\end{tabular}




\begin{tabular}{|l|l|c|}
\hline & Make/Model/Year & Ford/Ranger/2004 \\
\hline & EPA Class Size & Standard Pickup Truck \\
\cline { 2 - 3 } & Mission & Support \\
\hline & Contact & D. Pettengill/DCA Support \\
\hline & Parking Location & Building 8050 \\
\hline & Fleet Vehicle ID & G41-74299 \\
\hline & Fuel Type & Gas \\
\hline \multirow{4}{*}{} & Potential Replacement PEV Make/Model & Via VTRUX PU \\
\cline { 2 - 3 } & Potential Annual Fuel Cost Savings & \$474 \\
\hline & Potential Annual GHG Reduction & 2,326 lb-CO $\mathrm{C}_{2} \mathrm{e}$ \\
\hline & EVSE Type for Recharging & AC Level 1 \\
\cline { 2 - 3 } & Estimated Replacement Year & 2015 \\
\cline { 2 - 3 } & Vehicle Age at Estimated Replacement & 11 \\
\cline { 2 - 3 } & Odometer at Estimated Replacement Date & 26,654 \\
\hline
\end{tabular}

Vehicle G71-0684A

\begin{tabular}{|l|l|c|}
\hline & Make/Model/Year & Chevrolet/C6500 Stake/2005 \\
\hline & EPA Class Size & Stake Truck \\
\hline & Mission & Pool \\
\hline & Contact & D. Pettengill/DCA Support \\
\hline & Parking Location & G71-0684A \\
\hline & Fleet Vehicle ID & Diesel \\
\hline & Fuel Type & Via VTRUX PU \\
\hline & Potential Replacement PEV Make/Model & $\$ 393$ \\
\cline { 2 - 3 } & Potential Annual Fuel Cost Savings & 1,948 lb-CO $\mathrm{CO}_{2} \mathrm{e}$ \\
\hline & Potential Annual GHG Reduction & AC Level 1 \\
\hline & EVSE Type for Recharging & 2015 \\
\hline & Estimated Replacement Year & 10 \\
\hline & Vehicle Age at Estimated Replacement & 13,801 \\
\hline & Odometer at Estimated Replacement Date & \\
\hline
\end{tabular}




\begin{tabular}{|l|l|c|}
\hline & Make/Model/Year & Chevrolet/15 Pass Van/2011 \\
\hline EPA Class Size & Passenger Van \\
\hline Mission & Support \\
\hline Contact & Dettengill/DCA Support \\
\hline & Parking Location & G43-1195H \\
\hline & Fleet Vehicle ID & Gas/ETH \\
\hline & Fuel Type & Via VTRUX Pass Van \\
\hline \multirow{2}{*}{} & Potential Replacement PEV Make/Model & $\$ 2,925$ \\
\hline & Potential Annual Fuel Cost Savings & 14,501 lb-CO $\mathrm{CO}_{2} \mathrm{e}$ \\
\hline & Potential Annual GHG Reduction & AC Level 1 \\
\hline & EVSE Type for Recharging & 2015 \\
\hline & Estimated Replacement Year & 4 \\
\hline & Vehicle Age at Estimated Replacement & 65,000 \\
\hline & Odometer at Estimated Replacement Date & \\
\hline
\end{tabular}

Vehicle G42-0289G

\begin{tabular}{|c|c|c|}
\hline 27 & Make/Model/Year & Chevrolet/G1300/2008 \\
\hline & EPA Class Size & Cargo Van \\
\hline & Mission & Pool \\
\hline & Contact & D. Pettengill/DCA Support \\
\hline & Parking Location & Building 2057 \\
\hline & Fleet Vehicle ID & G42-0289G \\
\hline & Fuel Type & Gas/ETH \\
\hline & Potential Replacement PEV Make/Model & Nissan eNV200 \\
\hline & Potential Annual Fuel Cost Savings & $\$ 505$ \\
\hline & Potential Annual GHG Reduction & $2,508 \mathrm{lb}-\mathrm{CO}_{2} \mathrm{e}$ \\
\hline & EVSE Type for Recharging & AC Level 2 \\
\hline & Estimated Replacement Year & 2016 \\
\hline & Vehicle Age at Estimated Replacement & 8 \\
\hline & Odometer at Estimated Replacement Date & 12,855 \\
\hline
\end{tabular}




\section{Appendix C Public Works Vehicle Data Sheets}

Note: the replacement year identified in the following data sheets is the earliest year available for potential replacement based on the GSA requirements noted in Table 3. The final replacement approach may suggest later years based on vehicle use.

Table C-1 identifies a potential replacement approach for vehicles currently on the GSA list.

Table C-1. JBLM Public Works vehicle replacement (GSA-listed vehicle).

\begin{tabular}{|c|c|c|c|c|c|}
\hline \multicolumn{6}{|c|}{ GSA-Listed Vehicle Replacement Approach } \\
\hline $\begin{array}{c}\text { Fleet } \\
\text { Vehicle Id }\end{array}$ & Make/Model & Year & EPA Class & $\begin{array}{c}\text { GSA Replacement } \\
\text { Vehicle }\end{array}$ & $\begin{array}{c}\text { Replacement } \\
\text { Year }\end{array}$ \\
\hline G42-0658K & Ford F150 & 2010 & Pickup Truck & NA & NA \\
\hline G42-1054F & Ford F150 & 2008 & Pickup Truck & NA & NA \\
\hline G71-0133L & Ford E450 & 2011 & Passenger van & NA & NA \\
\hline G43-0944G & Chevrolet G3500 & 2008 & Passenger van & NA & NA \\
\hline G43-0822G & Ford F350 & 2008 & Pickup Truck & NA & NA \\
\hline G41-1100K & Dodge GR Caravan & 2010 & Minivan & NA & NA \\
\hline G42-0619K & Chevrolet C1500 & 2010 & Pickup Truck & NA & NA \\
\hline G41-1180K & Dodge GR Caravan & 2010 & Minivan & NA & NA \\
\hline G43-1892H & Chevrolet C2500HD & 2009 & Pickup Truck & NA & NA \\
\hline G43-1961H & Chevrolet C3500 & 2009 & Pickup Truck & NA & NA \\
\hline G42-0505A & Chevrolet G1300 & 2004 & Passenger van & NA & NA \\
\hline G43-1155L & Ford F350 & 2011 & Pickup Truck & NA & NA \\
\hline G41-1605L & Dodge Dakota & 2011 & Pickup Truck & NA & NA \\
\hline G42-0610K & Chevrolet C1500 & 2010 & Pickup Truck & NA & NA \\
\hline
\end{tabular}

Table C-2 identifies a potential replacement approach using all currently or soon-to-be available PEVs.

Table C-2. JBLM Public Works vehicle replacement (all potential vehicles).

\begin{tabular}{cccccc}
\hline \multicolumn{2}{c}{ Fleet } & \multicolumn{2}{c}{ GSA-Listed Vehicle Replacement } & Approach & Potential Replacement \\
Vehicle Id & Make/Model & Year & EPA Class & Vehicles & Year \\
\hline G42-0505A & Chevrolet G1300 & 2004 & Passenger van & Via VTRUX PU & 2015 \\
G42-1054F & Ford F150 & 2008 & Pickup Truck & Toyota Rav4 EV & 2016 \\
G43-0822G & FordF350 & 2008 & Pickup Truck & Toyota Rav4 EV & 2016 \\
G43-0944G & Chevrolet G3500 & 2008 & Passenger van & Via VTRUX Van & 2017 \\
G43-1892H & Chevrolet C2500HD & 2009 & Pickup Truck & Nissan eNV200 & 2017 \\
G43-1961H & Chevrolet C3500 & 2009 & Pickup Truck & Toyota Rav4 EV & 2017 \\
G41-1100K & Dodge GR Caravan & 2010 & Minivan & Mitsu. Outlander & 2018 \\
G41-1180K & Dodge GR Caravan & 2010 & Minivan & Nissan Leaf & 2018 \\
G42-0619K & CheroletC1500 & 2010 & Pickup Truck & Toyota Rav4 EV & 2018 \\
G42-0658K & Ford F150 & 2010 & Pickup Truck & Via VTRUX PU & 2018 \\
G43-1155L & Ford F350 & 2011 & Pickup Truck & Via VTRUX PU & 2018 \\
G41-1605L & Dodge Dakota & 2011 & Pickup Truck & Toyota Rav4 EV & 2019 \\
\hline
\end{tabular}




\begin{tabular}{cccccc}
\hline \multirow{2}{*}{$\begin{array}{c}\text { Fleet } \\
\text { Vehicle Id }\end{array}$} & Make/Model & Year & EPA Class & Potential Replacement & Replacement \\
Vehicles & Year \\
\hline G42-0610K & Chevrolet C1500 & 2010 & Pickup Truck & Nissan eNV200 & 2019 \\
G71-0133L & Ford E450 & 2011 & Passenger van & Via VTRUX Van & 2021 \\
\hline
\end{tabular}




\begin{tabular}{|c|c|c|}
\hline \multirow{7}{*}{10} & Make/Model/Year & Ford/F150/2010 \\
\hline & EPA Class Size & Standard Pickup Truck \\
\hline & Mission & Pool Vehicle \\
\hline & Contact & J. Ross/Public Works \\
\hline & Parking Location & $\begin{array}{c}\text { Building } 2044 / \text { Adkison } / \mathrm{N}^{\text {rd }} \\
\text { St }\end{array}$ \\
\hline & Fleet Vehicle ID & G42-0658K \\
\hline & Fuel Type & Gas/ETH \\
\hline \multirow{7}{*}{ ibn } & Potential Replacement PEV Make/Model & Via VTRUX PU \\
\hline & Potential Annual Fuel Cost Savings & $\$ 864$ \\
\hline & Potential Annual GHG Reduction & $4,273 \mathrm{lb}-\mathrm{CO}_{2} \mathrm{e}$ \\
\hline & EVSE Type for Recharging & AC Level 1 \\
\hline & Estimated Replacement Year & 2018 \\
\hline & Vehicle Age at Estimated Replacement & 8 \\
\hline & Odometer at Estimated Replacement Date & 30,782 \\
\hline
\end{tabular}

\section{Vehicle G42-1054F}

\begin{tabular}{|c|c|c|}
\hline A. 5 & Make/Model/Year & Ford/F150/2008 \\
\hline & EPA Class Size & Standard Pickup Truck \\
\hline & Mission & Pool \\
\hline & Contact & J. Ross/Public Works \\
\hline & Parking Location & $\begin{array}{c}\text { Building 2044/Adkison/N } 3^{\text {rd }} \\
\text { St }\end{array}$ \\
\hline & Fleet Vehicle ID & G42-1054F \\
\hline & Fuel Type & Gas \\
\hline & Potential Replacement PEV Make/Model & $\begin{array}{c}\text { Nissan Rav4 EV or BEV } \\
\text { Pickup }\end{array}$ \\
\hline & Potential Annual Fuel Cost Savings & $\$ 746$ \\
\hline & Potential Annual GHG Reduction & $3,692 \mathrm{lb}-\mathrm{CO}_{2} \mathrm{e}$ \\
\hline & EVSE Type for Recharging & AC Level 2 \\
\hline & Estimated Replacement Year & 2016 \\
\hline & Vehicle Age at Estimated Replacement & 8 \\
\hline & Odometer at Estimated Replacement Date & 25,040 \\
\hline
\end{tabular}


Vehicle G71-0133L

\begin{tabular}{|c|c|c|}
\hline \multirow{7}{*}{$\frac{\pi}{1+25 \sqrt{20}}$} & Make/Model/Year & Ford/E450/2011 \\
\hline & EPA Class Size & Vans, Passenger Type \\
\hline & Mission & Pool \\
\hline & Contact & J. Ross/Public Works \\
\hline & Parking Location & Building 2063/N. 4th St \\
\hline & Fleet Vehicle ID & G71-0133L \\
\hline & Fuel Type & Gas/ETH \\
\hline \multirow{7}{*}{ 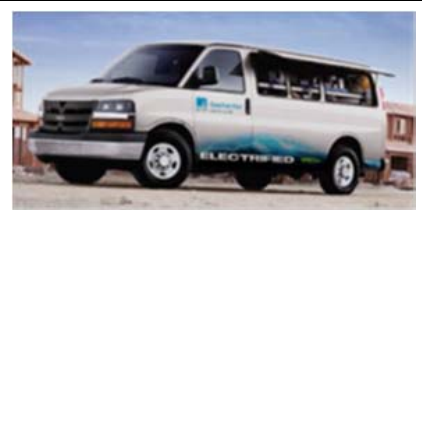 } & Potential Replacement PEV Make/Model & Via VTRUX Pass Van \\
\hline & Potential Annual Fuel Cost Savings & $\$ 1,229$ \\
\hline & Potential Annual GHG Reduction & $6,093 \mathrm{lb}-\mathrm{CO}_{2} \mathrm{e}$ \\
\hline & EVSE Type for Recharging & AC Level 1 \\
\hline & Estimated Replacement Year & 2021 \\
\hline & Vehicle Age at Estimated Replacement & 10 \\
\hline & Odometer at Estimated Replacement Date & 38,989 \\
\hline
\end{tabular}

Vehicle G43-0944G

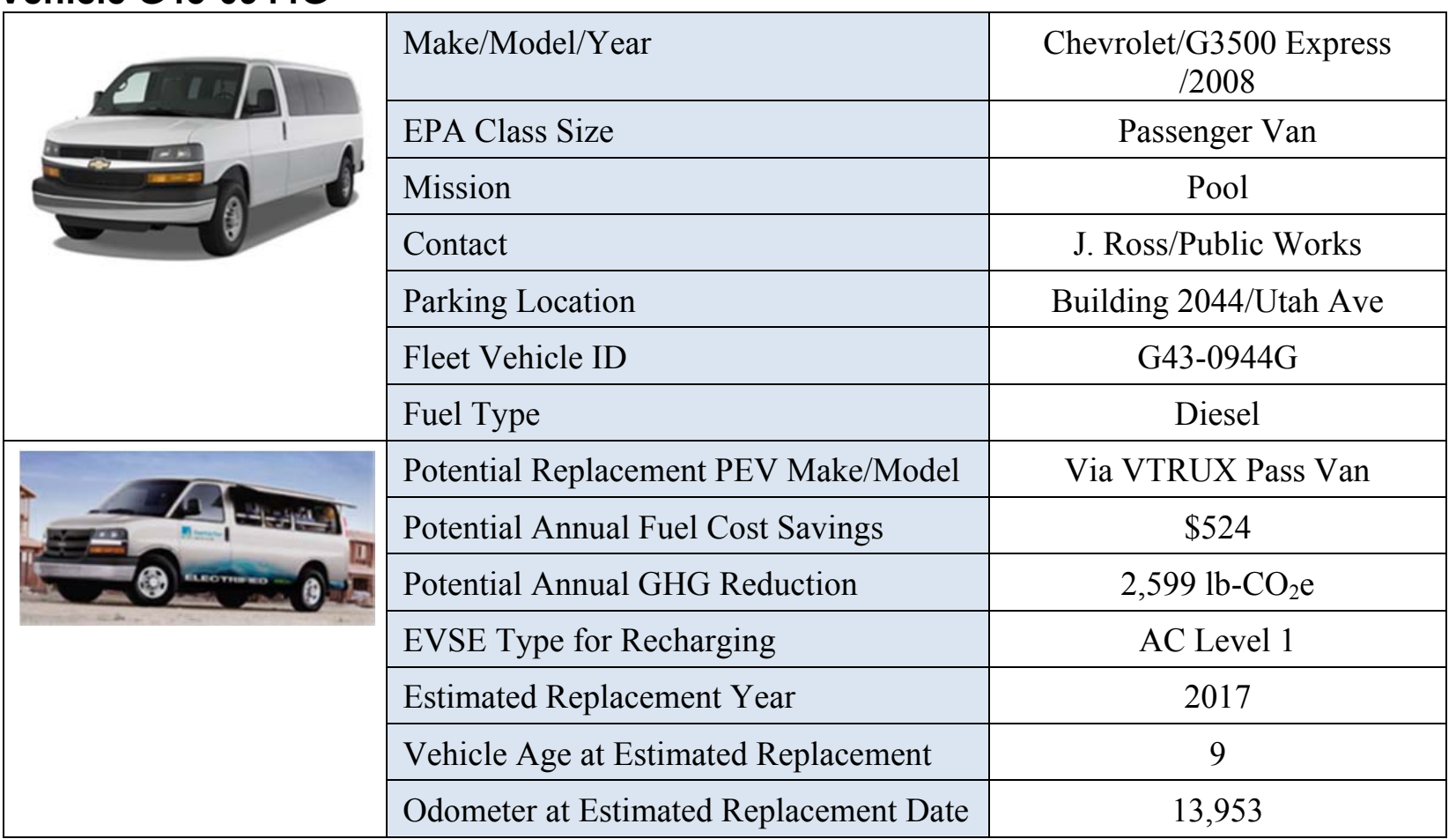




\begin{tabular}{|c|c|c|}
\hline \multirow{7}{*}{ 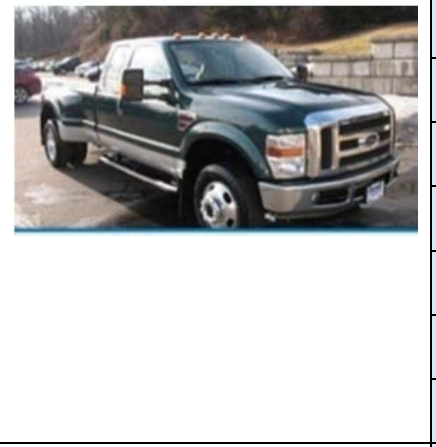 } & Make/Model/Year & Ford/F350/2008 \\
\hline & EPA Class Size & Pickup Trucks \\
\hline & Mission & Support \\
\hline & Contact & J. Ross/Public Works \\
\hline & Parking Location & Building 2044/Utah Ave \\
\hline & Fleet Vehicle ID & G43-0822G \\
\hline & Fuel Type & Gas \\
\hline \multirow{7}{*}{$\frac{28}{8 \theta 2}$} & Potential Replacement PEV Make/Model & $\begin{array}{c}\text { Nissan Rav4 EV or BEV } \\
\text { Pickup }\end{array}$ \\
\hline & Potential Annual Fuel Cost Savings & $\$ 1,364$ \\
\hline & Potential Annual GHG Reduction & $6,752 \mathrm{lb}-\mathrm{CO}_{2} \mathrm{e}$ \\
\hline & EVSE Type for Recharging & AC Level 2 \\
\hline & Estimated Replacement Year & 2016 \\
\hline & Vehicle Age at Estimated Replacement & 8 \\
\hline & Odometer at Estimated Replacement Date & 39,273 \\
\hline
\end{tabular}

\section{Vehicle G41-1100K}

\begin{tabular}{|c|c|c|}
\hline & Make/Model/Year & Dodge/Grand Caravan/2010 \\
\hline & EPA Class Size & Minivan \\
\hline & Mission & Pool \\
\hline & Contact & J. Ross/Public Works \\
\hline & Parking Location & Building 2012/Pendleton Ave \\
\hline & Fleet Vehicle ID & G41-1100K \\
\hline & Fuel Type & Gas/ETH \\
\hline & Potential Replacement PEV Make/Model & Mitsubishi Outlander \\
\hline & Potential Annual Fuel Cost Savings & $\$ 633$ \\
\hline$B$ & Potential Annual GHG Reduction & $3,127 \mathrm{lb}-\mathrm{CO}_{2} \mathrm{e}$ \\
\hline 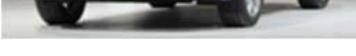 & EVSE Type for Recharging & AC Level 1 \\
\hline & Estimated Replacement Year & 2018 \\
\hline & Vehicle Age at Estimated Replacement & 8 \\
\hline & Odometer at Estimated Replacement Date & 21,772 \\
\hline
\end{tabular}




\begin{tabular}{|l|l|c|}
\hline Mehicle G42-0619K & Chevrolet/C1500/2010 \\
\hline & EPA Class Size & Pool \\
\hline Mission & J. Ross/Public Works \\
\hline Contact & Building 555/Lincoln Blvd \\
\hline \multirow{2}{*}{ Parking Location } & G42-0619K \\
\hline & Fleet Vehicle ID & Gas/ETH \\
\hline & Fuel Type & Nissan Rav4 EV or BEV \\
Pickup
\end{tabular}

\begin{tabular}{|c|c|c|}
\hline \multirow{7}{*}{$\underline{=}=$} & Make/Model/Year & Dodge/Grand Caravan/2010 \\
\hline & EPA Class Size & Minivan \\
\hline & Mission & Pool \\
\hline & Contact & J. Ross/Public Works \\
\hline & Parking Location & Building 540/A St SW \\
\hline & Fleet Vehicle ID & G41-1180K \\
\hline & Fuel Type & Gas/ETH \\
\hline & Potential Replacement PEV Make/Model & Nissan Leaf \\
\hline & Potential Annual Fuel Cost Savings & $\$ 523$ \\
\hline & Potential Annual GHG Reduction & 2,594 \\
\hline & EVSE Type for Recharging & AC Level 2 \\
\hline & Estimated Replacement Year & 2018 \\
\hline & Vehicle Age at Estimated Replacement & 8 \\
\hline & Odometer at Estimated Replacement Date & 17,790 \\
\hline
\end{tabular}




\begin{tabular}{|c|c|c|}
\hline & Make/Model/Year & Chevrolet/C2500HD/2009 \\
\hline & EPA Class Size & Pickup Truck \\
\hline & Mission & Support \\
\hline & Contact & J. Ross/Public Works \\
\hline & Parking Location & 6th St SW \\
\hline & Fleet Vehicle ID & G43-1892H \\
\hline & Fuel Type & Gas \\
\hline & Potential Replacement PEV Make/Model & $\begin{array}{c}\text { Nissan eNV200 or BEV } \\
\text { Pickup }\end{array}$ \\
\hline & Potential Annual Fuel Cost Savings & $\$ 879$ \\
\hline & Potential Annual GHG Reduction & $4,357 \mathrm{lb}-\mathrm{CO}_{2} \mathrm{e}$ \\
\hline & EVSE Type for Recharging & AC Level 2 \\
\hline & Estimated Replacement Year & 2017 \\
\hline & Vehicle Age at Estimated Replacement & 8 \\
\hline & Odometer at Estimated Replacement Date & 23,838 \\
\hline
\end{tabular}

\section{Vehicle G43-1961H}

\begin{tabular}{|l|l|c|}
\hline & Make/Model/Year & Pickup Truck \\
\hline & EPA Class Size & Support \\
\hline & Mission & J. Ross/Public Works \\
\hline Contact & 6th St SW \\
\hline Parking Location & G43-1961H \\
\hline & Fleet Vehicle ID & Gas \\
\hline & Fuel Type & Toyota Rav4 EV or BEV \\
Pickup
\end{tabular}




\begin{tabular}{|c|c|c|}
\hline \multirow{7}{*}{ 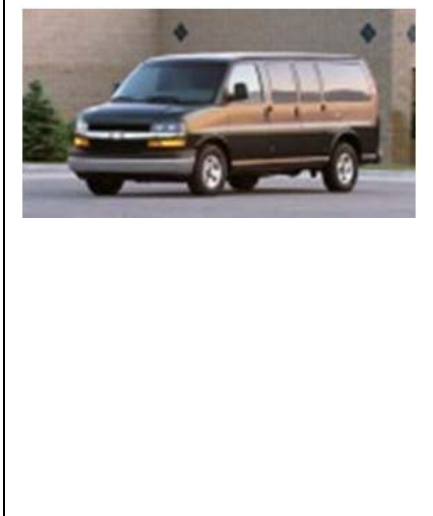 } & Make/Model/Year & $\begin{array}{c}\text { Chevrolet/G1500 Express } \\
\text { /2004 }\end{array}$ \\
\hline & EPA Class Size & Passenger Van \\
\hline & Mission & Support \\
\hline & Contact & J. Ross/Public Works \\
\hline & Parking Location & $\begin{array}{c}\text { Building 555/2012 Lincoln } \\
\text { Blvd }\end{array}$ \\
\hline & Fleet Vehicle ID & G42-0505A \\
\hline & Fuel Type & Gas \\
\hline \multirow{7}{*}{ if } & Potential Replacement PEV Make/Model & Via VTRUX Pass Van \\
\hline & Potential Annual Fuel Cost Savings & $\$ 1,343$ \\
\hline & Potential Annual GHG Reduction & $6,660 \mathrm{lb}-\mathrm{CO}_{2} \mathrm{e}$ \\
\hline & EVSE Type for Recharging & AC Level 1 \\
\hline & Estimated Replacement Year & 2015 \\
\hline & Vehicle Age at Estimated Replacement & 11 \\
\hline & Odometer at Estimated Replacement Date & 35,442 \\
\hline
\end{tabular}

\section{Vehicle G43-1155L}

\begin{tabular}{|c|c|c|}
\hline \multirow{7}{*}{ 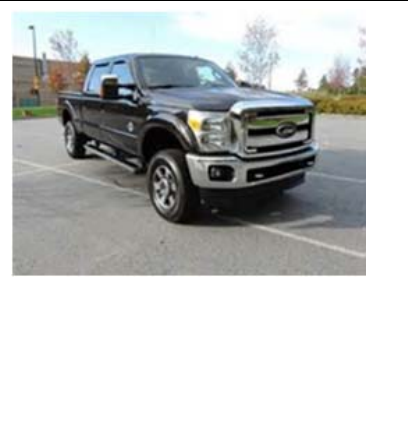 } & Make/Model/Year & Ford/F350/2011 \\
\hline & EPA Class Size & Pickup Truck \\
\hline & Mission & Support \\
\hline & Contact & J. Ross/Public Works \\
\hline & Parking Location & Building 2044/Utah Ave \\
\hline & Fleet Vehicle ID & G43-1155L \\
\hline & Fuel Type & Gas/ETH \\
\hline \multirow{7}{*}{ în } & Potential Replacement PEV Make/Model & Via VTRUX PU \\
\hline & Potential Annual Fuel Cost Savings & $\$ 384$ \\
\hline & Potential Annual GHG Reduction & $2,729 \mathrm{lb}-\mathrm{CO}_{2} \mathrm{e}$ \\
\hline & EVSE Type for Recharging & AC Level 1 \\
\hline & Estimated Replacement Year & 2018 \\
\hline & Vehicle Age at Estimated Replacement & 7 \\
\hline & Odometer at Estimated Replacement Date & 35,501 \\
\hline
\end{tabular}


Vehicle G41-1605L

\begin{tabular}{|c|c|c|}
\hline \multirow{7}{*}{ 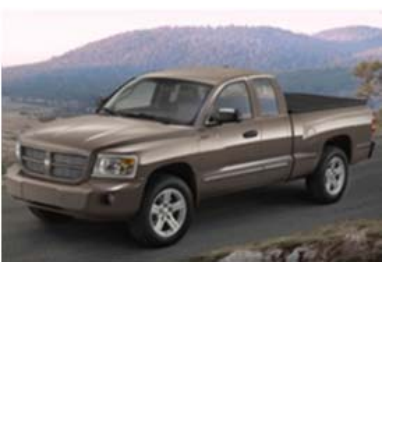 } & Make/Model/Year & Dodge/Dakota/2011 \\
\hline & EPA Class Size & Standard Pickup Truck \\
\hline & Mission & Support \\
\hline & Contact & J. Ross/Public Works \\
\hline & Parking Location & Building 2044 \\
\hline & Fleet Vehicle ID & G41-1605L \\
\hline & Fuel Type & Gas/ETH \\
\hline & Potential Replacement PEV Make/Model & $\begin{array}{c}\text { Toyota Rav4 EV or BEV } \\
\text { Pickup }\end{array}$ \\
\hline & Potential Annual Fuel Cost Savings & $\$ 423$ \\
\hline & Potential Annual GHG Reduction & $2,095 \mathrm{lb}-\mathrm{CO}_{2} \mathrm{e}$ \\
\hline & EVSE Type for Recharging & AC Level 2 \\
\hline & Estimated Replacement Year & 2019 \\
\hline & Vehicle Age at Estimated Replacement & 8 \\
\hline & Odometer at Estimated Replacement Date & 12,814 \\
\hline
\end{tabular}

\section{Vehicle G42-0610K}

\begin{tabular}{|c|c|c|}
\hline \multirow{7}{*}{ 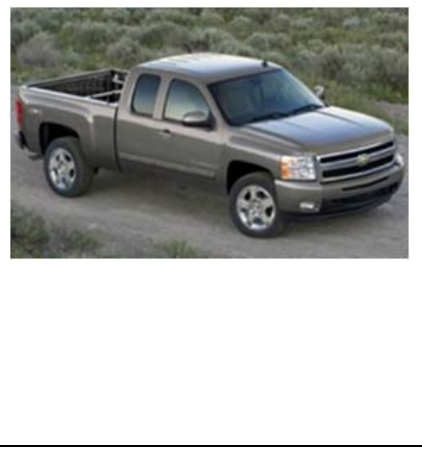 } & Make/Model/Year & Chevrolet/C1500/2010 \\
\hline & EPA Class Size & Standard Pickup Truck \\
\hline & Mission & Pool \\
\hline & Contact & J. Ross/Public Works \\
\hline & Parking Location & Building 2044/Pendleton Ave \\
\hline & Fleet Vehicle ID & G42-0610K \\
\hline & Fuel Type & $\mathrm{Gas} / \mathrm{ETH}$ \\
\hline \multirow{7}{*}{$y=\frac{1}{16}$} & Potential Replacement PEV Make/Model & Nissan eNV200 \\
\hline & Potential Annual Fuel Cost Savings & $\$ 706$ \\
\hline & Potential Annual GHG Reduction & $3,498 \mathrm{lb}-\mathrm{CO}_{2} \mathrm{e}$ \\
\hline & EVSE Type for Recharging & AC Level 2 \\
\hline & Estimated Replacement Year & 2019 \\
\hline & Vehicle Age at Estimated Replacement & 9 \\
\hline & Odometer at Estimated Replacement Date & 25,827 \\
\hline
\end{tabular}




\section{Appendix D Motor Transport Branch Vehicle Data Sheets}

Note: the replacement year identified in the following data sheets is the earliest year available for potential replacement based on the GSA requirements noted in Table 3. The final replacement approach may suggest later years based on vehicle use.

Table D-1 identifies a potential replacement approach for vehicles currently on the GSA list.

Table D-1. JBLM Motor Transport Branch vehicle replacement (GSA-listed vehicle).

\begin{tabular}{cccccc}
$\begin{array}{c}\text { Fleet } \\
\text { Vehicle Id }\end{array}$ & Make/Model & Year & EPA Class & $\begin{array}{c}\text { GSA Replacement } \\
\text { Vehicle }\end{array}$ & $\begin{array}{c}\text { Replacement } \\
\text { Year }\end{array}$ \\
\hline G10-7664F & Dodge Avenger & 2008 & Compact Sedan & Ford Focus & 2015 \\
G11-2676G & Chevrolet Impala & 2008 & Large Sedan & Ford Focus & 2015 \\
G11-0678K & Chevrolet Impala & 2010 & Large Sedan & Ford Focus & 2017 \\
G11-0493L & Chevrolet Impala & 2012 & Large Sedan & Ford Fusion & 2016 \\
G10-2878L & Chevrolet Malibu & 2011 & Midsize Sedan & Ford Focus & 2017 \\
G11-2675G & Chevrolet Impala & 2008 & Large Sedan & Chevrolet Volt & 2016 \\
G12-0662H & Ford Fusion HEV & 2010 & Midsize Sedan & Ford Fusion & 2015 \\
G10-6379L & Dodge Avenger & 2011 & Midsize Sedan & Ford Focus & 2017 \\
\hline
\end{tabular}

Table D-2 identifies a potential replacement approach using all currently or soon-to-be available PEVs.

Table D-2. JBLM Motor Transport Branch vehicle replacement (all potential vehicles).

\begin{tabular}{cccccc}
\hline Fleet & \multicolumn{5}{c}{ All Vehicle Replacement Approach } \\
Vehicle Id & Make/Model & Year & EPA Class & Replacement Vehicle & $\begin{array}{c}\text { Replacement } \\
\text { Year }\end{array}$ \\
\hline G10-7664F & Dodge Avenger & 2008 & Compact Sedan & Ford Focus & 2015 \\
G11-2676G & Chevrolet Impala & 2008 & Large Sedan & Nissan Leaf & 2015 \\
G12-0662H & Ford Fusion HEV & 2010 & Midsize Sedan & Ford Fusion & 2015 \\
G41-1180G & Chevrolet Uplander & 2008 & Minivan & Mitsu. Outlander & 2015 \\
G41-1288A & Ford Sport Trac & 2004 & Pickup Truck & Toyota Rav4 EV & 2015 \\
G41-1373G & Dodge Dakota & 2008 & Pickup Truck & Mitsu. Outlander & 2015 \\
G41-1392G & Chevrolet Uplander & 2008 & Minivan & Mitsu. Outlander & 2015 \\
G41-65991 & Dodge Dakota & 2002 & Pickup Truck & Via VTRUX PU & 2015 \\
G43-25839 & Ford F350 & 2003 & Pickup Truck & Toyota Rav4 EV & 2015 \\
G61-1155D & Ford Escape HYB & 2006 & SUV & Toyota Rav4 EV & 2015 \\
G11-0493L & Chevrolet Impala & 2012 & Large Sedan & Ford Fusion & 2016 \\
G11-2675G & Chevrolet Impala & 2008 & Large Sedan & Chevrolet Volt & 2016 \\
G41-1161G & Chevrolet Uplander & 2008 & Minivan & Toyota Rav4 EV & 2016 \\
G41-1367G & Dodge Dakota & 2008 & Pickup Truck & Toyota Rav4 EV & 2016 \\
G41-1376G & Dodge Dakota & 2008 & Pickup Truck & Nissan eNV200 & 2016 \\
G41-1395G & Chevrolet Uplander & 2008 & Minivan & Toyota Rav4 EV & 2016 \\
G42-0698K & Chevrolet C1500 & 2011 & Pickup Truck & Via VTRUX PU & 2016 \\
G42-0988F & Chevrolet Express 13 & 2007 & Cargo Van & Nissan eNV200 & 2016 \\
G42-3471A & Chevrolet G2300 & 2005 & Cargo Van & Nissan eNV200 & 2016 \\
G43-0792K & Chevrolet CG3300 & 2010 & Passenger Van & Via VTRUX Van & 2016 \\
\hline
\end{tabular}




\begin{tabular}{cccccc}
\hline \multicolumn{5}{c}{ Fleet } & \multicolumn{5}{c}{ All Vehicle Replacement Approach } \\
Vehicle Id & Make/Model & Year & EPA Class & Replacement Vehicle & $\begin{array}{c}\text { Replacement } \\
\text { Year }\end{array}$ \\
\hline G43-0860G & Chevrolet CG3300 & 2008 & Passenger Van & Via VTRUX Van & 2016 \\
G43-3717A & Ford E350 & 2004 & Cargo Van & Via VTRUX Van & 2016 \\
G43-4937A & Ford E350 & 2004 & Cargo Van & Nissan eNV200 & 2016 \\
G62-0979G & Dodge 1500 & 2008 & Pickup Truck & Via VTRUX PU & 2016 \\
G62-4526H & Chevrolet Tahoe & 2009 & SUV & Mitsubishi Outlander & 2016 \\
G63-0271A & Ford F350 & 2004 & Stake Truck & Via VTRUX PU & 2016 \\
G71-0674A & Fore F650 18'BO & 2004 & Delivery Van & Via VTRUX PU & 2016 \\
G82-0509A & Ford F650 STAKE & 2004 & Stake Truck & NA & 2016 \\
G10-2878L & Chevrolet Malibu & 2011 & Midsize Sedan & Nissan Leaf & 2017 \\
G10-6379L & Dodge Avenger & 2011 & Midsize Sedan & Nissan Leaf & 2017 \\
G11-0678K & Chevrolet Impala & 2010 & Large Sedan & Nissan Leaf & 2017 \\
G43-0801K & Chevrolet CG3300 & 2010 & Passenger Van & Via VTRUX Van & 2017 \\
G43-0875K & Ford E350 & 2010 & Cargo Van & Nissan eNV200 & 2017 \\
G43-3881H & Ford E350 & 2009 & Passenger Van & Via VTRUX Van & 2017 \\
G41-1100K & Dodge GR Caravan & 2010 & Minivan & Mitsubishi Outlander & 2018 \\
G43-0790K & Chevrolet CG3300 & 2010 & Passenger Van & Via VTRUX Van & 2018 \\
G43-1389K & Chevrolet CG3300 & 2010 & Passenger Van & Via VTRUX Van & 2018 \\
G62-1094L & Chevrolet Avalanche & 2011 & SUV & Nissan Leaf & 2018 \\
G71-0062G & Ford F750 & 2008 & Stake Truck & NA & 2018 \\
G43-1191L & Chevrolet CG3300 & 2011 & Passenger Van & Via VTRUX Van & 2019 \\
\hline
\end{tabular}




\begin{tabular}{|c|c|c|}
\hline \multirow{7}{*}{$\mathrm{C}^{2} \mathrm{e}$} & Make/Model/Year & Ford/E350/2010 \\
\hline & EPA Class Size & Cargo Van \\
\hline & Mission & Pool \\
\hline & Contact & J. Lamantia/Motor Transport \\
\hline & Parking Location & Near J. Ramp/Levitow Blvd \\
\hline & Fleet Vehicle ID & G43-0875K \\
\hline & Fuel Type & Gas/Eth \\
\hline \multirow{7}{*}{$=\frac{1}{3}$} & Potential Replacement PEV Make/Model & Nissan eNV200 \\
\hline & Potential Annual Fuel Cost Savings & $\$ 4,534$ \\
\hline & Potential Annual GHG Reduction & $22,519 \mathrm{lb}-\mathrm{CO}_{2} \mathrm{e}$ \\
\hline & EVSE Type for Recharging & AC Level 2 \\
\hline & Estimated Replacement Year & 2017 \\
\hline & Vehicle Age at Estimated Replacement & 7 \\
\hline & Odometer at Estimated Replacement Date & 76,222 \\
\hline
\end{tabular}

Vehicle G41-1288A

\begin{tabular}{|c|c|c|}
\hline \multirow{7}{*}{ 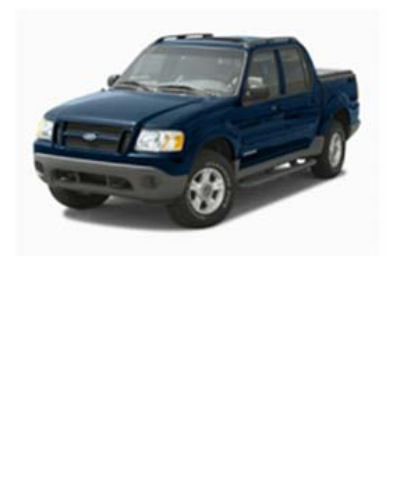 } & Make/Model/Year & Ford/Sport Trac /2004 \\
\hline & EPA Class Size & Standard Pickup Truck \\
\hline & Mission & Pool \\
\hline & Contact & J. Lamantia/Motor Transport \\
\hline & Parking Location & $\begin{array}{c}\text { Building 100/Col. Joe Jackson } \\
\text { Blvd } \\
\end{array}$ \\
\hline & Fleet Vehicle ID & G41-1288A \\
\hline & Fuel Type & Gas/Eth \\
\hline \multirow{7}{*}{$\frac{20}{\theta \theta} \theta$} & Potential Replacement PEV Make/Model & Toyota Rav4 EV \\
\hline & Potential Annual Fuel Cost Savings & $\$ 163$ \\
\hline & Potential Annual GHG Reduction & $807 \mathrm{lb}-\mathrm{CO}_{2} \mathrm{e}$ \\
\hline & EVSE Type for Recharging & AC Level 2 \\
\hline & Estimated Replacement Year & 2015 \\
\hline & Vehicle Age at Estimated Replacement & 11 \\
\hline & Odometer at Estimated Replacement Date & 15,923 \\
\hline
\end{tabular}




\begin{tabular}{|l|c|}
\hline \\
\hline
\end{tabular} \mid \begin{tabular}{c} 
Ford/E350/2004 \\
Cargo Van \\
\hline
\end{tabular}

Vehicle G10-7664F

\begin{tabular}{|c|c|c|}
\hline & Make/Model/Year & Dodge/Avenger / 2008 \\
\hline & EPA Class Size & Compact Sedan \\
\hline & Mission & Pool \\
\hline & Contact & J. Lamantia/Motor Transport \\
\hline & Parking Location & Building 100/ Westcott Hills \\
\hline & Fleet Vehicle ID & G10-7664F \\
\hline & Fuel Type & Gas/Eth \\
\hline & Potential Replacement PEV Make/Model & Ford Focus \\
\hline & Potential Annual Fuel Cost Savings & $\$ 246$ \\
\hline & Potential Annual GHG Reduction & $1,217 \mathrm{lb}-\mathrm{CO}_{2} \mathrm{e}$ \\
\hline & EVSE Type for Recharging & AC Level 2 \\
\hline & Estimated Replacement Year & 2015 \\
\hline & Vehicle Age at Estimated Replacement & 7 \\
\hline & Odometer at Estimated Replacement Date & 15,190 \\
\hline
\end{tabular}




\begin{tabular}{|c|c|c|}
\hline \multirow{7}{*}{ की 0} & Make/Model/Year & Dodge/Dakota/2002 \\
\hline & EPA Class Size & Standard Pickup Truck \\
\hline & Mission & Pool \\
\hline & Contact & J. Lamantia/ Transport \\
\hline & Parking Location & $\begin{array}{c}\text { Building 100/Barrack St or } \\
\text { 2nd St }\end{array}$ \\
\hline & Fleet Vehicle ID & G41-65991 \\
\hline & Fuel Type & Gas \\
\hline \multirow{7}{*}{ (6) } & Potential Replacement PEV Make/Model & Via VTRUX PU \\
\hline & Potential Annual Fuel Cost Savings & $\$ 287$ \\
\hline & Potential Annual GHG Reduction & $2,039 \mathrm{lb}-\mathrm{CO}_{2} \mathrm{e}$ \\
\hline & EVSE Type for Recharging & AC Level 1 \\
\hline & Estimated Replacement Year & 2015 \\
\hline & Vehicle Age at Estimated Replacement & 13 \\
\hline & Odometer at Estimated Replacement Date & 33,202 \\
\hline
\end{tabular}

Vehicle G11-2676G

\begin{tabular}{|c|c|c|}
\hline \multirow{7}{*}{$\frac{2 \pi-6 !}{\operatorname{lin} \theta}$} & Make/Model/Year & Chevrolet / Impala / 2008 \\
\hline & EPA Class Size & Large Cars \\
\hline & Mission & Pool \\
\hline & Contact & C. Sallinger/Motor Transport \\
\hline & Parking Location & Building 9190/Sansone St \\
\hline & Fleet Vehicle ID & G11-2676G \\
\hline & Fuel Type & Gas/E85 \\
\hline \multirow{7}{*}{ 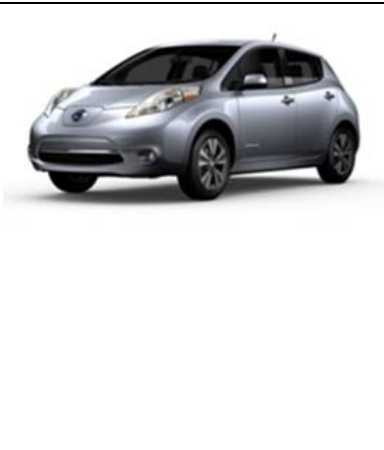 } & Potential Replacement PEV Make/Model & Nissan Leaf \\
\hline & Potential Annual Fuel Cost Savings & $\$ 986$ \\
\hline & Potential Annual GHG Reduction & 6,625 \\
\hline & EVSE Type for Recharging & AC Level 2 \\
\hline & Estimated Replacement Year & 2015 \\
\hline & Vehicle Age at Estimated Replacement & 7 \\
\hline & Odometer at Estimated Replacement Date & 48,773 \\
\hline
\end{tabular}


Vehicle G43-3717A

\begin{tabular}{|c|c|c|}
\hline \multirow{7}{*}{ 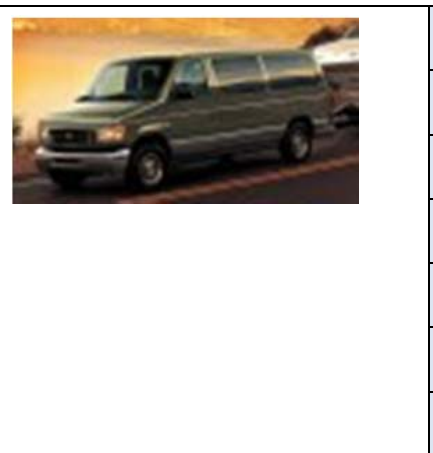 } & Make/Model/Year & Ford/E350 Econoline/2004 \\
\hline & EPA Class Size & Cargo Van \\
\hline & Mission & Pool \\
\hline & Contact & C. Sallinger/Motor Transport \\
\hline & Parking Location & Building 2027/N 8th St \\
\hline & Fleet Vehicle ID & G43-3717A \\
\hline & Fuel Type & Diesel \\
\hline \multirow{7}{*}{ 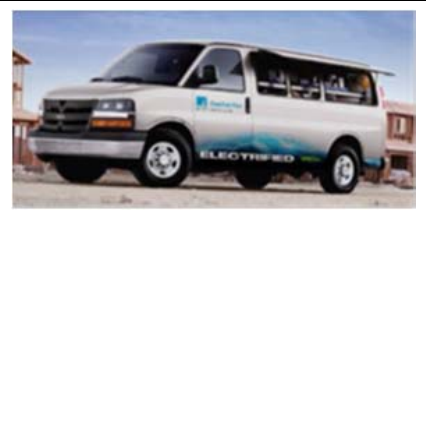 } & Potential Replacement PEV Make/Model & Via VTRUX Van \\
\hline & Potential Annual Fuel Cost Savings & $\$ 1,909$ \\
\hline & Potential Annual GHG Reduction & $9,455 \mathrm{lb}-\mathrm{CO}_{2} \mathrm{e}$ \\
\hline & EVSE Type for Recharging & AC Level 1 \\
\hline & Estimated Replacement Year & 2016 \\
\hline & Vehicle Age at Estimated Replacement & 12 \\
\hline & Odometer at Estimated Replacement Date & 60,126 \\
\hline
\end{tabular}

Vehicle G11-0678K

\begin{tabular}{|c|c|c|}
\hline \multirow{7}{*}{$6=6-2=$} & Make/Model/Year & Chevrolet/Impala/2010 \\
\hline & EPA Class Size & Large Sedan \\
\hline & Mission & Support \\
\hline & Contact & C. Sallinger/Motor Transport \\
\hline & Parking Location & Building 100/2nd St NW \\
\hline & Fleet Vehicle ID & G11-0678K \\
\hline & Fuel Type & Gas/ETH \\
\hline \multirow{7}{*}{$\longrightarrow 20$} & Potential Replacement PEV Make/Model & Nissan Leaf \\
\hline & Potential Annual Fuel Cost Savings & $\$ 1,066$ \\
\hline & Potential Annual GHG Reduction & $5,282 \mathrm{lb}-\mathrm{CO}_{2} \mathrm{e}$ \\
\hline & EVSE Type for Recharging & AC Level 2 \\
\hline & Estimated Replacement Year & 2017 \\
\hline & Vehicle Age at Estimated Replacement & 7 \\
\hline & Odometer at Estimated Replacement Date & 27,606 \\
\hline
\end{tabular}




\begin{tabular}{|c|c|c|}
\hline & Make/Model/Year & Chevrolet/Tahoe/2009 \\
\hline & EPA Class Size & SUV \\
\hline 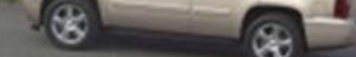 & Mission & Support \\
\hline & Contact & C. Sallinger/Motor Transport \\
\hline & Parking Location & Building 2007/Pendleton Ave \\
\hline & Fleet Vehicle ID & $\mathrm{G} 62-4526 \mathrm{H}$ \\
\hline & Fuel Type & Gas/ETH \\
\hline & Potential Replacement PEV Make/Model & Mitsubishi Outlander \\
\hline & Potential Annual Fuel Cost Savings & $\$ 2,378$ \\
\hline ? & Potential Annual GHG Reduction & $11,772 \mathrm{lb}-\mathrm{CO}_{2} \mathrm{e}$ \\
\hline & EVSE Type for Recharging & AC Level 1 \\
\hline & Estimated Replacement Year & 2016 \\
\hline & Vehicle Age at Estimated Replacement & 7 \\
\hline & Odometer at Estimated Replacement Date & 71,006 \\
\hline
\end{tabular}

\section{Vehicle G42-0698K}

\begin{tabular}{|c|c|c|}
\hline & Make/Model/Year & Chevrolet/C1500/2011 \\
\hline & EPA Class Size & Standard Pickup Truck \\
\hline B: & Mission & Support \\
\hline & Contact & J. Lamantia/Motor Transport \\
\hline & Parking Location & Near D. Ramp/2nd St NW \\
\hline & Fleet Vehicle ID & G42-0698K \\
\hline & Fuel Type & Gas/ETH \\
\hline & Potential Replacement PEV Make/Model & Via VTRUX PU \\
\hline & Potential Annual Fuel Cost Savings & $\$ 154$ \\
\hline 1.6. & Potential Annual GHG Reduction & $762 \mathrm{lb}-\mathrm{CO}_{2} \mathrm{e}$ \\
\hline & EVSE Type for Recharging & AC Level 1 \\
\hline & Estimated Replacement Year & 2016 \\
\hline & Vehicle Age at Estimated Replacement & 5 \\
\hline & Odometer at Estimated Replacement Date & 87,427 \\
\hline
\end{tabular}


Vehicle G11-0493L

\begin{tabular}{|c|c|c|}
\hline \multirow{7}{*}{$8-8 \leq 5$} & Make/Model/Year & Chevrolet/Impala/2012 \\
\hline & EPA Class Size & Large Sedan \\
\hline & Mission & Support \\
\hline & Contact & C. Sallinger/Motor Transport \\
\hline & Parking Location & Building 2007/Pendleton Ave \\
\hline & Fleet Vehicle ID & G11-0493L \\
\hline & Fuel Type & Gas/ETH \\
\hline \multirow{7}{*}{$2,0=$} & Potential Replacement PEV Make/Model & Ford Fusion \\
\hline & Potential Annual Fuel Cost Savings & $\$ 699$ \\
\hline & Potential Annual GHG Reduction & $3,452 \mathrm{lb}-\mathrm{CO}_{2} \mathrm{e}$ \\
\hline & EVSE Type for Recharging & AC Level 1 \\
\hline & Estimated Replacement Year & 2016 \\
\hline & Vehicle Age at Estimated Replacement & 4 \\
\hline & Odometer at Estimated Replacement Date & 46,378 \\
\hline
\end{tabular}

Vehicle G71-0062G

\begin{tabular}{|l|l|c|}
\hline & Make/Model/Year & Ford/F750/2008 \\
\cline { 2 - 3 } & EPA Class Size & Stake Truck \\
\cline { 2 - 3 } & Mission & Transport \\
\hline & Contact & C. Sallinger/Motor Transport \\
\hline & Parking Location & Building R9641 \\
\hline & Fleet Vehicle ID & G71-0062G \\
\hline & Fuel Type & Diesel \\
\hline & Potential Replacement PEV Make/Model & NA \\
\hline & Potential Annual Fuel Cost Savings & \\
\hline & Potential Annual GHG Reduction & \\
\cline { 2 - 3 } & EVSE Type for Recharging & 2018 \\
\hline & Estimated Replacement Year & 10 \\
\cline { 2 - 3 } & Vehicle Age at Estimated Replacement & 17,291 \\
\cline { 2 - 3 } & Odometer at Estimated Replacement Date & \\
\hline
\end{tabular}




\begin{tabular}{|c|c|c|}
\hline \multirow{7}{*}{$x-8=-8$} & Make/Model/Year & Chevrolet/Avalanche/2011 \\
\hline & EPA Class Size & SUV \\
\hline & Mission & Support \\
\hline & Contact & C. Sallinger/Motor Transport \\
\hline & Parking Location & Building 4074/Kaufman Ave \\
\hline & Fleet Vehicle ID & G62-1094L \\
\hline & Fuel Type & Gas/ETH \\
\hline \multirow{7}{*}{$=-2=0$} & Potential Replacement PEV Make/Model & Nissan Leaf \\
\hline & Potential Annual Fuel Cost Savings & $\$ 1,485$ \\
\hline & Potential Annual GHG Reduction & $7,377 \mathrm{lb}-\mathrm{CO}_{2} \mathrm{e}$ \\
\hline & EVSE Type for Recharging & AC Level 2 \\
\hline & Estimated Replacement Year & 2018 \\
\hline & Vehicle Age at Estimated Replacement & 7 \\
\hline & Odometer at Estimated Replacement Date & 40,755 \\
\hline
\end{tabular}

\section{Vehicle G41-1395G}

\begin{tabular}{|c|c|c|}
\hline & Make/Model/Year & Chevrolet/Uplander/2008 \\
\hline & EPA Class Size & Minivan \\
\hline & Mission & Pool \\
\hline & Contact & C. Sallinger/Motor Transport \\
\hline & Parking Location & Building R9641/Rainier Dr \\
\hline & Fleet Vehicle ID & G41-1395G \\
\hline & Fuel Type & Gas/ETH \\
\hline 7 & Potential Replacement PEV Make/Model & Toyota Rav4 EV \\
\hline & Potential Annual Fuel Cost Savings & $\$ 725$ \\
\hline & Potential Annual GHG Reduction & $3,579 \mathrm{lb}-\mathrm{CO}_{2} \mathrm{e}$ \\
\hline & EVSE Type for Recharging & AC Level 2 \\
\hline & Estimated Replacement Year & 2016 \\
\hline & Vehicle Age at Estimated Replacement & 8 \\
\hline & Odometer at Estimated Replacement Date & 26,600 \\
\hline
\end{tabular}




\begin{tabular}{|l|l|c|}
\hline & Make/Model/Year & Ford/Escape Hybrid/2006 \\
\hline & EPA Class Size & SUV \\
\hline & Mission & Pool \\
\hline & Contact & C. Sallinger/Motor Transport \\
\hline & Parking Location & G61-1155D \\
\hline & Fleet Vehicle ID & Gas \\
\hline & Fuel Type & Toyota Rav4 EV \\
\hline \multirow{2}{*}{} & Potential Replacement PEV Make/Model & $\$ 713$ \\
\hline & Potential Annual Fuel Cost Savings & 3,494 lb-CO $\mathrm{CO}_{2} \mathrm{e}$ \\
\hline & Potential Annual GHG Reduction & AC Level 2 \\
\hline & EVSE Type for Recharging & 2015 \\
\hline & Estimated Replacement Year & 9 \\
\hline & Vehicle Age at Estimated Replacement & 41,664 \\
\cline { 2 - 3 } & Odometer at Estimated Replacement Date & . \\
\hline
\end{tabular}

Vehicle G10-2878L

\begin{tabular}{|l|l|c|}
\hline & Make/Model/Year & Chevrolet/Malibu/2011 \\
\hline & EPA Class Size & Midsize Cars \\
\hline & Mission & Pool \\
\hline & Contact & C. Sallinger/Motor Transport \\
\hline Parking Location & Building R1407/West Way \\
\hline & Fleet Vehicle ID & G10-2878L \\
\hline & Fuel Type & Gas/E85 \\
\hline \multirow{2}{*}{} & Potential Replacement PEV Make/Model & Nissan Leaf \\
\hline & Potential Annual Fuel Cost Savings & $\$ 847$ \\
\cline { 2 - 3 } & Potential Annual GHG Reduction & 4,186 \\
\cline { 2 - 3 } & EVSE Type for Recharging & AC Level 2 \\
\cline { 2 - 3 } & Estimated Replacement Year & 2017 \\
\cline { 2 - 3 } & Vehicle Age at Estimated Replacement & 6 \\
\cline { 2 - 3 } & Odometer at Estimated Replacement Date & 28,179 \\
\hline
\end{tabular}


Vehicle G41-1100K

\begin{tabular}{|c|c|c|}
\hline \multirow{7}{*}{ 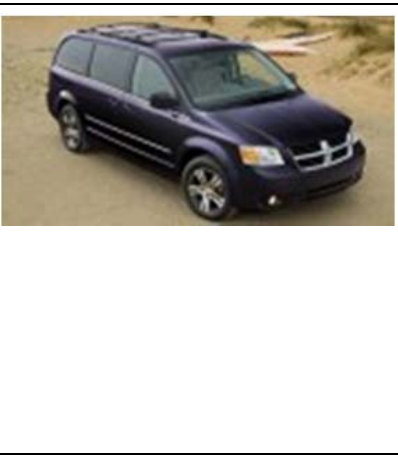 } & Make/Model/Year & Dodge/Grand Caravan/2010 \\
\hline & EPA Class Size & Minivan \\
\hline & Mission & Pool \\
\hline & Contact & C. Sallinger/Motor Transport \\
\hline & Parking Location & Building 2012/1210 \\
\hline & Fleet Vehicle ID & G41-1100K \\
\hline & Fuel Type & Gas/ETH \\
\hline \multirow{7}{*}{ 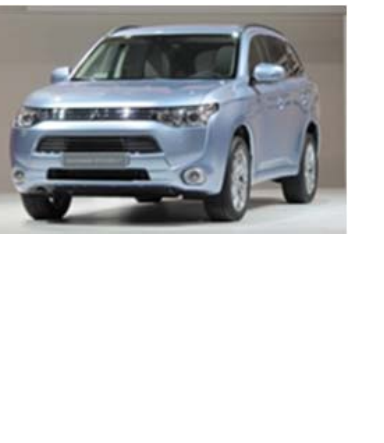 } & Potential Replacement PEV Make/Model & Mitsubishi Outlander \\
\hline & Potential Annual Fuel Cost Savings & $\$ 633$ \\
\hline & Potential Annual GHG Reduction & 3,127 \\
\hline & EVSE Type for Recharging & AC Level 1 \\
\hline & Estimated Replacement Year & 2018 \\
\hline & Vehicle Age at Estimated Replacement & 8 \\
\hline & Odometer at Estimated Replacement Date & 21,772 \\
\hline
\end{tabular}

\section{Vehicle G62-0979G}

\begin{tabular}{|c|c|c|}
\hline & Make/Model/Year & Dodge/1500/2008 \\
\hline$\sqrt{2}$ & EPA Class Size & Standard Pickup Truck \\
\hline 8) - & Mission & Pool \\
\hline & Contact & C. Sallinger/Motor Transport \\
\hline & Parking Location & Building 1210/Mann Ave \\
\hline & Fleet Vehicle ID & G62-0979G \\
\hline & Fuel Type & Gas/ETH \\
\hline $7=$ & Potential Replacement PEV Make/Model & Via VTRUX PU \\
\hline & Potential Annual Fuel Cost Savings & $\$ 612$ \\
\hline 6. & Potential Annual GHG Reduction & $3,028 \mathrm{lb}-\mathrm{CO}_{2} \mathrm{e}$ \\
\hline & EVSE Type for Recharging & AC Level 1 \\
\hline & Estimated Replacement Year & 2016 \\
\hline & Vehicle Age at Estimated Replacement & 8 \\
\hline & Odometer at Estimated Replacement Date & 42,498 \\
\hline
\end{tabular}


Vehicle G71-0674A

\begin{tabular}{|l|l|c|}
\hline Make/Model/Year & Ford/F650 18'BO/2004 \\
\hline EPA Class Size & Delivery Van \\
\cline { 2 - 3 } & Mission & Transport \\
\hline Contact & C. Sallinger/Motor Transport \\
\hline Parking Location & Building R9641/Perry Ave \\
\hline & Fleet Vehicle ID & G71-0674A \\
\hline & Fuel Type & Diesel \\
\hline \multirow{4}{*}{} & Potential Replacement PEV Make/Model & Via VTRUX PU \\
\cline { 2 - 3 } & Potential Annual Fuel Cost Savings & \$875 \\
\cline { 2 - 3 } & Potential Annual GHG Reduction & 4,338 lb-CO ${ }_{2} \mathrm{e}$ \\
\hline & EVSE Type for Recharging & AC Level 1 \\
\hline & Estimated Replacement Year & 2016 \\
\hline & Vehicle Age at Estimated Replacement & 12 \\
\hline & Odometer at Estimated Replacement Date & 50,098 \\
\hline
\end{tabular}

Vehicle G41-1373G

\begin{tabular}{|l|l|c|}
\hline Make/Model/Year & Dodge/Dakota/2008 \\
\hline EPA Class Size & Standard Pickup Truck \\
\hline Mission & Support \\
\hline Contact & C. Sallinger/Motor Transport \\
\cline { 2 - 3 } & Parking Location & Building R9654/Perry Ave \\
\cline { 2 - 3 } & Fleet Vehicle ID & G41-1373G \\
\hline & Fuel Type & Mitsubishi Outlander \\
\hline & Potential Replacement PEV Make/Model & $\$ 645$ \\
\cline { 2 - 3 } & Potential Annual Fuel Cost Savings & 3,197 lb-CO \\
\cline { 2 - 3 } & Potential Annual GHG Reduction & AC Level 1 \\
\cline { 2 - 3 } & EVSE Type for Recharging & 2015 \\
\hline & Estimated Replacement Year & 7 \\
\cline { 2 - 3 } & Vehicle Age at Estimated Replacement & 65,000 \\
\cline { 2 - 3 } & Odometer at Estimated Replacement Date & \\
\hline
\end{tabular}




\begin{tabular}{|c|c|c|}
\hline & Make/Model/Year & Dodge/Dakota/2008 \\
\hline 16 & EPA Class Size & Standard Pickup Truck \\
\hline 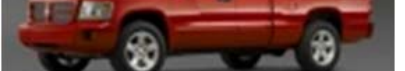 & Mission & Pool \\
\hline & Contact & C. Sallinger/Motor Transport \\
\hline & Parking Location & Building R9641/Rainier Dr \\
\hline & Fleet Vehicle ID & G41-1367G \\
\hline & Fuel Type & Gas/ETH \\
\hline & Potential Replacement PEV Make/Model & $\begin{array}{c}\text { Toyota Rav4 EV or BEV } \\
\text { Pickup } \\
\end{array}$ \\
\hline & Potential Annual Fuel Cost Savings & $\$ 1,031$ \\
\hline & Potential Annual GHG Reduction & $5,109 \mathrm{lb}-\mathrm{CO}_{2} \mathrm{e}$ \\
\hline & EVSE Type for Recharging & AC Level 2 \\
\hline & Estimated Replacement Year & 2016 \\
\hline & Vehicle Age at Estimated Replacement & 8 \\
\hline & Odometer at Estimated Replacement Date & 33,802 \\
\hline
\end{tabular}

Vehicle G43-0792K

\begin{tabular}{|l|l|c|}
\hline & $\begin{array}{c}\text { Chevrolet/CG3500 } \\
\text { Express/2010 }\end{array}$ \\
Passenger Van
\end{tabular}




\begin{tabular}{|l|l|c|}
\hline & $\begin{array}{c}\text { Chevrolet/Express } \\
\text { CG3500/2010 }\end{array}$ \\
Passenger Van \\
\hline
\end{tabular}

Vehicle G42-0988F

\begin{tabular}{|c|c|c|}
\hline & Make/Model/Year & Chevrolet/Express 13/2007 \\
\hline & EPA Class Size & Cargo Van \\
\hline & Mission & Support \\
\hline & Contact & C. Sallinger/Motor Transport \\
\hline & Parking Location & Building 9040/Fitzsimmons \\
\hline & Fleet Vehicle ID & G42-0988F \\
\hline & Fuel Type & Gas \\
\hline & Potential Replacement PEV Make/Model & Nissan eNV200 \\
\hline & Potential Annual Fuel Cost Savings & $\$ 2,503$ \\
\hline & Potential Annual GHG Reduction & $12,425 \mathrm{lb}-\mathrm{CO}_{2} \mathrm{e}$ \\
\hline & EVSE Type for Recharging & AC Level 2 \\
\hline & Estimated Replacement Year & 2016 \\
\hline & Vehicle Age at Estimated Replacement & 9 \\
\hline & Odometer at Estimated Replacement Date & 59,460 \\
\hline
\end{tabular}




\begin{tabular}{|c|c|c|}
\hline \multirow{7}{*}{ (2) } & Make/Model/Year & Chevrolet/CG3300/2008 \\
\hline & EPA Class Size & Passenger Van \\
\hline & Mission & Pool \\
\hline & Contact & C. Sallinger/Motor Transport \\
\hline & Parking Location & Building R9641or 19th St N \\
\hline & Fleet Vehicle ID & G43-0860G \\
\hline & Fuel Type & Gas \\
\hline \multirow{7}{*}{ 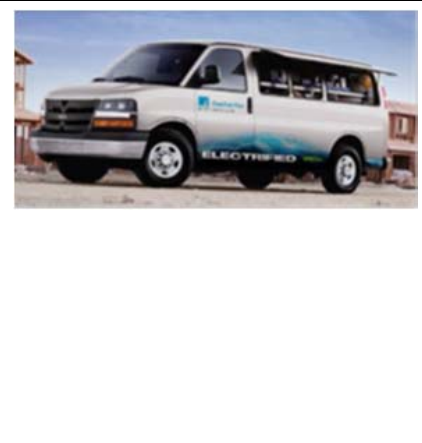 } & Potential Replacement PEV Make/Model & Via VTRUX Pass Van \\
\hline & Potential Annual Fuel Cost Savings & $\$ 1,951$ \\
\hline & Potential Annual GHG Reduction & $9,672 \mathrm{lb}-\mathrm{CO}_{2} \mathrm{e}$ \\
\hline & EVSE Type for Recharging & AC Level 1 \\
\hline & Estimated Replacement Year & 2015 \\
\hline & Vehicle Age at Estimated Replacement & 8 \\
\hline & Odometer at Estimated Replacement Date & 68,427 \\
\hline
\end{tabular}

Vehicle G43-1389K

\begin{tabular}{|c|c|c|}
\hline 31 & Make/Model/Year & Chevrolet/CG3300/2010 \\
\hline & EPA Class Size & Passenger Van \\
\hline & Mission & Pool \\
\hline & Contact & C. Sallinger/Motor Transport \\
\hline & Parking Location & Various \\
\hline & Fleet Vehicle ID & G43-1389K \\
\hline & Fuel Type & $\mathrm{Gas} / \mathrm{ETH}$ \\
\hline & Potential Replacement PEV Make/Model & Via VTRUX Pass Van \\
\hline & Potential Annual Fuel Cost Savings & $\$ 750$ \\
\hline & Potential Annual GHG Reduction & $3,718 \mathrm{lb}-\mathrm{CO}_{2} \mathrm{e}$ \\
\hline & EVSE Type for Recharging & AC Level 1 \\
\hline & Estimated Replacement Year & 2018 \\
\hline & Vehicle Age at Estimated Replacement & 8 \\
\hline & Odometer at Estimated Replacement Date & 59,091 \\
\hline
\end{tabular}


Vehicle G41-1180G

\begin{tabular}{|c|c|c|}
\hline \multirow{7}{*}{ 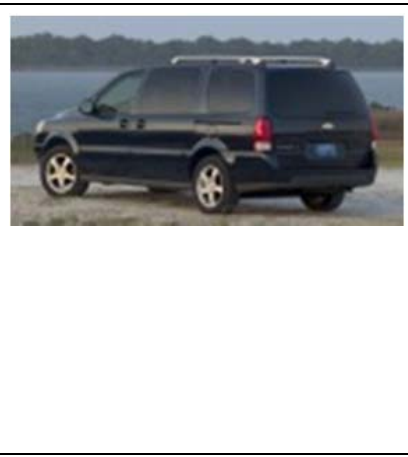 } & Make/Model/Year & Chevrolet/Uplander/2008 \\
\hline & EPA Class Size & Minivan \\
\hline & Mission & Support \\
\hline & Contact & J. Lamantia/Motor Transport \\
\hline & Parking Location & Building 9040/Fitzsimmons \\
\hline & Fleet Vehicle ID & G41-1180G \\
\hline & Fuel Type & $\mathrm{Gas} / \mathrm{ETH}$ \\
\hline \multirow{7}{*}{ 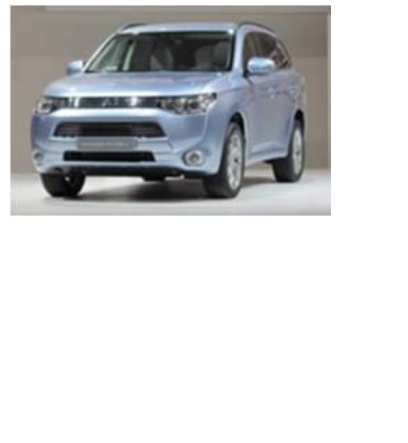 } & Potential Replacement PEV Make/Model & Mitsubishi Outlander \\
\hline & Potential Annual Fuel Cost Savings & $\$ 1,988$ \\
\hline & Potential Annual GHG Reduction & $9,812 \mathrm{lb}-\mathrm{CO}_{2} \mathrm{e}$ \\
\hline & EVSE Type for Recharging & AC Level 1 \\
\hline & Estimated Replacement Year & 2014 \\
\hline & Vehicle Age at Estimated Replacement & 6 \\
\hline & Odometer at Estimated Replacement Date & 65,000 \\
\hline
\end{tabular}

Vehicle G11-2675G

\begin{tabular}{|l|l|c|}
\hline Make/Model/Year & Chevrolet/Impala/2008 \\
\hline EPA Class Size & Large Cars \\
\hline Mission & Pool \\
\hline Contact & Cuilding 9040/9900 \\
\hline Parking Location & G11-2675G \\
\hline Fleet Vehicle ID & Gas/ETH \\
\hline Fuel Type & Chevrolet Volt \\
\hline & Potential Replacement PEV Make/Model & $\$ 193$ \\
\hline Potential Annual Fuel Cost Savings & 954 lb-CO ${ }_{2} \mathrm{e}$ \\
\hline Potential Annual GHG Reduction & $\mathrm{AC} \mathrm{Level} 1$ \\
\hline & EVSE Type for Recharging & 2014 \\
\hline & Estimated Replacement Year & 6 \\
\hline & Vehicle Age at Estimated Replacement & 6,842 \\
\hline
\end{tabular}


Vehicle G43-1191L

\begin{tabular}{|c|c|c|}
\hline \multirow{7}{*}{ 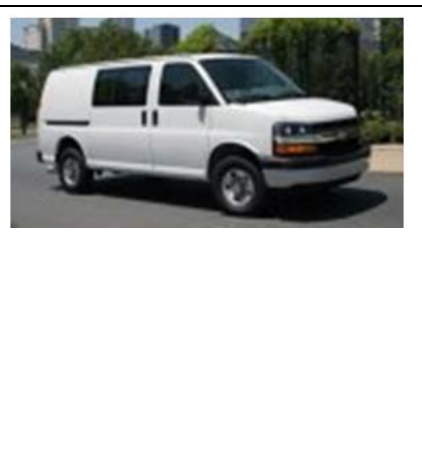 } & Make/Model/Year & Chevrolet/CG3300/2011 \\
\hline & EPA Class Size & Passenger Van \\
\hline & Mission & Pool \\
\hline & Contact & C. Sallinger/Motor Transport \\
\hline & Parking Location & Building R9641/Yakima \\
\hline & Fleet Vehicle ID & G43-1191L \\
\hline & Fuel Type & Gas/ETH \\
\hline \multirow{7}{*}{ 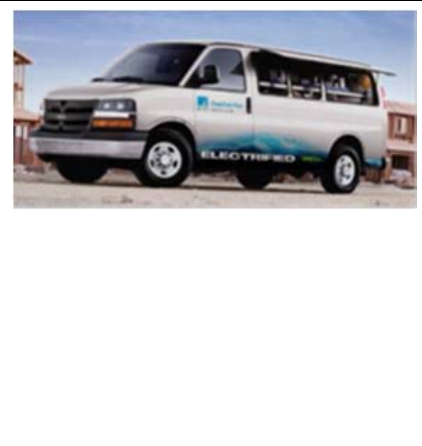 } & Potential Replacement PEV Make/Model & Via VTRUX Pass Van \\
\hline & Potential Annual Fuel Cost Savings & $\$ 1,377$ \\
\hline & Potential Annual GHG Reduction & $6,826 \mathrm{lb}-\mathrm{CO}_{2} \mathrm{e}$ \\
\hline & EVSE Type for Recharging & AC Level 1 \\
\hline & Estimated Replacement Year & 2018 \\
\hline & Vehicle Age at Estimated Replacement & 7 \\
\hline & Odometer at Estimated Replacement Date & 46,615 \\
\hline
\end{tabular}

Vehicle G12-0662H

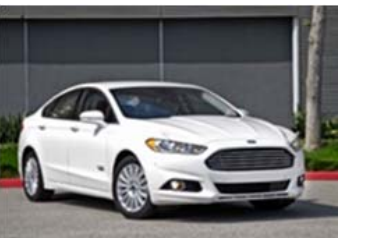

\begin{tabular}{|l|c|}
\hline Make/Model/Year & Ford/Fusion HEV/2010 \\
\hline EPA Class Size & Midsize Car \\
\hline Mission & Pool \\
\hline Contact & J. Lamantia/Motor Transport \\
\hline Parking Location & Building R9641/3674 \\
\hline Fleet Vehicle ID & G12-0662H \\
\hline Fuel Type & Gas \\
\hline Potential Replacement PEV Make/Model & Ford Fusion \\
\hline Potential Annual Fuel Cost Savings & $\$ 475$ \\
\hline Potential Annual GHG Reduction & 2,316 lb-CO $2 \mathrm{e}$ \\
\hline EVSE Type for Recharging & AC Level 1 \\
\hline Estimated Replacement Year & 2014 \\
\hline Vehicle Age at Estimated Replacement & 4 \\
\hline Odometer at Estimated Replacement Date & 32,100 \\
\hline
\end{tabular}


Vehicle G63-0271A

\begin{tabular}{|l|l|c|}
\hline & Make/Model/Year & Ford/F350 Stake/2004 \\
\cline { 2 - 3 } & EPA Class Size & Stake Truck \\
\cline { 2 - 3 } & Mission & Transport \\
\hline Contact & C. Sallinger/Motor Transport \\
\hline & Parking Location & Camp Murray/Yakima \\
\hline & Fleet Vehicle ID & G63-0271A \\
\cline { 2 - 3 } & Fuel Type & Gas \\
\hline \multirow{4}{*}{} & Potential Replacement PEV Make/Model & Via VTRUX PU \\
\cline { 2 - 3 } & Potential Annual Fuel Cost Savings & \$665 \\
\hline & Potential Annual GHG Reduction & AC Level 1 \\
\hline & EVSE Type for Recharging & 2014 \\
\hline & Estimated Replacement Year & 10 \\
\cline { 2 - 3 } & Vehicle Age at Estimated Replacement & 53,564 \\
\cline { 2 - 3 } & Odometer at Estimated Replacement Date & . \\
\hline
\end{tabular}

Vehicle G41-1392G

\begin{tabular}{|c|c|c|}
\hline & Make/Model/Year & Chevrolet/Uplander/2008 \\
\hline & EPA Class Size & Minivan \\
\hline & Mission & Support \\
\hline & Contact & C. Sallinger/Motor Transport \\
\hline & Parking Location & Building R9641/Building 3017 \\
\hline & Fleet Vehicle ID & G41-1392G \\
\hline & Fuel Type & Gas/ETH \\
\hline \multirow{7}{*}{ 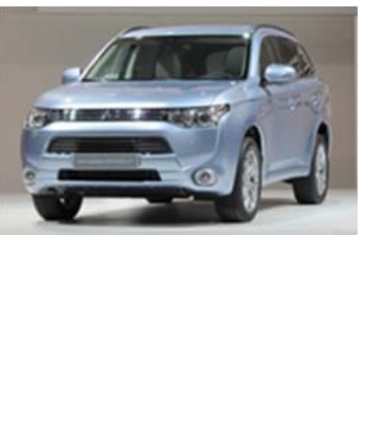 } & Potential Replacement PEV Make/Model & Mitsubishi Outlander \\
\hline & Potential Annual Fuel Cost Savings & $\$ 928$ \\
\hline & Potential Annual GHG Reduction & $4,583 \mathrm{lb}-\mathrm{CO}_{2} \mathrm{e}$ \\
\hline & EVSE Type for Recharging & AC Level 1 \\
\hline & Estimated Replacement Year & 2015 \\
\hline & Vehicle Age at Estimated Replacement & 7 \\
\hline & Odometer at Estimated Replacement Date & 41,466 \\
\hline
\end{tabular}




\begin{tabular}{|c|c|c|}
\hline \multirow{7}{*}{ 14 } & Make/Model/Year & Ford/E350/2009 \\
\hline & EPA Class Size & Passenger Van \\
\hline & Mission & Pool \\
\hline & Contact & C. Sallinger/Motor Transport \\
\hline & Parking Location & Building R9641/Perry Ave \\
\hline & Fleet Vehicle ID & G43-3881H \\
\hline & Fuel Type & Gas/ETH \\
\hline \multirow{7}{*}{ 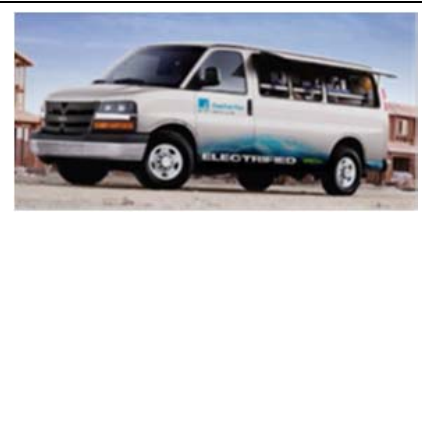 } & Potential Replacement PEV Make/Model & Via VTRUX Pass Van \\
\hline & Potential Annual Fuel Cost Savings & $\$ 801$ \\
\hline & Potential Annual GHG Reduction & $3,970 \mathrm{lb}-\mathrm{CO}_{2} \mathrm{e}$ \\
\hline & EVSE Type for Recharging & AC Level 1 \\
\hline & Estimated Replacement Year & 2016 \\
\hline & Vehicle Age at Estimated Replacement & 7 \\
\hline & Odometer at Estimated Replacement Date & 44,033 \\
\hline
\end{tabular}

Vehicle G43-25839

\begin{tabular}{|c|c|c|}
\hline \multirow{7}{*}{ 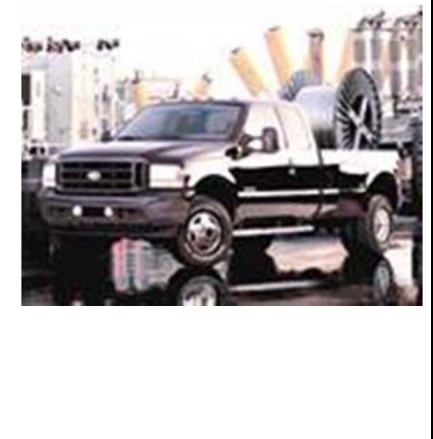 } & Make/Model/Year & Ford/F350/2003 \\
\hline & EPA Class Size & Pickup Truck \\
\hline & Mission & Transport \\
\hline & Contact & J. Lamantia/Motor Transport \\
\hline & Parking Location & Building R9641 \\
\hline & Fleet Vehicle ID & G43-25839 \\
\hline & Fuel Type & Diesel \\
\hline & Potential Replacement PEV Make/Model & $\begin{array}{c}\text { Toyota Rav4 EV or BEV } \\
\text { Pickup }\end{array}$ \\
\hline & Potential Annual Fuel Cost Savings & $\$ 1,425$ \\
\hline & Potential Annual GHG Reduction & $7,071 \mathrm{lb}-\mathrm{CO}_{2} \mathrm{e}$ \\
\hline & EVSE Type for Recharging & AC Level 2 \\
\hline & Estimated Replacement Year & 2014 \\
\hline & Vehicle Age at Estimated Replacement & 11 \\
\hline & Odometer at Estimated Replacement Date & 26,709 \\
\hline
\end{tabular}


Vehicle G41-1376G

\begin{tabular}{|l|l|c|}
\hline & Make/Model/Year & Dodge/Dakota/2008 \\
\hline EPA Class Size & Standard Pickup Truck \\
\hline & Mission & Support \\
\hline Contact & C. Sallinger/Motor Transport \\
\hline & Parking Location & Building R9640/Perry Ave \\
\cline { 2 - 3 } & Fleet Vehicle ID & G41-1376G \\
\cline { 2 - 3 } & Fuel Type & Gas/ETH \\
\hline & Potential Replacement PEV Make/Model & Nissan eNV200 \\
\hline & Potential Annual Fuel Cost Savings & $\$ 790$ \\
\hline & Potential Annual GHG Reduction & 3,918 lb-CO \\
\hline & EVSE Type for Recharging & AC Level 2 \\
\hline & Estimated Replacement Year & 2015 \\
\hline & Vehicle Age at Estimated Replacement & 7 \\
\cline { 2 - 3 } & Odometer at Estimated Replacement Date & 17,089 \\
\hline
\end{tabular}

\section{Vehicle G41-1161G}

\begin{tabular}{|c|c|c|}
\hline & Make/Model/Year & Chevrolet/Uplander/2008 \\
\hline & EPA Class Size & Minivan \\
\hline 8 & Mission & Pool \\
\hline & Contact & C. Sallinger/Motor Transport \\
\hline & Parking Location & Building 9040A/Fitzsimmons \\
\hline & Fleet Vehicle ID & G41-1161G \\
\hline & Fuel Type & Gas/ETH \\
\hline & Potential Replacement PEV Make/Model & Toyota Rav4 EV \\
\hline & Potential Annual Fuel Cost Savings & $\$ 341$ \\
\hline & Potential Annual GHG Reduction & $1,684 \mathrm{lb}-\mathrm{CO}_{2} \mathrm{e}$ \\
\hline & EVSE Type for Recharging & AC Level 2 \\
\hline & Estimated Replacement Year & 2015 \\
\hline & Vehicle Age at Estimated Replacement & 7 \\
\hline & Odometer at Estimated Replacement Date & 10,654 \\
\hline
\end{tabular}




\begin{tabular}{|l|l|l|}
\hline Make/Model/Year & Chevrolet/CG3300/2010 \\
\cline { 2 - 3 } & EPA Class Size & Passenger Van \\
\hline Mission & C Sallinger/Motor Transport \\
\hline Contact & Bldg R9641 \\
\cline { 2 - 3 } & Parking Location & G43-0790K \\
\hline & Fleet Vehicle ID & Gas/ETH \\
\hline & Fuel Type & Via VTRUX Pass Van \\
\hline \multirow{2}{*}{} & Potential Replacement PEV Make/Model & $\$ 1,987$ \\
\hline Potential Annual Fuel Cost Savings & $9,851 \mathrm{lb}-\mathrm{CO}_{2} \mathrm{e}$ \\
\hline & Potential Annual GHG Reduction & $\mathrm{AC} \mathrm{L1}$ \\
\hline & EVSE Type for Recharging & 2017 \\
\hline & Estimated Replacement Year & 7 \\
\cline { 2 - 3 } & Vehicle Age at Estimated Replacement & 55,311 \\
\hline & Odometer at Estimated Replacement Date & 5 \\
\hline
\end{tabular}

\section{Vehicle G82-0509A}

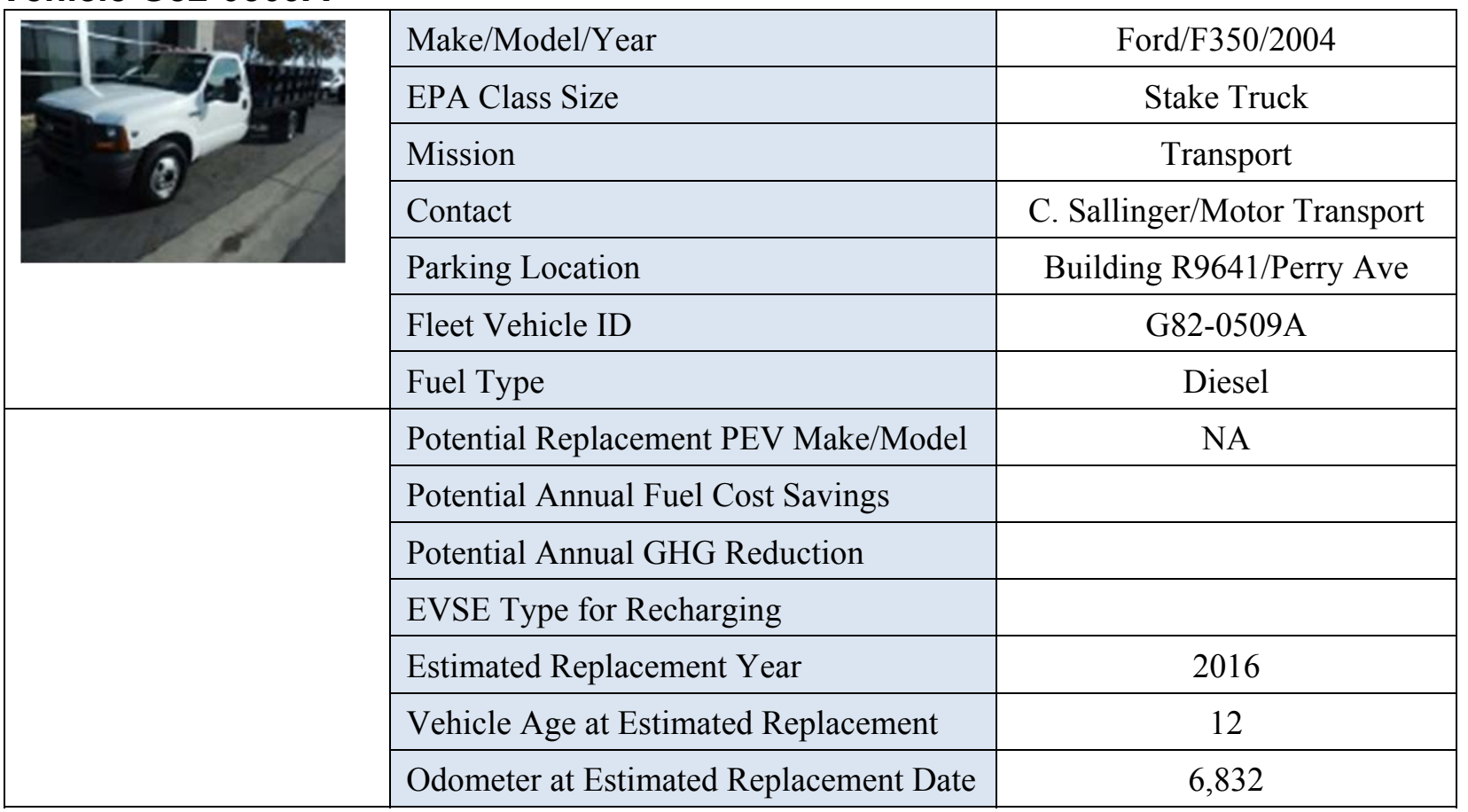


Vehicle G10-6379L

\begin{tabular}{|c|c|c|}
\hline \multirow{7}{*}{$\frac{2 \pi}{4=29}$} & Make/Model/Year & Dodge/Avenger/2011 \\
\hline & EPA Class Size & Midsize Car \\
\hline & Mission & Support \\
\hline & Contact & C. Sallinger/Motor Transport \\
\hline & Parking Location & $\begin{array}{c}\text { Building 9040/Gardner Loop } \\
\text { RD } \\
\end{array}$ \\
\hline & Fleet Vehicle ID & G10-6379L \\
\hline & Fuel Type & Gas/ETH \\
\hline \multirow{7}{*}{ 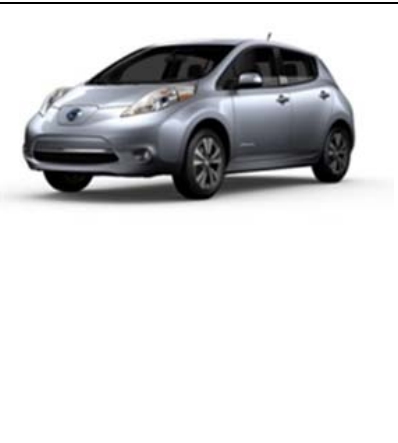 } & Potential Replacement PEV Make/Model & Nissan Leaf \\
\hline & Potential Annual Fuel Cost Savings & $\$ 1,319$ \\
\hline & Potential Annual GHG Reduction & $6,532 \mathrm{lb}-\mathrm{CO}_{2} \mathrm{e}$ \\
\hline & EVSE Type for Recharging & AC Level 2 \\
\hline & Estimated Replacement Year & 2016 \\
\hline & Vehicle Age at Estimated Replacement & 5 \\
\hline & Odometer at Estimated Replacement Date & 32,230 \\
\hline
\end{tabular}

Vehicle G42-3471A

\begin{tabular}{|c|c|c|}
\hline & Make/Model/Year & Chevrolet/G2300/2005 \\
\hline & EPA Class Size & Cargo Van \\
\hline & Mission & Transport \\
\hline & Contact & C. Sallinger/Motor Transport \\
\hline & Parking Location & Building 690 \\
\hline & Fleet Vehicle ID & G42-3471A \\
\hline & Fuel Type & Gas \\
\hline & Potential Replacement PEV Make/Model & Nissan eNV200 \\
\hline & Potential Annual Fuel Cost Savings & $\$ 827$ \\
\hline ( 3 & Potential Annual GHG Reduction & $4,100 \mathrm{lb}-\mathrm{CO}_{2} \mathrm{e}$ \\
\hline & EVSE Type for Recharging & AC Level 2 \\
\hline & Estimated Replacement Year & 2014 \\
\hline & Vehicle Age at Estimated Replacement & 9 \\
\hline & Odometer at Estimated Replacement Date & 29,235 \\
\hline
\end{tabular}




\section{Appendix E 6th MP Group Vehicle Replacement Approach}

There are four replacement approaches identified for the 6th MP Group:

- Monitored vehicles

- $\quad$ GSA-listed PEVs only

- All potential PEV types

- Full fleet

- GSA-Listed PEVs only for sedans

- All potential PEV types for non-sedan vehicles.

The extensive analysis conducted for monitored vehicles (Task 3) results in high confidence that the suggested vehicle can meet mission requirements. The suggested vehicles for the full fleet rely on the extrapolation of those monitored vehicles and the guidance identified in Section 3.

\section{E.1 Monitored Vehicle General Services Administration Replacement Approach}

The vehicles monitored include a minivan, an SUV, and a pickup truck for which no GSA-listed replacements are currently available.

\section{E.2 All Monitored Vehicle Replacement Approach}

Table E-1 provides a replacement approach using currently or soon-to-be available PEVs. Although not currently listed by GSA, these or similar vehicles may be listed by the year identified or JBLM may choose to justify the replacement.

Table E-1. 6th MP Group all monitored vehicle replacement approach.

\begin{tabular}{cccccc} 
Fleet & \multicolumn{4}{c}{ All Monitored Vehicle Replacement Approach } \\
Vehicle Id & Make/Model & Year & EPA Class & Replacement Vehicle & $\begin{array}{c}\text { Peplacement } \\
\text { Year }\end{array}$ \\
\hline G61-0689A & Ford Ranger & 2004 & Pickup & Via VTRUX PU & 2015 \\
G41-5433B & Dodge Caravan & 2006 & Minivan & Nissan Leaf & 2015 \\
G61-0546L & GMC Terrain & 2011 & SUV & Toyota Rav4 EV & 2018 \\
\hline
\end{tabular}

\section{E.3 Sedan Fleet Replacement Approach}

GSA currently lists only sedans for PEVs. It is assumed that additional sedans will be added to the list in the next few years. Table E-2 provides the list of sedans in the 6th MP Group fleet. The projected year of replacement is identified based on the GSA requirements and expected usage. The mileage is projected from the odometer reading in 2013 and annual mileage provided by JBLM. As noted above, none of these vehicles were monitored in this study. For illustration, the vehicles marked in green in this table reflect potential replacement vehicles that are included in Section 4.2.1.

Table E-2. 6th MP Group sedan fleet replacement approach.

\begin{tabular}{ccccccc} 
Fleet & \multicolumn{2}{c}{ Sedan Fleet Replacement Approach } & Potential & Estimated & Replacement \\
Vehicle Id & Make/Model & Year & EPA Class & Replacement Vehicle & Mileage & Year \\
\hline G10-7541F & Pontiac G6 & 2008 & Sedan - Compact & Focus & 37,883 & 2015 \\
G10-7540F & Pontiac G6 & 2008 & Sedan - Compact & Focus & 34,342 & 2016 \\
G10-2841L & Dodge Avenger & 2011 & Sedan - Compact & Focus & 43,911 & 2016 \\
G11-0479L & Chevrolet Impala & 2011 & Sedan - Large & Leaf & 45,262 & 2016 \\
G11-0481L & Chevrolet Impala & 2011 & Sedan - Large & Focus & 36,678 & 2016 \\
\hline
\end{tabular}




\begin{tabular}{ccccccc}
\hline $\begin{array}{c}\text { Fleet } \\
\text { Vehicle Id }\end{array}$ & Make/Model & Year & EPA Class & $\begin{array}{c}\text { Potential } \\
\text { Replacement Vehicle }\end{array}$ & $\begin{array}{c}\text { Estimated } \\
\text { Mileage }\end{array}$ & $\begin{array}{c}\text { Replacement } \\
\text { Year }\end{array}$ \\
\hline G10-6362L & Chevrolet Malibu & 2011 & Sedan - Midsize & Volt & 34,916 & 2017 \\
G11-0478L & Chevrolet Impala & 2011 & Sedan - Large & Leaf & 37,214 & 2017 \\
G11-0480L & Chevrolet Impala & 2011 & Sedan - Large & Rav4 EV & 41,249 & 2018 \\
G11-0482L & Chevrolet Impala & 2011 & Sedan - Large & Rav4 EV & 37,361 & 2018 \\
G10-6361L & Chevrolet Malibu & 2011 & Sedan - Midsize & Leaf & 30,586 & 2019 \\
G10-2629K & Ford Fusion HEV & 2011 & Sedan-Midsize & Leaf & 30,281 & 2021 \\
\hline
\end{tabular}

\section{E.4 Near-Term Non-Sedan Vehicle Replacement Approach}

Another approach to the replacement strategy is to consider non-sedan vehicles that may be replaced in the next 2 years. Table E-3 identifies the non-sedan vehicles in the 6th MP Group fleet that are projected to be replaced in 2015. No vehicles are projected to be replaced in 2016. The projected year of replacement is identified based on the GSA requirements and expected usage. The mileage is projected from the odometer reading in 2013 and annual mileage provided by JBLM. As before, the potential replacement vehicle may not be GSA-listed but could be by the replacement year identified or JBLM may consider its justification for replacement. (Note that JBLM may have replaced several of these vehicles in 2014.) For illustration, the vehicles marked in orange were monitored; therefore, high confidence exists in the potential replacement. Either minivan would meet the suggested replacement included in Section 4.2.2.

Table E-3. 6th MP Group near-term vehicles replacement approach.

\begin{tabular}{ccccccc} 
Fleet & \multicolumn{3}{c}{ Near-Term Replacement Approach } \\
Vehicle Id & Make/Model & Year & EPA Class & $\begin{array}{c}\text { Potential } \\
\text { Replacement Vehicle }\end{array}$ & $\begin{array}{c}\text { Estimated } \\
\text { Mileage }\end{array}$ & $\begin{array}{c}\text { Replacement } \\
\text { Year }\end{array}$ \\
\hline G41-5433B & Dodge Gr Caravan & 2006 & Minivan & Rav4 EV & 63,451 & 2015 \\
G41-2128F & Chevrolet Uplander & 2007 & Minivan & Rav4 EV & 38,644 & 2015 \\
G61-0689A & Ford Ranger & 2004 & Pickup & VTRUX PU & 29,006 & 2015 \\
G62-3684B & Chevrolet Tahoe & 2005 & SUV & Outlander & 109,869 & 2015 \\
G71-3311 & Ford E350 & 2004 & Van - Pass & VTRUX Van & 4,049 & 2015 \\
\hline
\end{tabular}




\section{Appendix F DCA Support Group Vehicle Analysis}

There are four replacement approaches identified for the DCA Support Group:

- Monitored vehicles

- GSA-listed PEVs only

- All potential PEV types

- $\quad$ Full fleet

- $\quad$ GSA-listed PEVs only for sedans

- All potential PEV types for non-sedan vehicles.

The extensive analysis conducted for monitored vehicles (Task 3) results in high confidence that the suggested vehicle can meet mission requirements. The suggested vehicles for the full fleet rely on the extrapolation of those monitored vehicles and the guidance identified in Section 3.

\section{F.1 Monitored Vehicle General Services Administration Replacement Approach}

The vehicles monitored include a pickup truck, a heavy-duty truck, a passenger van, and a cargo van for which no GSA-listed replacements are currently available.

\section{F.2 All Monitored Vehicle Replacement Approach}

Table F-1 provides a replacement approach using currently or soon-to-be available PEVs. Although not currently listed by GSA, these or similar vehicles may be listed by the year identified or JBLM may choose to justify the replacement.

Table F-1. DCA Support Group all monitored vehicle replacement approach.

\begin{tabular}{cccccc}
\hline \multicolumn{1}{c}{ Fleet } & \multicolumn{4}{c}{ All Monitored Vehicle Replacement Approach } \\
Vehicle Id & Make/Model & Year & EPA Class & $\begin{array}{c}\text { Potential } \\
\text { Replacement Vehicle }\end{array}$ & $\begin{array}{c}\text { Replacement } \\
\text { Year }\end{array}$ \\
\hline G41-74299 & Ford Ranger & 2004 & Pickup Truck & Outlander & 2016 \\
G71-0684A & Chev. C6500 Stake & 2005 & Stake Truck & NA & 2017 \\
G43-1195H & Chev. 15 Pas Van & 2011 & Passenger Van & VTRUX Van & 2018 \\
G42-0289G & Chev. G1300 & 2008 & Cargo Van & eNV200 & 2018 \\
\hline
\end{tabular}

\section{F.3 Sedan Fleet Replacement Approach}

GSA currently lists only sedans for PEVs. It is assumed that additional sedans will be added to the list in the next few years. Table F-2 provides the list of sedans in the DCA Support Group fleet. The projected year of replacement is identified based on the GSA requirements and expected usage. The mileage is projected from the odometer reading in 2013 and annual mileage provided by JBLM. No sedans are projected to be replaced in the next few years. For illustration, the vehicles marked in green in this table reflect potential replacement vehicles that are included in Section 4.3.1.

Table F-2. DCA Support Group sedan fleet replacement approach.

\begin{tabular}{ccccccc} 
Fleet & \multicolumn{7}{c}{ Sedan Fleet Replacement Approach } \\
Vehicle Id & Make/Model & Year & EPA Class & $\begin{array}{c}\text { Potential } \\
\text { Replacement } \\
\text { Vehicle }\end{array}$ & $\begin{array}{c}\text { Estimated } \\
\text { Mileage }\end{array}$ & $\begin{array}{c}\text { Replacement } \\
\text { Year }\end{array}$ \\
\hline $2455 \mathrm{~F}$ & Chevrolet Malibu & 2007 & Sedan - Midsize & Leaf & 23,974 & 2018 \\
$4586 \mathrm{~L}$ & Ford Focus & 2012 & Sedan - Compact & Volt & 38,540 & 2021 \\
$2998 \mathrm{~K}$ & Chevrolet Malibu & 2010 & Sedan - Midsize & Leaf & 28,724 & 2021 \\
\hline
\end{tabular}




\begin{tabular}{ccccccc}
\hline \multicolumn{1}{c}{ Sedan Fleet Replacement Approach } \\
$\begin{array}{c}\text { Fleet } \\
\text { Vehicle Id }\end{array}$ & Make/Model & Year & EPA Class & $\begin{array}{c}\text { Potential } \\
\text { Replacement } \\
\text { Vehicle }\end{array}$ & $\begin{array}{c}\text { Estimated } \\
\text { Mileage }\end{array}$ & $\begin{array}{c}\text { Replacement } \\
\text { Year }\end{array}$ \\
\hline 4590L & Ford Focus & 2012 & Sedan - Compact & Focus & 16,507 & 2022 \\
4589L & Ford Focus & 2012 & Sedan - Compact & Focus & 15,963 & 2022 \\
4588L & Ford Focus & 2012 & Sedan - Compact & Volt & 32,954 & 2022 \\
4587L & Ford Focus & 2012 & Sedan - Compact & Leaf & 24,265 & 2022 \\
4585L & Ford Focus & 2012 & Sedan - Compact & Leaf & 19,072 & 2022 \\
4591L & Ford Focus & 2012 & Sedan - Compact & Focus & 38,555 & 2022 \\
4592L & Ford Focus & 2012 & Sedan - Compact & Focus & 33,533 & 2022 \\
\hline
\end{tabular}

\section{F.4 Near-Term Non-Sedan Vehicle Replacement Approach}

Another approach to the replacement strategy is to consider vehicles that may be replaced in the next 2 years. Table F-3 identifies the non-sedan vehicles in the DCA Support Group fleet that are projected to be replaced in 2015 and 2016. The projected year of replacement is identified based on the GSA requirements and expected usage. The mileage is projected from the odometer reading in 2013 and annual mileage provided by JBLM. As before, the potential replacement vehicle may not be GSA-listed but could be by the replacement year identified or JBLM may consider its justification for replacement. (Note that JBLM may have replaced several of these vehicles in 2014.) For illustration, the vehicle marked in orange was monitored; therefore, high confidence exists in the potential replacement. That vehicle and the vehicles marked in green in this table reflect potential replacement vehicles that are included in Section 4.3.2.

Table F-3. DCA Support Group near-term replacement approach.

\begin{tabular}{ccccccc}
\hline \multicolumn{7}{c}{ Near-Term Replacement Approach } \\
$\begin{array}{c}\text { Fleet } \\
\text { Vehicle Id }\end{array}$ & Make/Model & Year & EPA Class & $\begin{array}{c}\text { Potential } \\
\text { Replacement } \\
\text { Vehicle }\end{array}$ & $\begin{array}{c}\text { Estimated } \\
\text { Mileage }\end{array}$ & $\begin{array}{c}\text { Replacement } \\
\text { Year }\end{array}$ \\
\hline G42-1051F & Ford F150 & 2007 & Pickup & VTRUX PU & 47,598 & 2015 \\
G43-23834 & Dodge 3500 & 2002 & Pickup & Rav4 EV & 26,156 & 2015 \\
G43-19791 & Dodge B3500 & 2002 & Van - Cargo & VTRUX Van & 17,148 & 2015 \\
G43-1404D & FordE250 & 2006 & Van - Pass & VTRUX Van & 38,067 & 2015 \\
G43-1394D & Chevrolet G2300 & 2006 & Van - Cargo & VTRUX Van & 48,710 & 2015 \\
G43-27624 & Chevrolet G2300 & 2004 & Van - Cargo & eNV200 & 34,837 & 2015 \\
G62-1480D & Ford F150 & 2006 & Pickup & VTRUX PU & 39,742 & 2015 \\
G41-74299 & Ford Ranger & 2004 & Pickup & Outlander & 32,933 & 2016 \\
G41-1805H & Dodge Dakota & 2009 & Pickup & VTRUX PU & 32,945 & 2016 \\
G42-0960D & Ford F150 & 2006 & Pickup & Rav4 EV & 12,144 & 2016 \\
G42-0886H & Ford F150 & 2006 & Pickup & Rav4 EV & 20,570 & 2016 \\
G42-0963D & Ford F150 & 2006 & Pickup & VTRUX PU & 33,600 & 2016 \\
G42-2361B & Chevrolet C1500 & 2006 & Pickup & Rav4 EV & 18,855 & 2016 \\
G42-2360B & Chevrolet C1500 & 2006 & Pickup & eNV200 & 27,269 & 2016 \\
G42-2362B & Chevrolet C1500 & 2006 & Pickup & eNV200 & 33,714 & 2016 \\
G43-1927H & Chevrolet CG3300 & 2009 & Van - Pass & VTRUX Van & 95,400 & 2016 \\
G43-1406D & Ford E250 & 2006 & Van - Pass & VTRUX Van & 20,029 & 2016 \\
G43-1403D & Ford E250 & 2006 & Van - Pass & VTRUX Van & 3,168 & 2016 \\
G43-1402D & Ford E250 & 2006 & Van - Pass & VTRUX Van & 30,061 & 2016 \\
\hline
\end{tabular}




\begin{tabular}{ccccccc}
\hline \multicolumn{1}{c}{ Near-Term Replacement Approach } \\
$\begin{array}{c}\text { Fleet } \\
\text { Vehicle Id }\end{array}$ & Make/Model & Year & EPA Class & $\begin{array}{c}\text { Potential } \\
\text { Replacement } \\
\text { Vehicle }\end{array}$ & $\begin{array}{c}\text { Estimated } \\
\text { Mileage }\end{array}$ & $\begin{array}{c}\text { Replacement } \\
\text { Year }\end{array}$ \\
\hline G43-1393D & Chevrolet G2300 & 2006 & Van - Cargo & VTRUX Van & 16,284 & 2016 \\
G43-1377D & Chevrolet G2300 & 2006 & Van - Cargo & eNV200 & 30,927 & 2016 \\
G43-1952H & Ford E350 & 2009 & Van - Pass & VTRUX Van & 22,510 & 2016 \\
G61-0958D & Ford Ranger & 2006 & Pickup & Rav4 EV & 22,473 & 2016 \\
G62-1479D & Ford F150 & 2006 & Pickup & Rav4 EV & 23,479 & 2016 \\
\hline
\end{tabular}




\section{Appendix G \\ Public Works Group Vehicle Analysis}

There are four replacement approaches identified for Public Works:

- Monitored vehicles

- $\quad$ GSA-listed PEVs only

- All potential PEV types

- Full fleet

- $\quad$ GSA-listed PEVs only for sedans

- All potential PEV types for non-sedan vehicles.

The extensive analysis conducted for monitored vehicles (Task 3) results in high confidence that the suggested vehicle can meet mission requirements. The suggested vehicles for the full fleet rely on the extrapolation of those monitored vehicles and the guidance identified in Section 3.

\section{G.1 Monitored Vehicle General Services Administration Replacement Approach}

The vehicles monitored include minivans, passenger vans, and pickup trucks for which no GSA-listed replacement is currently available.

\section{G.2 All Monitored Vehicle Replacement Approach}

Table G-1 provides a replacement approach using currently or soon-to-be available PEVs. Although not currently listed by GSA, these or similar vehicles may be listed by the year identified or JBLM may choose to justify the replacement.

Table G-1. Public Works all monitored vehicle replacement approach.

\begin{tabular}{|c|c|c|c|c|c|}
\hline \multicolumn{6}{|c|}{ All Monitored Vehicle Replacement Approach } \\
\hline $\begin{array}{c}\text { Fleet } \\
\text { Vehicle Id }\end{array}$ & Make/Model & Year & EPA Class & $\begin{array}{c}\text { Potential } \\
\text { Replacement Vehicle }\end{array}$ & $\begin{array}{c}\text { Replacement } \\
\text { Year }\end{array}$ \\
\hline G42-0505A & G1300 & 2004 & Passenger van & VTRUX Van & 2015 \\
\hline G42-1054F & F150 & 2008 & Pickup Truck & eNV200 & 2015 \\
\hline G43-0822G & F350 & 2008 & Pickup Truck & eNV200 & 2015 \\
\hline G43-1961H & $\mathrm{C} 3500$ & 2009 & Pickup Truck & eNV200 & 2016 \\
\hline G43-1892H & $\mathrm{C} 2500 \mathrm{HD}$ & 2009 & Pickup Truck & eNV200 & 2016 \\
\hline G42-0610K & $\mathrm{C} 1500$ & 2010 & Pickup Truck & Rav4 EV & 2017 \\
\hline G41-1100K & GR Caravan & 2010 & Minivan & Outlander & 2017 \\
\hline G42-0619K & $\mathrm{C} 1500$ & 2010 & Pickup Truck & Rav4 EV & 2017 \\
\hline G41-1180K & GR Caravan & 2010 & Minivan & Outlander & 2017 \\
\hline G42-0658K & F150 & 2010 & Pickup Truck & Rav4 EV & 2017 \\
\hline G43-0944G & G3500 & 2008 & Passenger van & VTRUX Van & 2018 \\
\hline G43-1155L & F350 & 2011 & Pickup Truck & Rav4 EV & 2018 \\
\hline G41-1605L & Dakota & 2011 & Pickup Truck & Rav4 EV & 2018 \\
\hline G71-0133L & E450 & 2011 & Passenger van & eNV200 & 2021 \\
\hline
\end{tabular}

\section{G.3 Sedan Fleet Replacement Approach}

GSA currently lists only sedans for PEVs. It is assumed that additional sedans will be added to the list in the next few years. Table G-2 provides the list of sedans in the Public Works fleet. The projected year of replacement is identified based on the GSA requirements and expected usage. The mileage is projected from the odometer reading in 2013 and annual mileage provided by JBLM. No sedans are projected to be 
replaced in the next few years. For illustration, the vehicles marked in green in this table reflect potential replacement vehicles that are included in Section 4.4.1.

Table G-2. Public Works sedan fleet replacement approach.

\begin{tabular}{ccccccc}
\hline \multicolumn{1}{c}{ Fleet } & \multicolumn{7}{c}{ Sedan Fleet Replacement Approach } \\
Vehicle Id & Make/Model & Year & EPA Class & $\begin{array}{c}\text { Potential } \\
\text { Replacement } \\
\text { PEV }\end{array}$ & $\begin{array}{c}\text { Estimated } \\
\text { Mileage }\end{array}$ & $\begin{array}{c}\text { Replacement } \\
\text { Year }\end{array}$ \\
\hline G11-2699G & Chevrolet Impala & 2008 & Sedan - Large & Leaf & 27,171 & 2018 \\
G10-7692F & Dodge Avenger & 2008 & Sedan - Compact & Leaf & 13,983 & 2018 \\
G10-7693F & Dodge Avenger & 2008 & Sedan - Compact & Leaf & 25,753 & 2018 \\
G13-1592H & Ford Focus & 2009 & Sedan - Compact & Focus & 24,863 & 2019 \\
G13-1593H & Ford Focus & 2009 & Sedan - Compact & Focus & 13,699 & 2019 \\
G10-6384L & Dodge Avenger & 2011 & Sedan - Compact & Focus & 31,736 & 2021 \\
\hline
\end{tabular}

\section{G.4 Near-Term Non-Sedan Vehicle Replacement Approach}

Another approach to the replacement strategy is to consider vehicles that may be replaced in the next 2 years. Table G-3 identifies the vehicles in the Public Works fleet that are projected to be replaced in 2015 and 2016. Heavy-duty trucks and specialty vehicles are not included in this list. The projected year of replacement is identified based on the GSA requirements and expected usage. The mileage is projected from the odometer reading in 2013 and annual mileage provided by JBLM. (Note that JBLM may have replaced several of these vehicles in 2014.) For illustration, the vehicles marked in orange were monitored; therefore, high confidence exists in the potential replacement. Those vehicles and the vehicles marked in green in this table reflect potential replacement vehicles that are included in Section 4.5.2.

Table G-3. Public Works near-term replacement approach.

\begin{tabular}{ccccccc}
\hline \multicolumn{7}{c}{ Near-Term Replacement Approach } \\
Fleet & \multicolumn{7}{c}{$\begin{array}{c}\text { Potential } \\
\text { Replacement }\end{array}$} & $\begin{array}{c}\text { Estimated } \\
\text { Vehicle Id }\end{array}$ & Make/Model & Year & EPA Class & PEV & Meplacement & Year \\
\hline G41-65969 & Chevrolet S10 & 2002 & Pickup & eNV200 & 21,182 & 2015 \\
G41-65886 & Chevrolet S10 & 2002 & Pickup & eNV200 & 30,322 & 2015 \\
G41-1373A & Chevrolet Colorado & 2004 & Pickup & eNV200 & 38,556 & 2015 \\
G41-1390A & Dodge Caravan & 2005 & Minivan & Outlander & 27,323 & 2015 \\
G41-54255 & Chevrolet S10 & 2001 & Pickup & eNV200 & 36,931 & 2015 \\
G41-71760 & Ford Ranger & 2003 & Pickup & eNV200 & 39,157 & 2015 \\
G42-42268 & Chevrolet G1500 & 2002 & Van - Cargo & eNV200 & 33,268 & 2015 \\
G42-3440A & Chevrolet G1300 & 2004 & Van - Cargo & eNV200 & 43,496 & 2015 \\
G42-1054F & Ford F150 & 2008 & Pickup & eNV200 & 34,940 & 2015 \\
G42-0540A & Chevrolet G1300 & 2004 & Van - Cargo & Rav4 EV & 52,435 & 2015 \\
G42-0506A & Chevrolet G1300 & 2004 & Van - Cargo & eNV200 & 65,738 & 2015 \\
G42-0505A & Chevrolet G1300 & 2004 & Van - Cargo & eNV200 & 38,222 & 2015 \\
G42-3472A & Chevrolet C1500 & 2005 & Pickup & eNV200 & 41,387 & 2015 \\
G42-3476A & Ford F150 & 2006 & Pickup & VTRUX PU & 96,998 & 2015 \\
G42-49108 & Chevrolet C1500 & 2003 & Pickup & eNV200 & 29,859 & 2015 \\
G42-49085 & Chevrolet C1500 & 2002 & Pickup & VTRUX PU & 56,207 & 2015 \\
G43-4932A & Ford E350 & 2004 & Van - Pass & VTRUX Van & 11,966 & 2015 \\
G43-3464B & Chev. C2500HD & 2006 & Pickup & VTRUX PU & 79,539 & 2015 \\
G43-3438B & Ford F350 & 2005 & Pickup & VTRUX PU & 56,247 & 2015 \\
\hline
\end{tabular}




\begin{tabular}{|c|c|c|c|c|c|c|}
\hline \multicolumn{7}{|c|}{ Near-Term Replacement Approach } \\
\hline $\begin{array}{c}\text { Fleet } \\
\text { Vehicle Id }\end{array}$ & Make/Model & Year & EPA Class & $\begin{array}{c}\text { Potential } \\
\text { Replacement } \\
\text { PEV }\end{array}$ & $\begin{array}{c}\text { Estimated } \\
\text { Mileage }\end{array}$ & $\begin{array}{c}\text { Replacement } \\
\text { Year }\end{array}$ \\
\hline G43-25849 & Ford E350 & 2003 & Van - Pass & VTRUX Van & 30,507 & 2015 \\
\hline G43-25835 & Chevrolet C3500 & 2003 & Pickup & eNV200 & 29,102 & 2015 \\
\hline G43-25821 & Ford E350 & 2003 & Van - Pass & VTRUX Van & 23,230 & 2015 \\
\hline G43-21439 & Chevrolet C2500 & 2003 & Pickup & VTRUX PU & 33,382 & 2015 \\
\hline G43-21392 & Ford E350 & 2002 & Van - Pass & VTRUX Van & 54,071 & 2015 \\
\hline G43-1774F & Ford E350 & 2005 & Van - Pass & VTRUX Van & 26,875 & 2015 \\
\hline G43-9862 & Dodge 3500 & 2001 & Pickup & eNV200 & 28,489 & 2015 \\
\hline G43-0958A & Ford F350 & 2004 & Pickup & VTRUX PU & 49,625 & 2015 \\
\hline G43-0824G & Ford F350 & 2008 & Pickup & VTRUX PU & 49,502 & 2015 \\
\hline G43-0822G & Ford F350 & 2008 & Pickup & Rav4 EV & 37,766 & 2015 \\
\hline G43-0821G & Ford F350 & 2008 & Pickup & eNV200 & 37,875 & 2015 \\
\hline G43-0814G & Ford F350 & 2008 & Pickup & eNV200 & 41,063 & 2015 \\
\hline G43-0811G & Ford F250 & 2008 & Pickup & VTRUX PU & 48,619 & 2015 \\
\hline G43-0942G & Chevrolet G3500 & 2008 & Van - Pass & VTRUX Van & 34,682 & 2015 \\
\hline G43-0946G & Chevrolet G3500 & 2008 & Van - Pass & VTRUX Van & 32,652 & 2015 \\
\hline G43-0943G & Chevrolet G3500 & 2008 & Van - Pass & VTRUX Van & 37,168 & 2015 \\
\hline G43-0963A & Ford F250 & 2004 & Pickup & eNV200 & 83,842 & 2015 \\
\hline G43-25846 & Ford F350 & 2003 & Pickup & eNV200 & 36,997 & 2015 \\
\hline G43-27635 & E350 CUTAW & 2004 & Van - Cargo & eNV200 & 54,122 & 2015 \\
\hline G43-3431B & Dodge 2500 & 2005 & Pickup & eNV200 & 23,108 & 2015 \\
\hline G43-3429B & RAM 2500 & 2005 & Pickup & VTRUX PU & 47,321 & 2015 \\
\hline G43-3419B & Chevrolet C3500 & 2005 & Pickup & eNV200 & 57,858 & 2015 \\
\hline G43-3440B & Dodge 2500 & 2005 & Pickup & eNV200 & 46,072 & 2015 \\
\hline G43-3448B & Ford E350 & 2003 & Van - Pass & VTRUX Van & 25,502 & 2015 \\
\hline G43-3462B & Dodge Sprinter & 2006 & Van - Cargo & VTRUX Van & 36,066 & 2015 \\
\hline G61-14332 & Chevrolet S10 & 2003 & Pickup & VTRUX PU & 33,010 & 2015 \\
\hline G61-14331 & Chevrolet S10 & 2003 & Pickup & eNV200 & 29,473 & 2015 \\
\hline G61-0715A & Chevrolet Blazer & 2004 & SUV & Outlander & 48,757 & 2015 \\
\hline G61-0702A & Ford Ranger & 2004 & Pickup & VTRUX PU & 39,872 & 2015 \\
\hline G61-0286G & Ford Escape HYB & 2008 & SUV & Rav4 EV & 35,129 & 2015 \\
\hline G62-3694B & Chevrolet Tahoe & 2005 & SUV & Outlander & 67,732 & 2015 \\
\hline G62-3689B & Chevrolet Tahoe & 2005 & SUV & Outlander & 55,497 & 2015 \\
\hline G62-18256 & Chevrolet K2500 & 2003 & Pickup & eNV200 & 41,158 & 2015 \\
\hline G62-1472D & Ford F150 & 2006 & Pickup & eNV200 & 25,679 & 2015 \\
\hline $\begin{array}{l}\text { G62- } \\
1375 \mathrm{M}\end{array}$ & Dodge Ram 1500 & 2007 & Pickup & eNV200 & 73,434 & 2015 \\
\hline G62-0727A & Chevrolet K1500 & 2004 & Pickup & eNV200 & 49,511 & 2015 \\
\hline G62-0726A & Chevrolet K1500 & 2004 & Pickup & VTRUX PU & 59,968 & 2015 \\
\hline G62-0725A & Chevrolet K1500 & 2004 & Pickup & eNV200 & 59,972 & 2015 \\
\hline G63-12057 & Chevrolet K2500 & 2002 & Pickup & VTRUX PU & 53,946 & 2015 \\
\hline G63-7560 & Dodge 3500 & 2001 & Pickup & VTRUX PU & 49,946 & 2015 \\
\hline G63-0684L & Ford F250 & 2008 & Pickup & VTRUX PU & 43,087 & 2015 \\
\hline G63-2737B & Chevrolet K3500 & 2005 & Pickup & eNV200 & 43,087 & 2015 \\
\hline
\end{tabular}




\begin{tabular}{ccccccc}
\hline \multicolumn{7}{c}{ Near-Term Replacement Approach } \\
Fleet & \multicolumn{7}{c}{$\begin{array}{c}\text { Potential } \\
\text { Replacement }\end{array}$} & Estimated & Replacement \\
Vehicle Id & Make/Model & Year & EPA Class & PEV & Mileage & Year \\
\hline G63-2751B & Chevrolet K3500 & 2005 & Pickup & eNV200 & 39,407 & 2015 \\
G63-2738B & Chevrolet K3500 & 2005 & Pickup & eNV200 & 39,653 & 2015 \\
G63-0616A & Chevrolet K3500 & 2004 & Pickup & eNV200 & 37,171 & 2015 \\
G63-0606A & Ford F350 & 2004 & Pickup & VTRUX PU & 35,199 & 2015 \\
G63-0605A & Ford F350 & 2004 & Pickup & eNV200 & 61,177 & 2015 \\
G71-0120A & Ford F550 & 2004 & Pickup & eNV200 & 56,202 & 2015 \\
G71-0128A & Ford F550 & 2004 & Pickup & VTRUX PU & 41,730 & 2015 \\
G71-3294 & Ford F450 & 2003 & Pickup & eNV200 & 125,364 & 2015 \\
G71-3290 & Ford F450 & 2003 & Pickup & eNV200 & 38,473 & 2015 \\
G42-0883H & Ford F150 & 2009 & Pickup & Outlander & 25,779 & 2015 \\
G43-3447B & Ford E350 & 2006 & Pickup & VTRUX Van & 31,157 & 2016 \\
G43-25896 & Ford E350 & 2004 & Van - Pass & VTRUX Van & 23,787 & 2016 \\
G43-25893 & Ford E350 & 2004 & Van - Pass & VTRUX Van & 37,639 & 2016 \\
G43-25891 & Ford E350 & 2004 & Van - Pass & VTRUX Van & 29,130 & 2016 \\
G43-1961H & Chevrolet C3500 & 2009 & Pickup & eNV200 & 30,409 & 2016 \\
G43-1892H & Chevrolet C2500HD & 2009 & Pickup & eNV200 & 22,378 & 2016 \\
G43-0904K & Ford F350 & 2008 & Pickup & eNV200 & 35,537 & 2016 \\
G43-0825G & Ford F350 & 2008 & Pickup & Outlander & 32,346 & 2016 \\
G43-0812G & Ford F250 & 2008 & Pickup & eNV200 & 40,313 & 2016 \\
G43-0807G & Ford F250 & 2008 & Pickup & Outlander & 35,053 & 2016 \\
G62-1076G & Chevrolet K1500 & 2008 & Pickup & Outlander & 38,749 & 2016 \\
G62-0208H & Chevrolet K1500 & 2009 & Pickup & Outlander & 32,148 & 2016 \\
\hline
\end{tabular}




\section{Appendix $\mathrm{H}$ Motor Transport Branch Vehicle Analysis}

There are four replacement approaches identified for the Motor Transport Branch:

- Monitored vehicles

- GSA-listed PEVs only

- All potential PEV types

- $\quad$ Full fleet

- $\quad$ GSA-listed PEVs only for sedans

- All potential PEV types for non-sedan vehicles.

The extensive analysis conducted for monitored vehicles (Task 3) results in high confidence that the suggested vehicle can meet mission requirements. The suggested vehicles for the full fleet rely on the extrapolation of those monitored vehicles and the guidance identified in Section 3.

\section{H.1 Monitored Vehicle General Services Administration Replacement Approach}

The vehicles monitored include several vehicle types for which no GSA-listed replacement is currently available. The sedans monitored are shown in Table H-1, along with potential replacement PEVs and year of potential replacement.

Table H-1. Motor Transport Branch GSA vehicle replacement approach.

\begin{tabular}{cccccc}
\hline $\begin{array}{c}\text { Fleet } \\
\text { Vehicle Id }\end{array}$ & Make/Model & Year & EPA Class & $\begin{array}{c}\text { Potential } \\
\text { Replacement PEV }\end{array}$ & $\begin{array}{c}\text { Replacement } \\
\text { Year }\end{array}$ \\
\hline G11-2676G & Chevrolet Impala & 2008 & Large Car & Leaf & 2015 \\
G12-0662H & Ford Fusion HEV & 2010 & Midsize Sedan & Fusion & 2015 \\
G10-6379L & Dodge Avenger & 2011 & Midsize Sedan & Leaf & 2017 \\
G11-0493L & Chevrolet Impala & 2012 & Large Car & Fusion & 2017 \\
G10-2878L & Chevrolet Malibu & 2011 & Midsize Sedan & Leaf & 2018 \\
G11-2675G & Chevrolet Impala & 2008 & Large Sedan & Leaf & 2018 \\
G11-0678K & Chevrolet Impala & 2010 & Large Car & Leaf & 2018 \\
G10-7664F & Dodge Avenger & 2008 & Compact Sedan & Volt & 2018 \\
\hline
\end{tabular}

Note that the GSA schedule does not currently list the Leaf, although it did in previous years. It is expected that it will be listed again by 2015 .

\section{H.2 Monitored Non-Sedan Vehicle All Replacement Approach}

Table H-2 provides a replacement approach for the non-sedan-type monitored vehicles using currently or soon-to-be available PEVs. Although not currently listed by GSA, these or similar vehicles may be listed by the year identified or JBLM may choose to justify the replacement.

Table H-2. Motor Transport Branch non-sedan monitored vehicle replacement approach.

\begin{tabular}{cccccc} 
Fleet & \multicolumn{4}{c}{ Monitored Vehicle All Replacement Approach } \\
Vehicle Id & Model & Year & EPA Class & $\begin{array}{c}\text { Potential } \\
\text { Replacement PEV }\end{array}$ & $\begin{array}{c}\text { Replacement } \\
\text { Year }\end{array}$ \\
\hline G41-65991 & Dodge Dakota & 2002 & Pickup Truck & VTRUX PU & 2015 \\
G43-25839 & Ford F350 & 2003 & Pickup Truck & eNV200 & 2015 \\
G41-1288A & Sport Trac & 2004 & Pickup Truck & Rav4 EV & 2015 \\
G43-3717A & Ford E350 & 2004 & Cargo Van & VTRUX Van & 2015 \\
\hline
\end{tabular}




\begin{tabular}{|c|c|c|c|c|c|}
\hline \multicolumn{6}{|c|}{ Monitored Vehicle All Replacement Approach } \\
\hline $\begin{array}{c}\text { Fleet } \\
\text { Vehicle Id }\end{array}$ & Model & Year & EPA Class & $\begin{array}{c}\text { Potential } \\
\text { Replacement PEV }\end{array}$ & $\begin{array}{c}\text { Replacement } \\
\text { Year }\end{array}$ \\
\hline G43-4937A & Ford E350 & 2004 & Cargo Van & VTRUX Van & 2015 \\
\hline G63-0271A & Ford F350Stake & 2004 & Stake Truck & NA & 2015 \\
\hline G71-0674A & Ford F650 18'BO & 2004 & Delivery Van & VTRUX Van & 2015 \\
\hline G42-3471A & Chevrolet G2300 & 2005 & Cargo Van & eNV200 & 2015 \\
\hline G61-1155D & Ford Escape HYB & 2006 & SUV & Rav4 EV & 2015 \\
\hline G42-0988F & Chev. Express 13 & 2007 & Cargo Van & VTRUX Van & 2015 \\
\hline G41-1161G & Chevrolet Uplander & 2008 & Minivan & Rav4 EV & 2015 \\
\hline G41-1180G & Chevrolet Uplander & 2008 & Minivan & Rav4 EV & 2015 \\
\hline G41-1367G & Dodge Dakota & 2008 & Pickup Truck & Rav4 EV & 2015 \\
\hline G41-1373G & Dodge Dakota & 2008 & Pickup Truck & Rav4 EV & 2015 \\
\hline G41-1376G & Dodge Dakota & 2008 & Pickup Truck & Rav4 EV & 2015 \\
\hline G41-1392G & Chevrolet Uplander & 2008 & Minivan & Outlander & 2015 \\
\hline G41-1395G & Chevrolet Uplander & 2008 & Minivan & Rav4 EV & 2015 \\
\hline G43-0860G & Chevrolet CG3300 & 2008 & Passenger Van & VTRUX Van & 2015 \\
\hline G62-0979G & Dodge 1500 & 2008 & Pickup Truck & VTRUX PU & 2015 \\
\hline G82-0509A & Ford F650 Stake & 2004 & Stake Truck & NA & 2016 \\
\hline G43-3881H & Ford E350 & 2009 & Passenger Van & VTRUX Van & 2016 \\
\hline G62-4526H & Chevrolet Tahoe & 2009 & SUV & Outlander & 2016 \\
\hline G41-1100K & Dodge GR Caravan & 2010 & Minivan & Outlander & 2017 \\
\hline G43-0790K & Chevrolet CG3300 & 2010 & Passenger Van & VTRUX Van & 2017 \\
\hline G43-0792K & Chevrolet CG3300 & 2010 & Passenger Van & VTRUX Van & 2017 \\
\hline G43-0801K & Chevrolet CG3300 & 2010 & Passenger Van & VTRUX Van & 2017 \\
\hline G43-0875K & Ford E350 & 2010 & Cargo Van & VTRUX Van & 2017 \\
\hline G43-1389K & Chevrolet CG3300 & 2010 & Passenger Van & VTRUX Van & 2017 \\
\hline G71-0062G & Ford F750 & 2008 & Stake Truck & NA & 2018 \\
\hline G42-0698K & Chevrolet C1500 & 2011 & Pickup Truck & VTRUX PU & 2018 \\
\hline G43-1191L & Chevrolet CG3300 & 2011 & Passenger Van & VTRUX Van & 2018 \\
\hline G62-1094L & Chev. Avalanche & 2011 & SUV & Rav4 EV & 2018 \\
\hline
\end{tabular}

\section{H.3 Sedan Fleet Replacement Approach}

GSA currently lists only sedans for PEVs. It is assumed that additional sedans will be added to the list in the next few years. Table H-3 provides the list of sedans in the Motor Transport fleet. The projected year of replacement is identified based on the GSA requirements and expected usage. The mileage is projected from the odometer reading in 2013 and annual mileage provided by JBLM.

Because of the large number of sedans in the Motor Transport Branch fleet (122), only those whose replacement is projected in 2015 and 2016 are identified in the table. For illustration, the vehicles marked in orange were monitored; therefore, high confidence exists in the potential replacement. These vehicles and the vehicles marked in green in this table reflect potential replacement vehicles that are included in Section 4.5.1.

Table H-3. Motor Transport Branch sedan fleet replacement approach.

\begin{tabular}{ccccccc}
\hline Fleet & \multicolumn{3}{c}{ Sedan Fleet Replacement Approach } \\
Vehicle Id & Make/Model & Year & EPA Class & Replacement PEV & $\begin{array}{c}\text { Estimated } \\
\text { Mileage }\end{array}$ & $\begin{array}{c}\text { Replacement } \\
\text { Year }\end{array}$ \\
\hline G10-5386H & Pontiac G6 & 2009 & Sedan - Compact & Focus & 58,385 & 2015 \\
\hline
\end{tabular}




\begin{tabular}{|c|c|c|c|c|c|c|}
\hline \multicolumn{7}{|c|}{ Sedan Fleet Replacement Approach } \\
\hline $\begin{array}{c}\text { Fleet } \\
\text { Vehicle Id }\end{array}$ & Make/Model & Year & EPA Class & $\begin{array}{c}\text { Potential } \\
\text { Replacement PEV }\end{array}$ & $\begin{array}{l}\text { Estimated } \\
\text { Mileage }\end{array}$ & $\begin{array}{c}\text { Replacement } \\
\text { Year }\end{array}$ \\
\hline G12-0371L & Pontiac G6 & 2009 & Sedan - Compact & Volt & 56,293 & 2015 \\
\hline G13-0180A & Ford Focus & 2008 & Sedan - Compact & Focus & 43,174 & 2015 \\
\hline G10-3046K & Ford Fusion HEV & 2010 & Sedan - Midsize & Fusion & 46,519 & 2015 \\
\hline G10-3048K & Ford Fusion HEV & 2010 & Sedan - Midsize & Fusion & 48,489 & 2015 \\
\hline G12-0622H & Ford Fusion HEV & 2010 & Sedan - Midsize & Fusion & 62,327 & 2015 \\
\hline G12-0623H & Ford Fusion HEV & 2010 & Sedan - Midsize & Fusion & 61,312 & 2015 \\
\hline G12-0625H & Ford Fusion HEV & 2010 & Sedan - Midsize & Fusion & 42,231 & 2015 \\
\hline G12-0627H & Ford Fusion HEV & 2010 & Sedan - Midsize & Fusion & 40,268 & 2015 \\
\hline G12-0632H & Ford Fusion HEV & 2010 & Sedan - Midsize & Fusion & 62,985 & 2015 \\
\hline G12-0633H & Ford Fusion HEV & 2010 & Sedan - Midsize & Fusion & 64,221 & 2015 \\
\hline G12-0634H & Ford Fusion HEV & 2010 & Sedan - Midsize & Fusion & 73,208 & 2015 \\
\hline G12-0648H & Ford Fusion HEV & 2010 & Sedan - Midsize & Fusion & 54,366 & 2015 \\
\hline G12-0650H & Ford Fusion HEV & 2010 & Sedan - Midsize & Fusion & 52,078 & 2015 \\
\hline G11-0498L & Chevrolet Impala & 2012 & Sedan - Large & Fusion & 84,574 & 2015 \\
\hline G11-0499L & Chevrolet Impala & 2012 & Sedan - Large & Fusion & 67,368 & 2015 \\
\hline G11-0500L & Chevrolet Impala & 2012 & Sedan - Large & Fusion & 106,276 & 2015 \\
\hline G11-0673K & Chevrolet Impala & 2010 & Sedan - Large & Leaf & 37,394 & 2015 \\
\hline G11-0675K & Chevrolet Impala & 2010 & Sedan - Large & Fusion & 83,377 & 2015 \\
\hline G11-0676K & Chevrolet Impala & 2010 & Sedan - Large & Fusion & 108,700 & 2015 \\
\hline G11-0677K & Chevrolet Impala & 2010 & Sedan - Large & Leaf & 37,357 & 2015 \\
\hline G11-0679K & Chevrolet Impala & 2010 & Sedan - Large & Fusion & 43,496 & 2015 \\
\hline G11-0680K & Chevrolet Impala & 2010 & Sedan - Large & Leaf & 38,653 & 2015 \\
\hline G11-0681K & Chevrolet Impala & 2010 & Sedan - Large & Fusion & 87,368 & 2015 \\
\hline G11-0689K & Dodge Charger & 2010 & Sedan - Large & Fusion & 113,004 & 2015 \\
\hline G11-0690K & Dodge Charger & 2010 & Sedan - Large & Fusion & 101,041 & 2015 \\
\hline G11-0691K & Dodge Charger & 2010 & Sedan - Large & Fusion & 109,055 & 2015 \\
\hline G11-0692K & Dodge Charger & 2010 & Sedan - Large & Fusion & 124,104 & 2015 \\
\hline G11-1290H & Chevrolet Impala & 2009 & Sedan - Large & Fusion & 46,318 & 2015 \\
\hline G11-1292H & Chevrolet Impala & 2010 & Sedan - Large & Leaf & 36,589 & 2015 \\
\hline G11-2665G & Chevrolet Impala & 2008 & Sedan - Large & Fusion & 44,157 & 2015 \\
\hline G11-2666G & Chevrolet Impala & 2008 & Sedan - Large & Leaf & 38,352 & 2015 \\
\hline G11-2669G & Chevrolet Impala & 2008 & Sedan - Large & Leaf & 36,185 & 2015 \\
\hline G11-2674G & Chevrolet Impala & 2008 & Sedan - Large & Fusion & 51,376 & 2015 \\
\hline G11-2676G & Chevrolet Impala & 2008 & Sedan - Large & Fusion & 52,163 & 2015 \\
\hline G11-2677G & Chevrolet Impala & 2008 & Sedan - Large & Fusion & 40,467 & 2015 \\
\hline G11-2678G & Chevrolet Impala & 2008 & Sedan - Large & Fusion & 50,390 & 2015 \\
\hline G11-2684G & Chevrolet Impala & 2008 & Sedan - Large & Leaf & 36,748 & 2015 \\
\hline G11-2685G & Chevrolet Impala & 2008 & Sedan - Large & Fusion & 55,842 & 2015 \\
\hline G11-2692G & Chevrolet Impala & 2008 & Sedan - Large & Fusion & 54,718 & 2015 \\
\hline G11-2711G & Chevrolet Impala & 2008 & Sedan - Large & Fusion & 61,389 & 2015 \\
\hline G11-2748G & Chevrolet Impala & 2008 & Sedan - Large & Fusion & 99,461 & 2015 \\
\hline G11-2751G & Chevrolet Impala & 2008 & Sedan - Large & Fusion & 87,723 & 2015 \\
\hline G11-3665F & Chevrolet Impala & 2007 & Sedan - Large & Fusion & 43,262 & 2015 \\
\hline G11-8395F & Chevrolet Impala & 2008 & Sedan - Large & Leaf & 35,524 & 2015 \\
\hline
\end{tabular}




\begin{tabular}{ccccccc}
\hline $\begin{array}{c}\text { Fleet } \\
\text { Vehicle Id }\end{array}$ & Make/Model & Year & EPA Class & $\begin{array}{c}\text { Potential } \\
\text { Replacement PEV }\end{array}$ & $\begin{array}{c}\text { Estimated } \\
\text { Mileage }\end{array}$ & $\begin{array}{c}\text { Replacement } \\
\text { Year }\end{array}$ \\
\hline G10-7531F & Pontiac G6 & 2008 & Sedan - Compact & Volt & 45,555 & 2016 \\
G10-7539F & Pontiac G6 & 2008 & Sedan - Compact & Volt & 31,238 & 2016 \\
G13-0181A & Ford Focus & 2008 & Sedan - Compact & Focus & 43,800 & 2016 \\
G10-0417F & Saturn Aura Hyb & 2007 & Sedan - Midsize & Leaf & 31,463 & 2016 \\
G10-3047K & Ford Fusion HEV & 2010 & Sedan - Midsize & Fusion & 43,334 & 2016 \\
G12-0636H & Ford Fusion HEV & 2010 & Sedan - Midsize & Fusion & 39,380 & 2016 \\
G12-0637H & Ford Fusion HEV & 2010 & Sedan - Midsize & Fusion & 41,510 & 2016 \\
G11-0473L & Chevrolet Impala & 2011 & Sedan - Large & Fusion & 80,052 & 2016 \\
G11-1412L & Chevrolet Impala & 2008 & Sedan - Large & Leaf & 39,935 & 2016 \\
G11-2659G & Chevrolet Impala & 2008 & Sedan - Large & Leaf & 38,736 & 2016 \\
G11-2680G & Chevrolet Impala & 2008 & Sedan - Large & Leaf & 37,029 & 2016 \\
G11-2688G & Chevrolet Impala & 2008 & Sedan - Large & Leaf & 37,686 & 2016 \\
G11-2697G & Chevrolet Impala & 2008 & Sedan - Large & Leaf & 36,803 & 2016 \\
G11-3666F & Chevrolet Impala & 2007 & Sedan - Large & Leaf & 35,362 & 2016 \\
\hline
\end{tabular}

\section{H.4 Near-Term Non-Sedan Vehicle Replacement Approach}

Another approach to the replacement strategy is to consider vehicles that may be replaced in the next 2 years. Motor Transport Branch had 1,060 vehicles at the time of the analysis, with 927 remaining after subtracting the heavy-duty vehicles, specialty vehicles, low-speed vehicles, and buses. Of those 927 vehicles, 637 vehicles are projected to be replaced in 2015 and 2016.

There are 120 vehicles with a projected odometer reading over 70,000 miles at replacement. The 82 vehicles with mileage over 80,000 miles are identified in Table H-4, along with the vehicles monitored and certain other vehicles eligible for replacement. As before, many of these vehicles may have been replaced in 2014. For illustration, the vehicles marked in orange were monitored; therefore, high confidence exists in the potential replacement. These vehicles and the vehicles marked in green in this table reflect potential replacement vehicles that are included in Section 4.5.2.

Table H-4. Motor Transport Branch near-term non-sedan replacement approach.

\begin{tabular}{ccccccc} 
Fleet & \multicolumn{3}{c}{ Near-Term Fleet Replacement Approach } \\
Vehicle Id & Make/Model & Year & EPA Class & $\begin{array}{c}\text { Potential } \\
\text { Replacement PEV }\end{array}$ & $\begin{array}{c}\text { Estimated } \\
\text { Mileage }\end{array}$ & $\begin{array}{c}\text { Replacement } \\
\text { Year }\end{array}$ \\
\hline G61-1155D & Ford Escape HYB & 2006 & SUV & Rav4 EV & & 2015 \\
G41-1161G & Chevrolet Uplander & 2008 & Minivan & Rav4 EV & & 2015 \\
G41-1180G & Chevrolet Uplander & 2008 & Minivan & Rav4 EV & & 2015 \\
G41-1392G & Chevrolet Uplander & 2008 & Minivan & Outlander & 2015 \\
G43-3717A & Ford E350 & 2004 & Cargo Van & VTRUX Van & & 2015 \\
G43-4937A & Ford E350 & 2004 & Cargo Van & VTRUX Van & & 2015 \\
G43-0860G & Chevrolet CG3300 & 2008 & Passenger Van & VTRUX Van & & 2015 \\
G41-65991 & Dodge Dakota & 2002 & Pickup Truck & VTRUX PU & & 2015 \\
G62-0979G & Dodge 1500 & 2008 & Pickup Truck & VTRUX PU & & 2015 \\
G41-1376G & Dodge Dakota & 2008 & Pickup Truck & Rav4 EV & 2015 \\
G31-1390 & Ford E450 & 2002 & Van - Cargo & VTRUX Van & 97,055 & 2015 \\
G32-0108F & Chevrolet Senator & 2008 & Van - Pass & VTRUX Van & 119,703 & 2015 \\
G32-0215F & Chevrolet Senator & 2008 & Van - Pass & VTRUX Van & 111,956 & 2015 \\
G32-0217F & Chevrolet Senator & 2008 & Van - Pass & VTRUX Van & 110,567 & 2015 \\
\hline
\end{tabular}




\begin{tabular}{|c|c|c|c|c|c|c|}
\hline \multicolumn{7}{|c|}{ Near-Term Fleet Replacement Approach } \\
\hline $\begin{array}{c}\text { Fleet } \\
\text { Vehicle Id }\end{array}$ & Make/Model & Year & EPA Class & $\begin{array}{c}\text { Potential } \\
\text { Replacement PEV }\end{array}$ & $\begin{array}{l}\text { Estimated } \\
\text { Mileage }\end{array}$ & $\begin{array}{c}\text { Replacement } \\
\text { Year }\end{array}$ \\
\hline G32-0104F & Supreme SII & 2008 & Van - Pass & VTRUX Van & 85,842 & 2015 \\
\hline G41-68897 & Dodge Caravan & 2005 & Minivan & Outlander & 103,079 & 2015 \\
\hline G41-1379A & Dodge GR Caravan & 2005 & Minivan & Outlander & 101,838 & 2015 \\
\hline G41-1620D & Dodge GR Caravan & 2006 & Minivan & Rav4EV & 94,324 & 2015 \\
\hline G41-5435B & Dodge GR Caravan & 2006 & Minivan & Rav4EV & 90,674 & 2015 \\
\hline G41-71778 & Dodge Caravan SE & 2005 & Minivan & Rav4EV & 89,698 & 2015 \\
\hline G41-1369G & Dodge Dakota & 2008 & Pickup & Outlander & 84,651 & 2015 \\
\hline G41-1642D & Ford Ranger & 2006 & Pickup & Rav4EV & 82,467 & 2015 \\
\hline G41-2146F & Chevrolet Uplander & 2007 & Minivan & Rav4EV & 82,069 & 2015 \\
\hline G42-0536A & Ford E150 & 2004 & Van - Pass & VTRUX Van & 94,728 & 2015 \\
\hline G42-3452A & Chevrolet G1300 & 2004 & Van - Cargo & VTRUX Van & 84,474 & 2015 \\
\hline G42-2834H & Ford F150 & 2008 & Pickup & VTRUX PU & 82,789 & 2015 \\
\hline G43-1366D & Chevrolet G2300 & 2006 & Van - Cargo & VTRUX Van & 119,159 & 2015 \\
\hline G43-0904G & Chevrolet CG3300 & 2008 & Van - Pass & VTRUX Van & 101,774 & 2015 \\
\hline G43-2605L & Chevrolet CG3300 & 2005 & Van - Pass & VTRUX Van & 101,664 & 2015 \\
\hline G43-4945A & Chevrolet G2300 & 2005 & Van - Cargo & eNV200 & 97,928 & 2015 \\
\hline G43-0960A & Chevrolet CG3300 & 2004 & Van - Pass & VTRUX Van & 97,607 & 2015 \\
\hline G43-1385D & Chevrolet G2300 & 2006 & Van - Cargo & eNV200 & 97,447 & 2015 \\
\hline G43-0905G & Chevrolet CG3300 & 2008 & Van - Pass & VTRUX Van & 96,349 & 2015 \\
\hline G43-1367D & Chevrolet G2300 & 2006 & Van - Cargo & eNV200 & 92,293 & 2015 \\
\hline G43-4960A & Ford E350 & 2005 & Van - Pass & VTRUX Van & 92,124 & 2015 \\
\hline G43-1380D & Chevrolet G2300 & 2006 & Van - Cargo & eNV200 & 88,024 & 2015 \\
\hline G43-1381D & Chevrolet G2300 & 2006 & Van - Cargo & eNV200 & 86,670 & 2015 \\
\hline G43-4944A & Chevrolet G2300 & 2005 & Van - Cargo & eNV200 & 86,607 & 2015 \\
\hline G43-0956A & Chevrolet C3500 & 2004 & Pickup & VTRUX PU & 86,463 & 2015 \\
\hline G43-4956A & Ford E350 & 2005 & Van - Pass & VTRUX Van & 85,910 & 2015 \\
\hline G43-1365D & Chevrolet G2300 & 2006 & Van - Cargo & eNV200 & 85,843 & 2015 \\
\hline G43-1358D & Ford E350 & 2006 & Van - Pass & VTRUX Van & 84,492 & 2015 \\
\hline G43-1359D & Ford E350 & 2006 & Van - Pass & VTRUX Van & 84,420 & 2015 \\
\hline G43-0859G & Chevrolet CG3300 & 2008 & Van - Pass & VTRUX Van & 83,134 & 2015 \\
\hline G43-0876G & Chevrolet CG3300 & 2008 & Van - Pass & VTRUX Van & 82,854 & 2015 \\
\hline G43-0853G & Chevrolet CG3300 & 2008 & Van - Pass & VTRUX Van & 81,629 & 2015 \\
\hline G43-0863G & Chevrolet CG3300 & 2008 & Van - Pass & VTRUX Van & 80,451 & 2015 \\
\hline G62-0976G & Dodge 1500 & 2008 & Pickup & VTRUX PU & 168,153 & 2015 \\
\hline G62-1071G & Chevrolet K1500 & 2008 & Pickup & VTRUX PU & 150,535 & 2015 \\
\hline G62-0977G & Dodge 1500 & 2008 & Pickup & VTRUX PU & 145,643 & 2015 \\
\hline G62-1062G & Chevrolet Tahoe & 2008 & SUV & Outlander & 143,726 & 2015 \\
\hline G62-0683A & Ford Expedition & 2004 & SUV & Outlander & 132,471 & 2015 \\
\hline G62-1052L & Chevrolet K1500 & 2005 & Pickup & VTRUX PU & 126,116 & 2015 \\
\hline G62-0694A & Ford Explorer & 2004 & SUV & Outlander & 109,891 & 2015 \\
\hline G62-1432D & Chev. Trailblazer & 2006 & SUV & Outlander & 106,496 & 2015 \\
\hline G62-1063G & Chevrolet Tahoe & 2008 & SUV & Outlander & 106,020 & 2015 \\
\hline G62-1068G & Chevrolet K1500 & 2008 & Pickup & VTRUX PU & 102,970 & 2015 \\
\hline G62-3741B & Dodge Durango & 2006 & SUV & Rav4EV & 81,789 & 2015 \\
\hline
\end{tabular}


Near-Term Fleet Replacement Approach

\begin{tabular}{|c|c|c|c|c|c|c|}
\hline \multicolumn{7}{|c|}{ Near-Term Fleet Replacement Approach } \\
\hline $\begin{array}{c}\text { Fleet } \\
\text { Vehicle Id }\end{array}$ & Make/Model & Year & EPA Class & $\begin{array}{c}\text { Potential } \\
\text { Replacement PEV }\end{array}$ & $\begin{array}{c}\text { Estimated } \\
\text { Mileage }\end{array}$ & $\begin{array}{c}\text { Replacement } \\
\text { Year }\end{array}$ \\
\hline G62-4630D & Dodge Durango & 2007 & SUV & Rav4EV & 80,989 & 2015 \\
\hline G63-0621D & Ford F350 & 2006 & Pickup & VTRUX PU & 107,461 & 2015 \\
\hline G63-9491 & Chevrolet K3500 & 2002 & Pickup & VTRUX PU & 94,044 & 2015 \\
\hline G63-2057A & Ford F350 CREWC & 2004 & Pickup & VTRUX PU & 88,257 & 2015 \\
\hline G71-2739 & Ford F450 & 2002 & Pickup & Rav4EV & 88,181 & 2015 \\
\hline G71-3295 & Ford F550 & 2003 & Pickup & Rav4EV & 87,534 & 2015 \\
\hline G71-0115A & Ford F650 18'BO & 2004 & Van - Cargo & eNV200 & 80,748 & 2015 \\
\hline G62-4526H & Chevrolet Tahoe & 2009 & SUV & Outlander & & 2016 \\
\hline G41-5863H & Chevrolet HHR & 2009 & SUV & Rav4EV & 13,188 & 2016 \\
\hline G62-4517H & Chev. Avalanche & 2009 & SUV & Rav4EV & 19,652 & 2016 \\
\hline G62-0277H & Chev. Trailblazer & 2009 & SUV & Rav4EV & 21,475 & 2016 \\
\hline G41-5864H & Chevrolet HHR & 2009 & SUV & Rav4EV & 25,876 & 2016 \\
\hline G41-1773H & Dodge GR Caravan & 2009 & Minivan & Outlander & 33,652 & 2016 \\
\hline G41-5843H & Dodge GR Caravan & 2009 & Minivan & Rav4EV & 39,195 & 2016 \\
\hline G41-5857H & Dodge GR Caravan & 2009 & Minivan & Rav4EV & 42,807 & 2016 \\
\hline G41-5841H & Dodge GR Caravan & 2009 & Minivan & Rav4EV & 47,894 & 2016 \\
\hline G41-5844H & Dodge GR Caravan & 2009 & Minivan & Outlander & 52,131 & 2016 \\
\hline G41-1772H & Dodge GR Caravan & 2009 & Minivan & Outlander & 53,640 & 2016 \\
\hline G41-1776H & Ford Ranger & 2009 & Pickup & VTRUX PU & 91,982 & 2016 \\
\hline G42-0900H & Chevrolet G1300 & 2009 & Van - Cargo & VTRUX Van & 100,068 & 2016 \\
\hline G42-0906H & Chevrolet G1300 & 2009 & Van - Cargo & VTRUX Van & 94,020 & 2016 \\
\hline G43-3881H & Ford E350 & 2009 & Van - Pass & VTRUX Van & 49,085 & 2016 \\
\hline G43-1934H & Chevrolet CG3300 & 2009 & Van - Pass & VTRUX Van & 121,591 & 2016 \\
\hline G43-3880H & Ford E350 & 2009 & Van - Pass & VTRUX Van & 119,178 & 2016 \\
\hline G43-3891H & Ford E350 & 2009 & Van - Pass & VTRUX Van & 110,431 & 2016 \\
\hline G43-1887H & Chevrolet CG3300 & 2009 & Van - Pass & VTRUX Van & 103,472 & 2016 \\
\hline G43-3884H & Ford E350 & 2009 & Van - Pass & VTRUX Van & 91,956 & 2016 \\
\hline G43-1962H & Ford F350 & 2009 & Pickup & Rav4EV & 82,004 & 2016 \\
\hline G43-3890H & Ford E350 & 2009 & Van - Pass & VTRUX Van & 80,296 & 2016 \\
\hline G62-4527H & Chevrolet Tahoe & 2009 & SUV & Outlander & 220,642 & 2016 \\
\hline G62-0200H & Chevrolet K1500 & 2009 & Pickup & VTRUX PU & 117,369 & 2016 \\
\hline G62-4136G & Chev. Avalanche & 2009 & SUV & Outlander & 102,536 & 2016 \\
\hline G62-0216H & Chevrolet G1300 & 2009 & Van - Cargo & VTRUX Van & 92,105 & 2016 \\
\hline G42-0907H & Chevrolet G1300 & 2009 & Van - Cargo & VTRUX Van & 41,150 & 2016 \\
\hline G42-0904H & Chevrolet G1300 & 2009 & Van - Cargo & VTRUX Van & 45,820 & 2016 \\
\hline G42-0901H & Chevrolet G1300 & 2009 & Van - Cargo & VTRUX Van & 47,520 & 2016 \\
\hline G43-1965H & Ford E350 & 2009 & Van - Pass & VTRUX Van & 76,746 & 2016 \\
\hline G43-3882H & Ford E350 & 2009 & Van - Pass & VTRUX Van & 78,805 & 2016 \\
\hline G43-3889H & Ford E350 & 2009 & Van - Pass & VTRUX Van & 79,980 & 2016 \\
\hline G63-1464H & K2500HD & 2009 & Pickup & VTRUX Van & 54,122 & 2016 \\
\hline G41-1804H & Dodge Dakota & 2009 & Pickup & VTRUX Van & 49,191 & 2016 \\
\hline G41-1819H & Dodge Dakota & 2009 & Pickup & VTRUX Van & 47,053 & 2016 \\
\hline G42-0912H & Chevrolet C1500 & 2009 & Pickup & VTRUX Van & 46,039 & 2016 \\
\hline G62-0199H & Chevrolet K1500 & 2009 & Pickup & VTRUX Van & 46,039 & 2016 \\
\hline
\end{tabular}




\begin{tabular}{ccccccc}
\hline $\begin{array}{c}\text { Fleet } \\
\text { Vehicle Id }\end{array}$ & Make/Model & Year & EPA Class & $\begin{array}{c}\text { Potential } \\
\text { Replacement PEV }\end{array}$ & $\begin{array}{c}\text { Estimated } \\
\text { Mileage }\end{array}$ & $\begin{array}{c}\text { Replacement } \\
\text { Year }\end{array}$ \\
\hline G42-0910H & Chevrolet C1500 & 2009 & Pickup & VTRUX Van & 42,248 & 2016 \\
G41-1803H & Dodge Dakota & 2009 & Pickup & VTRUX Van & 38,834 & 2016 \\
G62-0220H & K1500 & 2009 & Pickup & VTRUX Van & 35,891 & 2016 \\
G63-1458H & K3500 & 2009 & Pickup & VTRUX Van & 35,317 & 2016 \\
G42-0913H & C1500 & 2009 & Pickup & VTRUX Van & 34,012 & 2016 \\
G62-4246H & 1500 & 2009 & Pickup & VTRUX Van & 33,419 & 2016 \\
G61-1857H & DAKOTA & 2009 & Pickup & VTRUX Van & 30,824 & 2016 \\
\hline
\end{tabular}




\section{Appendix I \\ Balance of JBLM Fleet}

The balance of the JBLM Fleet includes 205 vehicles, without the specialty vehicles, buses, and heavy-duty trucks. These vehicles were not monitored during the study, but have vehicles that may be replaced in the near term.

\section{I.1 Sedan Fleet Replacement Approach}

GSA currently lists only sedans for PEVs. It is assumed that additional sedans will be added to the list in the next few years. Table I-1 provides the list of the 32 sedans in the balance of the JBLM fleet not previously addressed that are projected to be replaced by 2017 . The projected year of replacement is identified based on the GSA requirements and expected usage. The mileage is projected from the odometer reading in 2013 and annual mileage provided by JBLM. Vehicles marked in green in this table reflect potential replacement vehicles that are included in Section 4.6.1.

Table I-1. Balance of Fleet sedan fleet replacement approach.

\begin{tabular}{|c|c|c|c|c|c|c|}
\hline \multicolumn{7}{|c|}{ Sedan Fleet Replacement Approach } \\
\hline $\begin{array}{c}\text { Fleet } \\
\text { Vehicle Id }\end{array}$ & Make/Model & Year & EPA Class & $\begin{array}{c}\text { Potential } \\
\text { Replacement } \\
\text { Vehicle }\end{array}$ & $\begin{array}{l}\text { Estimated } \\
\text { Mileage }\end{array}$ & $\begin{array}{c}\text { Replacement } \\
\text { Year }\end{array}$ \\
\hline G10-7541F & Pontiac G6 & 2008 & Sedan - Compact & Focus & 37,883 & 2015 \\
\hline G10-5325H & Pontiac G6 & 2009 & Sedan - Compact & Volt & 54,236 & 2015 \\
\hline G10-1069K & Ford Fusion HEV & 2010 & Sedan - Midsize & Fusion & 41,552 & 2015 \\
\hline G10-7540F & Pontiac G6 & 2008 & Sedan - Compact & C-Max & 34,342 & 2016 \\
\hline G10-2841L & Dodge Avenger & 2011 & Sedan - Compact & Volt & 43,911 & 2016 \\
\hline G10-7529F & Pontiac G6 & 2008 & Sedan - Compact & Leaf & 35,346 & 2016 \\
\hline G10-7668F & Dodge Avenger & 2008 & Sedan - Compact & Volt & 67,699 & 2016 \\
\hline G10-2950L & Ford Fusion HEV & 2011 & Sedan - Midsize & Fusion & 15,581 & 2016 \\
\hline G11-0476L & Chevrolet Impala & 2011 & Sedan - Large & Leaf & 11,311 & 2016 \\
\hline G11-0475L & Chevrolet Impala & 2011 & Sedan - Large & Volt & 75,455 & 2016 \\
\hline G11-2543G & Chevrolet Impala & 2008 & Sedan - Large & Leaf & 37,242 & 2016 \\
\hline G11-0477L & Chevrolet Impala & 2011 & Sedan - Large & Fusion & 72,698 & 2016 \\
\hline G11-0466K & Chevrolet Impala & 2011 & Sedan - Large & Leaf & 36,445 & 2016 \\
\hline G11-2053G & Chevrolet Impala & 2011 & Sedan - Large & Fusion & 66,055 & 2016 \\
\hline G11-0479L & Chevrolet Impala & 2011 & Sedan - Large & Leaf & 45,262 & 2016 \\
\hline G11-0481L & Chevrolet Impala & 2011 & Sedan - Large & Focus & 36,678 & 2016 \\
\hline G10-7525F & Pontiac G6 & 2008 & Sedan - Compact & Leaf & 23,000 & 2017 \\
\hline G10-3003K & Chevrolet Malibu & 2010 & Sedan - Midsize & Volt & 56,473 & 2017 \\
\hline G10-5364H & Pontiac G6 & 2009 & Sedan - Compact & Focus & 53,519 & 2017 \\
\hline G10-7669F & Dodge Avenger & 2008 & Sedan - Compact & Focus & 46,324 & 2017 \\
\hline G10-6362L & Chevrolet Malibu & 2011 & Sedan - Midsize & Volt & 34,916 & 2017 \\
\hline G10-5715M & Hyundai Sonata HEV & 2012 & Sedan - Large & Fusion & 15,371 & 2017 \\
\hline G10-5714M & Hyundai Sonata HEV & 2012 & Sedan - Large & Fusion & 74,09 & 2017 \\
\hline G10-5713M & Hyundai Sonata HEV & 2012 & Sedan - Large & Fusion & 17,524 & 2017 \\
\hline G11-2552G & Chevrolet Impala & 2008 & Sedan - Large & Volt & 40,153 & 2017 \\
\hline G11-2551G & Chevrolet Impala & 2008 & Sedan - Large & Leaf & 17,475 & 2017 \\
\hline G11-2550G & Chevrolet Impala & 2008 & Sedan - Large & Leaf & 31,661 & 2017 \\
\hline G11-2547G & Chevrolet Impala & 2008 & Sedan - Large & Leaf & 57,003 & 2017 \\
\hline G11-2545G & Chevrolet Impala & 2008 & Sedan - Large & Fusion & 43,527 & 2017 \\
\hline
\end{tabular}




\begin{tabular}{ccccccc}
\hline \multicolumn{7}{c}{ Sedan Fleet Replacement Approach } \\
$\begin{array}{c}\text { Fleet } \\
\text { Vehicle Id }\end{array}$ & Make/Model & Year & EPA Class & $\begin{array}{c}\text { Potential } \\
\text { Replacement } \\
\text { Vehicle }\end{array}$ & $\begin{array}{c}\text { Estimated } \\
\text { Mileage }\end{array}$ & $\begin{array}{c}\text { Replacement } \\
\text { Year }\end{array}$ \\
\hline G11-2544G & Chevrolet Impala & 2008 & Sedan - Large & Leaf & 35,778 & 2017 \\
G11-0478L & Chevrolet Impala & 2011 & Sedan - Large & Leaf & 37,214 & 2017 \\
G13-4623L & Ford Focus & 2012 & Sedan - Compact & Focus & 21,572 & 2017 \\
\hline
\end{tabular}

\section{I.2 Near-Term Non-Sedan Vehicle Replacement Approach}

Another approach to the replacement strategy is to consider non-sedan vehicles that may be replaced in the next 2 years. Of the 205 vehicles in the balance of the fleet, there are 47 vehicles whose odometer is expected to exceed 60,000 miles at the time of project replacement. They are identified in Table I-2, along with other vehicles (marked in green), whose potential replacement flows into those identified in Section 4.6.2. Table I-2 identifies the balance of fleet vehicles that are projected to be replaced in 2015 and 2016. (Note that JBLM may have replaced several of these vehicles in 2014.)

Table I-2. Balance of Fleet near-term replacement approach.

\begin{tabular}{|c|c|c|c|c|c|c|}
\hline \multicolumn{7}{|c|}{ Near-Term Replacement Approach } \\
\hline $\begin{array}{c}\text { Fleet } \\
\text { Vehicle Id }\end{array}$ & Make/Model & Year & EPA Class & $\begin{array}{c}\text { Potential } \\
\text { Replacement Vehicle }\end{array}$ & $\begin{array}{c}\text { Estimated } \\
\text { Mileage }\end{array}$ & $\begin{array}{c}\text { Replacement } \\
\text { Year }\end{array}$ \\
\hline G41-2114F & Chevrolet Uplander & 2007 & Minivan & Rav4 EV & 72,645 & 2015 \\
\hline G41-1177G & Chevrolet Uplander & 2008 & Minivan & Rav4 EV & 68,954 & 2015 \\
\hline G41-4535F & Chevrolet Uplander & 2007 & Minivan & Rav4 EV & 66,553 & 2015 \\
\hline G41-5433B & Dodge GR Caravan & 2006 & Minivan & Rav4 & 63,451 & 2015 \\
\hline G42-0034G & Chevrolet C1500 & 2008 & Pickup & VTRUX PU & 70,455 & 2015 \\
\hline G43-1409D & Ford E350 & 2006 & Van - Pass & VTRUX Van & 95,847 & 2015 \\
\hline G43-1415D & Ford E350 & 2006 & Van - Pass & VTRUX Van & 80,320 & 2015 \\
\hline G43-1755F & Ford E350 & 2007 & Van - Pass & VTRUX Van & 64,489 & 2015 \\
\hline G61-1144B & Dodge Dakota & 2005 & Pickup & Rav4 EV & 83,122 & 2015 \\
\hline G61-0259G & Saturn Vue AWD & 2008 & SUV & Outlander & 72,194 & 2015 \\
\hline G61-0210G & Dodge Dakota & 2008 & Pickup & Rav4 EV & 67,056 & 2015 \\
\hline G62-3684B & Chevrolet Tahoe & 2005 & SUV & Outlander & 109,869 & 2015 \\
\hline G62-0668A & Chevrolet Tahoe & 2004 & SUV & Rav4 EV & 85,325 & 2015 \\
\hline G62-1468D & Ford F150 & 2006 & Pickup & Rav4 EV & 84,373 & 2015 \\
\hline G62-4284A & Ford F150 CREW & 2005 & Pickup & Rav4 EV & 79,443 & 2015 \\
\hline G62-2208F & Dodge Durango & 2007 & SUV & Rav4 EV & 78,714 & 2015 \\
\hline G62-3737B & Ford F150 & 2006 & Pickup & Rav4 EV & 64,735 & 2015 \\
\hline G62-1415D & Chevrolet Suburban & 2006 & SUV & Rav4 EV & 64,659 & 2015 \\
\hline G62-1495D & Chevrolet K1500 & 2007 & Pickup & VTRUX PU & 63,721 & 2015 \\
\hline G63-2647D & Chevrolet Suburban & 2007 & SUV & Rav4 EV & 82,641 & 2015 \\
\hline G63-2634D & Dodge Ram 2500 & 2007 & Pickup & Rav4 EV & 76,553 & 2015 \\
\hline G71-0101G & Ford F550 & 2003 & Pickup & VTRUX PU & 71,511 & 2015 \\
\hline G41-1792H & Dodge GR Caravan & 2009 & Minivan & Outlander & 95,580 & 2016 \\
\hline G41-1790H & Dodge GR Caravan & 2009 & Minivan & Outlander & 94,162 & 2016 \\
\hline G41-1791H & Dodge GR Caravan & 2009 & Minivan & Outlander & 90,585 & 2016 \\
\hline G62-2498H & Chev. Trailblazer & 2009 & SUV & Outlander & 59,303 & 2016 \\
\hline G61-1865H & Ford Escape & 2009 & SUV & Rav4 EV & 57,534 & 2016 \\
\hline G62-0215H & Chevrolet G1300 & 2009 & Van - Cargo & VTRUX Van & 56,550 & 2016 \\
\hline
\end{tabular}




\begin{tabular}{ccccccc}
\hline \multirow{2}{*}{$\begin{array}{c}\text { Fleet } \\
\text { Vehicle Id }\end{array}$} & Make/Model & Year & EPA Class & Replacement Vehicle & $\begin{array}{c}\text { Estimated } \\
\text { Mileage }\end{array}$ & $\begin{array}{c}\text { Replacement } \\
\text { Year }\end{array}$ \\
\hline G62-0219H & Chevrolet G1300 & 2009 & Van - Cargo & VTRUX Van & 46,703 & 2016 \\
G41-1800H & Ford Ranger & 2009 & Pickup & Rav4 EV & 64,577 & 2016 \\
G43-1957H & Chevrolet CG3300 & 2009 & Van - Pass & VTRUX Van & 77,382 & 2016 \\
G43-3888H & Ford E350 & 2009 & Van - Pass & VTRUX Van & 64,284 & 2016 \\
G43-1928H & Chevrolet CG3300 & 2009 & Van - Pass & VTRUX Van & 62,652 & 2016 \\
G43-2775H & Chevrolet CG3300 & 2009 & Van - Pass & VTRUX Van & 61,838 & 2016 \\
G62-4512H & Dodge 1500 & 2009 & Pickup & VTRUX PU & 99,643 & 2016 \\
G63-1482H & Chevrolet K2500 & 2009 & Pickup & VTRUX PU & 93,293 & 2016 \\
\hline
\end{tabular}

